sen sogar französische Kulturpropaganda war, sei hier dahingestellt. Dieses Beispiel verdeutlicht jedoch, daß die im folgenden dargestellten Aktivitäten der deutschen Kulturpropaganda in Paris sowie deren Erfolge und Mißerfolge nicht ohne Widersprüchlichkeiten waren.

\title{
1. „In dem Ringen um die kulturelle Weltgeltung Deutschlands": deutsche Gastspiele und Theaterstücke in Paris
}

Im Februar 1942 erläuterte der Theaterreferent der Propaganda Staffel in einem Bericht die Bedeutung der deutschen Kulturpolitik im besetzten Frankreich. Er sah seine Aufgabe darin, Deutschland mit Hilfe der Kulturpropaganda in einem sogenannten geistigen Wettlauf der Nationen zum Siege zu verhelfen. Dieser sei jedoch bedroht von einem französischen Kulturexport:

Der Kulturkampf zwischen Deutschland und dem Westen hat durch die Zerschlagung der militärischen und politischen Weltmachtstellung Frankreichs nur eine kurze Unterbrechung erfahren. Heute ist diese Auseinandersetzung auf der ganzen Linie wieder in Gang gekommen, und zwar unter Auspizien, die für unseren Gegner nicht ungünstig lauten. Während der deutsche Kulturapparat mit einem Minimum an organisatorischem und künstlerischem Personal auskommen muß, ist Frankreich als nichtkriegführende Nation in der glücklichen Lage, eine Fülle von Kräften ansetzen zu können. Man hat diesen Vorteil in Vichy schnell genug begriffen und versucht jetzt mit Hilfe französischen Kulturexports zu retten, was an Ansehen zu retten ist ${ }^{10}$.

Demnach stellten die französischen kulturellen Aktivitäten im Ausland eine Gefahr für den Erfolg deutscher Kulturpropaganda dar, was nach Ansicht Franks eine Unterdrückung jeglicher französischer Kulturpropaganda notwendig machte. Diese Furcht vor der französischen kulturellen Ausstrahlungskraft war jedoch gepaart mit einer Überzeugung von der angeblich größeren Qualität der deutschen künstlerischen Leistung und der angeblichen "Vorrangstellung“, so Frank, der deutschen Kultur:

Aufgabe der Kulturpropaganda ist es, diesen Vorsprung vor der Welt zu dokumentieren. Auf Paris angewandt heißt das: Deutsches Theater vor den Augen der Pariser zu zeigen, sei es durch französische Aufführungen guter Übersetzungen, sei es durch beispielgebende deutsche Gastspielvorstellungen, sei es durch andere Veranstaltungen in Verbindung mit dem Theaterwesen ${ }^{11}$.

Einerseits war das Theaterreferat davon überzeugt, daß Deutschland eine qualitativ überragende Kultur besitze - in diese Richtung gingen auch Vorstellungen von der angeblichen Dekadenz französischer Kultur - und andererseits fürchtete es die kulturelle Ausstrahlungskraft Frankreichs. Während

10 AN, AJ40 1001-7, Prop.Abt., Gr.Kult.Th., Bericht, ohne Angabe von Titel und Autor, 3. 2. 1942; wahrscheinlich verfaßte Theaterreferent Frank diesen Bericht.

11 Ibid. 
deutsche Theaterstücke und Gastspiele demnach verstärkt Eingang in das kulturelle Leben Frankreichs und Europas finden sollten, war die Besatzungsmacht auch darauf bedacht, einen französischen Kulturexport zu verhindern. In Deutschland waren Theaterstücke französischer Autoren übrigens weitgehend verboten und es wurden dort nur wenige französische Filme gezeigt ${ }^{12}$. Die Bedeutung gerade des Theaters in dem Kampf der Kulturen übertrieb der Theaterreferent in seinem Bericht allerdings erheblich:

In dem Ringen um die kulturelle Weltgeltung Deutschlands verteidigt das Theater nur einen Sektor, aber einen der wichtigsten. Denn auf der Bühne regiert das gesprochene Wort, dessen kulturpropagandistische Bedeutung, nicht zuletzt seit den Erfahrungen der nationalsozialistischen Kampfzeit, unbestritten ist ${ }^{13}$.

Das Theater kann sicherlich nicht als einer der wichtigsten Sektoren deutscher Kulturpropaganda in Frankreich gesehen werden. Schon in den zwanziger und dreißiger Jahren spielten die Pariser Bühnen nur sehr selten deutsche Autoren ${ }^{14}$. Im Gegensatz dazu ließen sich Filme viel leichter und in größerem Umfang exportieren und die Nationalsozialisten maßen dem Film generell eine weit größere - auch propagandistische - Bedeutung zu als dem Theater. Dem Theaterreferenten waren die Schwierigkeiten der Kulturpropaganda im Bereich des Theaters bewußt, denn er beklagte in einem seiner Berichte, das Theater sei auf zeitraubende Übersetzungen angewiesen; dagegen seien Musik und bildende Künste international verständlich. Das in Frankreich vorhandene Material sei zudem nicht gut und veraltet. Deutschsprachige Gastspiele könnten nur unter bestimmten politischen Voraussetzungen stattfinden. Er resümierte: „Schon dadurch sind den nach außen sichtbaren Erfolgsmöglichkeiten Grenzen gezogen"15.

Eine Einflußnahme auf die Pariser Spielpläne mit dem Ziel der Aufführung deutscher Theaterstücke oder deutschsprachiger Gastspiele war grundsätzlich nicht unproblematisch. Während der vier Jahre deutscher Besatzung führten die Pariser Bühnen sieben deutsche Theaterstücke auf ${ }^{16}$, während in den Filmtheatern allein im Jahre 1942 rund 125 deutsche Filme zu sehen waren. Ferner traten vier deutsche Theaterensembles mit Gastspielen vor Pari-

$12 \mathrm{Zu}$ französischen Filmen und Theaterstücken in Deutschland während des Dritten Reiches siehe DrewnIaK, Der deutsche Film, S. 838-840; Ders., Das Theater, S. 260263.

13 AN, AJ40 1001-7, Prop.St., Gr.Kult.Th., Bericht, ohne Titel, 3. 2. 1942.

14 Darüber klagte beispielsweise in einem tendenziösen Artikel der kollaborierende $\mathrm{Pa}$ riser Theaterkritiker Alain Laubreaux, Le Théâtre allemand à Paris, in: DeutschlandFrankreich 7 (1944) S. 96-98.

15 AN, AJ40 1001-7, Prop.St., Gr.Kult.Th., Bericht, ohne Titel, 3. 2. 1942.

16 Im April 1942 wurden Goethes "Iphigenie auf Tauris“ und Schillers "Don Carlos ${ }^{*}$ aufgeführt, im Januar 1943 Hauptmanns "Rose Bernd “, dessen „Fuhrmann Henschel " im Februar 1943 und im Juni 1943 seine "Iphigenie in Delphi“. Hebbels „Maria Magdalena" und Forsters "Robinson soll nicht sterben" wurden im September 1943 an französischen Bühnen inszeniert. 
ser Publikum auf ${ }^{17}$. In einem Bericht der SIPO-SD vom 1. November 1943 heißt es sogar, während der Okkupation seien weniger deutsche Bühnenwerke in Paris zu sehen gewesen als vor dem Kriege ${ }^{18}$. In den Pariser Theatern waren also während der Okkupation nur wenige deutsche Bühnenstücke sowie deutschsprachige Theater- und Operngastspiele zu sehen. Die Gastspiele dienten zudem nicht immer nur der deutschen Kulturpropaganda, sondern auch der Truppenbetreuung durch die Pariser Stelle der Organisation Kraft durch Freude (KDF). Die begrenzte Anzahl an Theaterstücken und Gastspielen auf Pariser Bühnen ging jedoch keinesfalls mit einer nur geringen Bedeutung dieses Bereiches für die Aktivitäten der Dienststellen einher; deren umfangreiche Planungen überstiegen während der gesamten Zeit der Besatzung bei weitem die Anzahl der tatsächlich realisierten Veranstaltungen. Die folgenden Ausführungen zum deutschen Theater auf Pariser Bühnen stellen daher auch eine Untersuchung gescheiterter Planungen dar.

Trotzdem führten die Pariser Dienststellen und Berliner Ministerien, insbesondere Abetz und Goebbels, gerade um die Frage deutscher Gastspiele im besetzten Paris einen erbitterten Kampf. Der Aufgabenbereich der Propaganda im Ausland war in Berlin Gegenstand von Streitigkeiten zwischen dem AA unter Ribbentrop und dem RMVP unter Goebbels. Nach dem Arbeitsabkommen beider Ministerien im Herbst 1941 ging im Sommer 1942 der Aufgabenbereich der Kulturpropaganda offiziell an die Deutsche Botschaft über, was jedoch eine weitere inoffizielle Tätigkeit der Propaganda Abteilung auf diesem Gebiet nicht ausschloß. Sie verlor damit formell ein Betätigungsfeld, welches im Mai 1943 vom Theaterreferat als seine „ursprünglich wesentlichste Aufgabe" 19 bezeichnet wurde. Die Ausführungen zu Theatergastspielen behandeln insofern auch den Bereich der Musik, als dies für eine eingehende Untersuchung der Kompetenzstreitigkeiten notwendig ist. Welche Rolle spielten die Konkurrenzkämpfe der deutschen Dienststellen bei der Umsetzung deutscher Kulturpropaganda und nach welchen inhaltlichen oder pragmatischen Kriterien geschah die Auswahl der Stücke für Auslandsgastspiele? Von wem gingen die Initiativen aus und woran scheiterten solche Planungen? Neben den Bemühungen der deutschen Dienststellen, deutsches Theater auf Pariser Bühnen zu bringen, soll anschließend auch die Rezeption deutscher Werke auf Pariser Bühnen sowie die Rolle der Künstler innerhalb der deutschen Kulturpropaganda thematisiert werden.

17 Im Januar 1941 gab das Schillertheater Berlin an der Comédie-Française Schillers

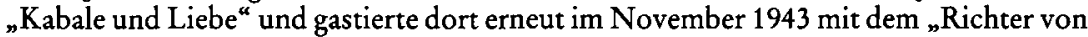
Zalamea"; im April 1942 war an der Comédie-Française parallel zur französischen Inszenierung des gleichen Stückes ein Gastspiel des Bayerischen Staatsschauspiels mit Goethes "Iphigenie auf Tauris“ zu sehen und im Mai 1944 gab das Staatsspielhaus Hamburg Hebbels „Gyges und sein Ring“ am Théâtre de l'Odéon.

18 BA-KO, R58/190, Reichssicherheitshauptamt, Der Chef der Sipo-SD, SD-Berichte zu Inlandsfragen, 1.11. 1943.

19 AN, AJ40 1001-7, Prop.Abt., Gr.Kult.Th., Geheim, Paris, den 20.V.1943, Richtlinien für die Kulturarbeit der Staffeln und Außenstellen. 


\subsection{Streit um deutsche Gastspiele in Paris: $1940-1942$}

Gegensätzliche Positionen der konkurrierenden Dienststellen machten sich im Bereich deutscher Gastspiele schon zu Beginn der Besatzungszeit bemerkbar. Während die Propaganda Staffel zunächst vornehmlich mit Aufgaben der Kontrolle und Wiederauflebens des Pariser Theaterbetriebs beschäftigt war ${ }^{20}$, bemühte sich das Deutsche Institut als Kulturabteilung der Deutschen Botschaft schon sehr früh um Theater-, Opern- und Musikgastspiele. Im Dezember 1940 sandte die Botschaft eine Reihe von Gastspielvorschlägen an das AA. Sie plante unter anderem Aufführungen des Berliner Schillertheaters unter Heinrich George an der Comédie-Française. Die Botschaft wollte sämtliche Vorhaben aus eigenen Mitteln finanzieren, ohne den Kulturfonds des Auswärtigen Amtes in Anspruch zu nehmen ${ }^{21}$. Allein das genannte Gastspiel des Schillertheaters fand später tatsächlich statt. Abgesehen von den eigenen Planungen organisierte die Botschaft zunächst im Zusammenhang mit KDF-Veranstaltungen zur Truppenbetreuung auch einige Aufführungen vor französischem Publikum. Im Dezember 1940 kam Herbert von Karajan mit Chor und Orchester der Stadt Aachen nach Paris, um dort einige Wehrmachtskonzerte zu geben. Abetz holte beim Reichsleiter des KDF, Ley, die Erlaubnis ein, das Deutsche Institut als Veranstalter eines weiteren öffentlichen Konzertes auftreten zu lassen. So dirigierte Karajan am 19. Oktober 1940 im Théâtre National du Palais de Chaillot die H-Moll Messe von Johann Sebastian Bach vor französischem Publikum. Epting berichtete an das Auswärtige Amt, das Konzert sei ausverkauft und ein großer Erfolg gewesen $^{22}$. Im Januar 1941 kam der österreichische Operettenkomponist Franz Lehár auf Einladung des Deutschen Instituts für mehrere Wochen nach Paris und dirigierte neben einigen Wehrmachtsveranstaltungen in mehreren öffentlichen Galavorstellungen seine Operette „Das Land des Lächelns“ im Theater Gaieté Lyrique. Die Aufführungen waren ausverkauft. Die kollaborierende Pariser Presse veröffentlichte gute Kritiken und das französische Publikum soll angeblich begeistert gewesen sein. Laut Epting fand Lehàrs Aufenthalt in Paris in Theaterkreisen sowie in der breiteren Öffentlichkeit große Aufmerksamkeit ${ }^{23}$. Und obgleich die Politik des Instituts generell auf die französische Elite abzielte, betonte ex, man habe Teile der Bevölkerung

20 Ibid. Prop.St., Gr.Kult.Th., Tätigkeitsbericht der Gruppe IV: Kultur, Arbeitsgebiet Theater, undatiert; dem Inhalt nach wurde der Bericht zwischen dem 27.9. 1940 und dem 5. 10. 1940 verfaßt.

21 PA-AA, 1379, Kult 12 Nr. 2, DBP, Hirzel an AA, Betr.: Kult K 11690, 17. 12. 1940; ferner sollte das Bremer Schauspielhaus mit Lessings „Minna von Barnhelm“ in Paris gastieren. Eine Mozart-Oper, entweder des Dresdner oder Frankfurter Opernhauses sowie eine Aufführung des Bochumer Stadttheaters unter Saladin Schmidt waren für das Frühjahr 1941 vorgesehen.

22 PA-AA, 1380, Kult 12 Nr. 3, DBP, Epting an AA, Betr.: Kult K, 21. 12. 1940; ibid. Epting an AA, Tel. Nr. 1575, 20.12. 1940.

${ }^{23}$ PA-AA, 1379, Kult 12 Nr. 2, DBP, Epting an AA, 21. 1. 1941. 
erreichen können, die ansonsten keine Konzerte ernster Musik besuchten; die Gaieté Lyrique lag in einem sogenannten Arbeiterviertel ${ }^{24}$.

Als erstes deutsches Theaterensemble im besetzten Paris spielte am 25. und 26. Februar 1941 das Schillertheater unter Heinrich George an der ComédieFrançaise, dem renommiertesten französischen Nationaltheater und „Hause Molières“. Seine Truppe führte „Kabale und Liebe“ auf, das in Deutschland zu dieser Zeit meistgespielte Werk Friedrich von Schillers ${ }^{25}$. Es gehörte am Schillertheater zu den Wiederaufnahmen bewährter Klassiker und George hatte dieses Stück neben Heinrich von Kleists „Prinzen Friedrich von Homburg “ selbst für Gastspiele in der Spielzeit 1940/41 vorgeschlagen ${ }^{26}$. Die Auswahl des Stückes geschah hier also nicht aufgrund kulturpropagandistischer Wünsche der deutschen Dienststellen. Die Planung dieser Aufführungen war keineswegs im Einvernehmen mit dem Propagandaministerium geschehen. Bereits im Herbst 1940 war deren Durchführung von der Propaganda Staffel verhindert worden ${ }^{27}$. Goebbels stand größeren deutschen Theater- und Operngastspielen im besetzten Paris ablehnend gegenüber. Einen Monat vor dem Gastspiel des Schillertheaters, im Januar 1941, hatte die Propaganda Abteilung beim RMVP noch angefragt, ob nun endlich der Zeitpunkt für deutsche Gastspiele auf Pariser Bühnen gekommen sei. Am 11. Februar erfuhr sie, dies sei grundsätzlich noch nicht erwünscht. Doch nur einen Tag später informierte Rainer Schlösser, Reichsdramaturg und Leiter der Abteilung Theater im RMVP, die Pariser Dienststelle über das bevorstehende Gastspiel des Schillertheaters ${ }^{28}$. Jene wurde von dieser Ankündigung also völlig überrascht. Sie erfuhr davon aus Berlin und übrigens an demselben Tage wie die Pariser Öffentlichkeit, denn am 12. Februar hatte Epting in einer Pressekonferenz die Presse darüber informiert. Die ersten Vorankündigungen erschienen noch an diesem Tage in den französischen Zeitungen ${ }^{29}$. Es hatte vorher keinerlei Informationsfluß oder gar Koordination zwischen den deutschen Dienststellen in Paris gegeben. Obgleich sich die Propaganda Abteilung um die Planung von Gastspielen hatte bemühen wollen, war ihr das

24 PA-AA, 1380, Kult 12 Nr. 3, DBP, Epting an AA, 28. 2. 1941.

25 DrewniaK, Das Theater, S. 172 f. "Kabale und Liebe“ war 1940-1943 mit 1170 Aufführungen auf deutschen Bühnen Schillers meistgespieltes Werk, gefolgt von „Maria Stuart“ (935) und „Don Carlos" (381).

${ }^{26}$ BAB, 50.01-290, Die Spielzeit 1940/41 des Schillertheaters der Reichshauptstadt, ohne Datum.

27 PA-AA, 1379, Kult 12 Nr. 2, DBP, Epting an AA, Telegramm Nr. 2287, Auf Telegramm Nr. 3818 vom 29. 7., 31. 7. 1941.

${ }^{28}$ AN, AJ40 1002-2, Prop.Abt., Schmidtke an Hadamowsky, Ministeramt, RMVP, Fernschreiben, 10.25 Uhr, 13. 2. 1941. Zu Beginn des Fernschreibens heißt es: „Eilt! Sofort auf den Tisch!“

29 Siehe beispielsweise den Artikel „Schiller sera joué au Téâtre Français“, in: Le Matin, 12. 2. 1941; La Comédie Française recevra les 25 et 26 février le Schillertheater de Berlin, in: L'CEuvre, 12. 2. 1941. 
von Berlin aus untersagt worden und so war sie schließlich vom konkurrierenden Deutschen Institut überflügelt worden.

Als Schmidtke von dem bevorstehenden Gastspiel erfuhr, sandte er sogleich ein Fernschreiben nach Berlin, das auf seinen Wunsch hin Goebbels noch an demselben Tag vorgelegt werden sollte. Er war verärgert über die gegensätzlichen Informationen aus Berlin und meinte, die Frage deutscher Gastspiele bedürfe dringend einer Klärung. Falls die bisherige grundsätzlich ablehnende Haltung des Ministeriums geändert würde, müßten solche $\mathrm{Pla}-$ nungen mit mehr System behandelt werden. Deutsches Theater dürfe nicht durch „eigenmächtiges Verhalten verschiedener Dienststellen" 30 auf französischen Bühnen „wahllos und steuerlos" gezeigt werden. Zudem wies Schmidtke auf die besondere Bedeutung dieser Aufführungen an einer so renommierten Bühne wie der Comédie-Française hin. Es war das erste Mal in der Geschichte des Hauses, daß dort ein ausländisches Ensemble auftrat. Die Tatsache, daß seit dem dreihundertjährigen Bestehen dieses berühmten $\mathrm{Na}-$ tionaltheaters dort nun zum ersten Mal eine deutsche Theatertruppe spielte, hob auch Heinrich George besonders hervor, als er Hitler später vom Erfolg dieses Gastspiels berichtete. George fügte hinzu:

Wir und alle, die dieses einmalige erhebende Ereignis miterlebt haben, wissen, daß wir es dem Sieg der deutschen Wehrmacht unter Ihrer genialen Führung verdanken. Wir hoffen Ihnen und Ihrer politischen Führung mit unseren Waffen der Kunst und des Geistes gedient zu haben ${ }^{31}$.

Angesichts der zweifellos besonderen Bedeutung der Comédie-Française für das französische Kulturleben, kam das deutsche Gastspiel gerade an dieser Bühne einer Eroberung des Pariser Theaterlebens gleich, der durch Waffengewalt der Weg geebnet worden war. Umgekehrt empfand die französische Seite dies insbesondere rückblickend als zusätzliche Demütigung ${ }^{32}$. Für das Deutsche Institut und die Deutsche Botschaft hatte das Gastspiel zusätzlich noch eine andere Bedeutung: Sie hatten hiermit gleichzeitig einen Erfolg im Kompetenzstreit mit Propaganda Staffel und Propaganda Abteilung erzielt. Schlösser, den das RMVP anläßlich der Aufführungen von „Kabale und

30 AN, AJ40 1002-2, Prop.Abt., Schmidtke an Hadamowsky, Ministeramt, RMVP, Fernschreiben, 10.25 Uhr, 13.2. 1941. In dem Original ist vorher der Term anderer Dienststellen“ durchgestrichen und durch "verschiedener Dienststellen“ ersetzt worden.

31 PA-AA, 1379, Kult 12 Nr. 2, DBP, Epting an AA, 3. 3. 1941, Abschrift des Telegramms Georges an Hitler vom 25. 2. 1941 sowie der Antwort - ein einfacher Dank Hitlers an George vom 27.2. 1941. Georges Rolle im Nationalsozialismus ist nach wie vor umstritten; nach Ende des Krieges starb der Schauspieler während seiner Internierung durch die russische Besatzungsmacht; eine ihn verteidigende Biographie liefert Werner MASER, Heinrich George, Mensch, aus Erde gemacht, Berlin 1998.

32 JouberT, La Comédie-Française, S. 353-369, siehe S. 165-171 zum Gastspiel des Schillertheaters mit „Kabale und Liebe ${ }^{\text {. }}$. Diese Sichtweise bestätigen auch die Vorwürfe, die den Intendanten dieser Bühne, zunächst Jacques Copeau und später JeanLouis Vaudoyer, nach der Libération gemacht wurden. 
Liebe" nach Paris gesandt hatte, versuchte während eines anschließenden Empfangs im Deutschen Institut, einer Einigung mit Abetz in der sogenannten Gastspielfrage vorzufühlen. Anschließend ließ er Goebbels wissen, Abetz habe sich kooperationsbereit gezeigt und durchblicken lassen, er betrachte sich als Außenseiter des AA und sei grundsätzlich in der Frage der Durchführung von Gastspielen zur Zusammenarbeit bereit. Der Botschafter wolle die konkurrierenden Stellen zukünftig über Planungen der Botschaft informieren, falls diese ihrerseits zur Zusammenarbeit bereit wären. Vor diesem Hintergrund plädierte Schlösser für eine gemäßigte Haltung. Das RMVP sollte seiner Ansicht nach den zahlreichen Wünschen von Abetz in bezug auf Pariser Gastspielpläne gelegentlich nachkommen und sich in die Planungen mit einschalten. Allerdings habe Schmidtke bei der Botschaft bereits heftig gegen die Aufführungen des Schillertheaters protestiert und allgemein einen strikten Standpunkt vertreten, der laut Schlösser jegliche Kooperation der beiden Dienststellen in Zukunft erschweren würde ${ }^{33}$. Ob Abetz tatsächlich so kooperationsbereit und in diesem Punkt gar ein Außenseiter im AA war, ist angesichts der Position, die er später generell in dieser Frage vertrat, eher zweifelhaft. In jedem Fall aber fanden Schlössers Vorschläge allein deswegen nicht das Gehör des Propagandaministers, weil dieser weiterhin eine unnachgiebige Haltung gegen die Durchführung deutscher Gastspiele im besetzen Paris einnahm. Hierfür gab es verschiedene Gründe.

Zunächst einmal mißfiel Goebbels im Falle der Aufführungen des Schillertheaters in Paris vor allem die Auswahl des Stückes. Seiner Meinung nach sollte „Kabale und Liebe“ grundsätzlich von deutschen Ensembles nicht im Ausland gespielt werden ${ }^{34}$. Insbesondere störten ihn an diesem Werk die Passagen, die sich auf England beziehen. Als George das gleiche Stück zu einem späteren Zeitpunkt erneut für eine Gastspielreise durchzusetzen versuchte, schlug er vor, die betreffenden Stellen zu kürzen, um so die Zustimmung von Goebbels zu erhalten. Lady Milforth, die sich nach einer unerfüllten Liebe im Verlaufe des Stückes entscheidet, in ihre englische Heimat zurückzukehren, sollte nach diesen Kürzungen ,ausschließlich im Lichte ihrer etwas ramponierten fraulichen Unschuld stehen [...] ohne daß Schiller dadurch ver-

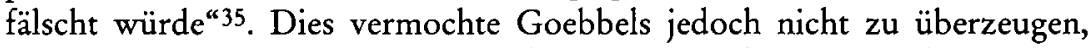
denn er lehnte das Stück auch weiterhin für Auslandsgastspiele ab. Der Propagandaminister war generell der Ansicht, daß bei Gastspielen im Ausland nicht nur die Aufführung durch ein möglichst renommiertes deutsches Theater, sondern auch das Stück selbst werbend für Deutschland wirken sollte.

33 BAB, 50.01-506, RMVP, Abt.Th., Schlösser an Goebbels, 6. 5. 1941, Betr. Gastspiel Staatsoper Berlin in Paris. Schlösser nimmt hier auf die Vorgänge um das Gastspiel des Schillertheaters bezug.

34 BAB, 50.01-507, RMVP, Abt.Th., Schlösser an George, 19. 12. 1942.

35 BAB, 50.01-291, RMVP, Abt.Th., Schlösser an Goebbels Betr.: Auslandsreisen des Schillertheaters, 30. 9. 1943. BAB, 50.01-291, RMVP, Ministeramt, Dr. Naumann an Leiter der Abt.Th., Betr.: Auslandsreisen des Schillertheaters, 2. 10. 1943. 
„Kabale und Liebe“ war zudem stark von den Ideen Jean-Jacques Rousseaus beeinflußt, worauf eine Vorankündigung des Deutschen Instituts in den Deutsch-französischen Monatsheften auch noch besonders hinwies. Das Institut dagegen war mit der Auswahl des Stückes, mit dem sich gut für eine vorgebliche deutsch-französische Verständigung werben ließ, zufrieden ${ }^{36}$. Auf die Propagierung eines vorgeblichen deutsch-französischen Kulturaustauschs im Umfeld des Gastspiels soll später noch näher eingegangen werden. ${ }^{37}$ In Goebbels Augen dürfte ein von den Ideen der Französischen Revolution beeinflußtes Werk, das somit auf den geistigen Leistungen des französischen Volkes beruhte, nicht geeignet gewesen sein, dem Pariser Publikum die angeblich höher stehende deutsche Kultur anzupreisen. Die Gründe für seine ablehnende Haltung gegenüber Gastspielen im besetzten Paris waren zum Teil auch innenpolitischer Natur; seine Anweisungen an die deutsche Presse im Anschluß an den Sieg über den französischen Nachbarn zeigen, daß er in Deutschland in keinem Fall ein zu positives Bild von Frankreich oder etwa einer eventuellen deutsch-französischen Verständigung entstehen lassen wollte. So wies er beispielsweise im Juli 1940 die deutsche Presse an, "nicht zuviel Lob an Frankreich auszuteilen" 38 , da ansonsten die Gefahr einer Welle von Francophilie in Deutschland bestehe. Der Ruf der französischen Hauptstadt sollte in Deutschland nicht genährt werden ${ }^{39}$. Deutsche Theatergastspiele im besetzten Paris hätten somit nur mehr zu dem bisherigen Bild von Paris als einer Kulturmetropole beigetragen. Ein Schweigen über das Pariser Kulturleben in der deutschen Presse war der besonderen $\mathrm{Be}-$ tonung deutscher Kulturveranstaltungen in dieser Stadt vorzuziehen. Aufwendige prestigeträchtige deutsche Gastspiele in der französischen Hauptstadt konnten zwar der Errichtung einer deutschen „kulturellen Hegemonie“ dienen. Sie konnten aber auch den Eindruck erwecken, Deutschland sehe Frankreich in bezug auf einen kulturellen Austausch beider Länder als gleichberechtigten Partner. Die Entsendung der besten deutschen Ensembles nach Paris konnte somit eine Ehrung und Anerkennung des Nachbarlandes symbolisieren, was in Goebbels Augen wenig wünschenswert war.

Grundsätzlich waren sich trotzdem alle beteiligten Pariser Dienststellen und Berliner Vorgesetzten darüber einig, daß in Paris nur erstklassige deut-

36 Wilhelm Fraenger, Schiller à la Comédie Française, in: DFMH 1-2 (1941) S. 58 f. 37 Siehe Kapitel III. 1.4. dieser Arbeit.

38 GoebBeLS, Tagebücher, hg. von REUTH, Bd. 4, S. 1449, Tagebucheintragung vom 6.7. 1940 .

39 BoELCKE, Kriegspropaganda, S. 409. In diesem Sinne heißt es zur Ansicht Goebbels in einer Ministerkonferenz vom 26. Juni 1940: „Die Presse soll Frankreich gegenüber nicht allzu freundschaftliche Töne anschlagen [...] Ebenso sollen sich die Zeitungen davor hüten, Paris nun allzu lockend zu schildern, und aus PK-Berichten sind alle zu frankophilen Äußerungen zu entfernen. Unsere Haltung gegenüber Frankreich hat kühl und reserviert zu sein" (BOELCKE, Kriegspropaganda, S. 406 f.). 
sche Ensembles zu gastieren hatten ${ }^{40}$. Zwar galt dieses Prinzip auch für Gastspiele in anderen Ländern, denn immerhin sollten diese zur deutschen kulturellen Ausstrahlungskraft beitragen, aber im Falle von Paris wurde hierauf besonderer Wert gelegt; dies galt zum Teil auch für die anderen Großstädte in den besetzten Ost- und Westgebieten. Der Export deutscher Kultur traf hier auf ein anspruchsvolles Großstadtpublikum, das nicht enttäuscht werden durfte, wenn die Bemühungen deutscher Kulturpropaganda erfolgreich sein sollten ${ }^{41}$. Dementsprechend äußerte Goebbels in einem Gespräch mit Schmidtke, „daß, wenn überhaupt deutsche Kultur in Form von Aufführungen den Franzosen zugänglich gemacht werden sollte, nur das Beste, was Deutschland bzw. Berlin bietet, im Anfang wie auch in der Folgezeit gezeigt werden würde“42. Der Maßstab für deutsche Gastspiele im besetzten Paris wurde möglichst weit oben angelegt, damit sich die deutsche Kultur vor dem anspruchsvollen Pariser Publikum nicht blamieren mußte, sondern die angebliche kulturelle Größe Deutschlands unterstrich. Die Sorge um qualitativ möglichst gute deutsche Gastspiele und eine positive Rezeption war auch ein Grund dafür, daß die Aufführungen von „Kabale und Liebe" hauptsächlich vor geladenen Gästen stattfanden ${ }^{43}$. Angesichts der hohen Ansprüche an Pariser Gastspiele war deren Planung allerdings auch aus rein praktischen Gründen nicht unproblematisch. Gerade die besten Theater- und Filmschauspieler wurden in Deutschland selbst benötigt, wo die Kultur die Bevölkerung vor allem bei Laune halten und zudem erziehen sollte ${ }^{44}$. Im weiteren Verlauf des Krieges, insbesondere 1943 und 1944, litten die deutschen Bühnen und Orchester mehr und mehr an einem Mangel an Künstlern, da ihre Mitarbeiter zum Teil einzogen worden waren ${ }^{45}$. Es ist wahrscheinlich, daß Goebbels der Ansicht war, der aufbauenden Aufgabe der Kultur in Deutschland sei der Vorrang vor etwaigen prestigeträchtigen Aufführungen im Ausland zu geben, zumal er sich im Falle des anspruchsvollen Pariser Publikums nicht ohne weiteres der Erfolge sicher sein konnte. Diese Überlegungen stehen im Einklang mit der Haltung Goebbels, die er in bezug auf die französischen Continental-Filme einnahm. Demnach war es wichtiger, die besten

40 PA-AA, 1215, Kult 12 Nr. 2, DBP an AA, Betr.: Konzertmeister Rudolf Schulz, 29. 5. 1942; ibid. DBP, Abetz an AA, Telegramm, 9. 5. 1944.

41 BAB, 50.01-503, Schiller Theater der Reichshauptstadt, Intendant Heinrich George an Schlösser, 10. 5. 1940.

42 AN, AJ40 1002-2, Prop.Abt., Schmidtke an Hadamowsky, Ministeramt, RMVP, Fernschreiben, 10.25 Uhr, 13. 2. 1941.

43 BAB, R58/661, Meldungen aus dem Reich, Das Theaterleben in den besetzten Westgebieten, 5. 6. 1941 .

44 REICHEL, Der schöne Schein, S. 180, 336 - 345. Siehe auch beispielsweise BAB, RMVP,50.01.-1211, Kulturnachrichten des DNB, Das deutsche Theater im Kriege, 11. 12. 1942, die Rede Dr. Rainer Schlössers in Hannover.

45 Zum Künstlermangel in Orchestern siehe PA-AA, 1142, Kult $12 \mathrm{Nr} 3(4)$, Knothe an AA, Fernschreiben Nr. 6848, 21. 10. 1943. 
französischen Künstler für den deutschen Film zu gewinnen anstatt mit Hilfe der Continental-Films gute französische Filme herzustellen.

Obgleich die Propaganda Abteilung grundsätzlich in Goebbels Sinne handelte, nahm sie in der Frage der Gastspiele trotzdem eine andere Haltung als dieser ein. Von ihr und nicht vom RMVP gingen mehrere Initiativen zu Gastspielen aus ${ }^{46}$. Zum einen hatten die Mitarbeiter in Paris besonders im weiteren Verlauf des Krieges ein vitales persönliches Interesse daran, ein reiches Arbeitsgebiet zu besitzen und dort unabkömmlich zu sein. Zum anderen mußten sich Propaganda Abteilung und Propaganda Staffel im Streit um den Aufgabenbereich der Kulturpropaganda mit der Botschaft vor Ort behaupten und waren darauf bedacht, ihre Kontrahenten durch eine größere Aktivität in den Schatten zu stellen. Dies war freilich angesichts der entgegengesetzten Weisungen aus Berlin nicht unproblematisch. Auch Abetz und Epting waren in der Folge weiterhin bestrebt, deutsche Theater- und Operngastspiele auf Pariser Bühnen zu bringen. Im Gegensatz zu Goebbels waren sie keineswegs darum besorgt, in Deutschland könne ein zu positives Bild vom Pariser Kulturleben entstehen. Die Botschaft verfolgte, in Ermangelung klarer Aussagen Hitlers zur zukünftigen Rolle Frankreichs im „neuen Europa “, eine Politik, die mit Hilfe von deutsch-französischen Kulturereignissen den französischen Künstlern und Intellektuellen einen Kulturaustausch vorgaukelte. Deutsche Gastspiele und deren Begleitprogramme fügten sich so ohne weiteres in die allgemein von der Botschaft verfolgte Kulturpolitik ein; diese versuchte, durch Veranstaltungen und Empfänge Bindungen zur französischen Elite zu knüpfen und die Basis für eine französische Kollaboration zu schaffen. Nutzen sollte diese Politik letztlich vor allem den Zielen der Besatzungsmacht ${ }^{47}$.

Für die Propaganda Abteilung bedeutete das Gastspiel des Schillertheaters in erster Linie einen Rückschlag im Konkurrenzkampf mit der Botschaft, während die gemeinsamen Ziele deutscher Kulturpropaganda hier in den Hintergrund traten. Dementsprechend berichtete das Theaterreferat der Propaganda Staffel nach Berlin, die französischen Presseartikel zu dem Gastspiel seien eine "persönlich gehaltene Reklame des Deutschen Instituts, bzw. dessen Leiters" 48 gewesen, während eine Zurückhaltung der militärischen Dienststellen sichtbar geworden wäre. Das Deutsche Institut maß dem Gastspiel des Schillertheaters eine zukunftsweisende Bedeutung bei. Laut Epting hatte man damit das französische Publikum von der Qualität des deutschen Schauspiels überzeugen können und die Möglichkeit geschaffen, weitere Gastspiele deutscher Theater mit Erfolg in Paris zu organisieren ${ }^{49}$. Ende März hieß es in den Planungen des Instituts, man wolle zukünftig in Paris ein

46 AN, AJ40 1001-7, Prop.St., Gr.Kult.Th., Tätigkeitsbericht, 1. 7.-31. 7. 1942.

47 Siehe bei Michels, Das Deutsche Institut, S. 255-266.

48 AN, AJ40 1001-7, Prop.St., Gr.Kult.Th., Tätigkeitsbericht, 27. 3.-4. 3.1941.

49 PA-AA, 1379, Kult 12 Nr. 2, DBP, Epting an AA, 12.3. 1941; Anlage, Bericht über die Weiterentwicklung des Theaterwinters in Paris, Kaspar Pinette. 
vielseitiges und lebendiges Bild des deutschen Theaters liefern. Das AA sollte in dieser Angelegenheit eine Einigung mit deth RMVP herbeiführen ${ }^{50}$. Allerdings stellte sich die Propaganda Staffel im Auftrag des RMVP diesen Gastspielplänen weiterhin entgegen. So verhinderte sie laut Epting ein für Anfang Juli 1941 geplantes Gastspiel des Wiener Burgtheaters sowie einige für Mitte April vorgesehene öffentliche Konzerte des Wiener Philharmonischen Orchesters in Paris und Bordeaux ${ }^{51}$. Goebbels sprach sich Mitte April erneut grundsätzlich gegen deutsche Gastspiele im besetzten Paris aus. Das RMVP teilte der Propaganda Abteilung in einem Erlaß vom 19. April 1941 mit, Goebbels habe entschieden, in Zukunft sollten in den besetzten Gebieten keine größeren Ensembles, Opernbühnen „oder andere besonders qualifizierte Gastspieltruppen vor Belgiern und Franzosen auftreten "52. Diese Entscheidung hatte jedoch, wie Abetz gegenüber dem AA kritisierte, nicht den Dienstweg über das Oberkommando der Wehrmacht, Abteilung Wehrmachtpropaganda (OKW/WPr) berücksichtigt; Propaganda Staffel und Abteilung unterstanden eigentlich dieser Stelle, während Goebbels ihnen offiziell keine direkten Weisungen erteilen durfte. Abetz empörte sich über dessen Vorgehen und betonte die Bedeutung der Gastspielfrage, die grundsätzlich die deutsche Politik im besetzten Frankreich berühre, womit er freilich meinte, daß sie allein in den Bereich seiner Kompetenzen fiel. Zudem war Goebbels Entscheidung sowohl dem AA als auch der Deutschen Botschaft zunächst nur mündlich bekannt, weil sie nicht offiziell informiert worden waren, sondern davon eher durch Zufall erfahren hatten ${ }^{53}$. Epting hatte im April 1941 bei der Auslandsstelle für Musik im Namen des Instituts einen Antrag auf einen Zuschuß des RMVP für einige geplante Pariser Konzerte des Kölner Kammertrios gestellt. In ihrer Antwort verwies die Auslandsstelle zum Erstaunen Eptings auf die oben genannte Weisung des Propagandaministers. Über Eptings Vorgehen, das ebenfalls nicht dem vorgeschriebenen Dienstweg entsprach, äußerte sich später das AA verärgert. Wiederholt betonte es, die Pariser Stellen sollten jegliche Anfragen an das RMVP oder deren Nebenstellen nur über das AA leiten. Außerdem behielt sich das AuBenministerium grundsätzlich das Recht vor, zu entscheiden, ob eine Beantragung von Zuschüssen beim RMVP notwendig sei ${ }^{54}$. Generell verlief die

50 Ibid. DBP, Epting an AA, 20. 3. 1941; geplant waren Aufführungen der Kammerspiele des Schauspielhauses München unter Intendant Otto Falkenberg in einer neuen Inszenierung von Johann Wolfgang von Goethes „Urfaust“ für Mai oder Juni 1941.

51 Ibid. DBP, Epting an AA, Telegramm Nr. 2287, Auf Telegramm Nr. 3818 vom 29. 7., 31. 7. 1941.

52 BAB, 50.01-506, Prop.Abt., Schmidtke, Meldung 25007 an RMVP, 12. 5. 1941; Schmidtke nimmt darin Bezug auf die Weisung des RMVP vom 19.4. 1941; siehe auch PA-AA, 1379, Kult 12 Nr. 2, AA, Kolb an DBP, Kult K 818, 31. 3. 1941.

53 PA-AA, 1380, Kult 12 Nr. 3, Abetz an AA, 11.6.1941.

54 Ibid. AA, Stahlecker an RMVP, zu Kult K 2381, Durchdruck, 19. 5. 1941; abschriftlich der DBP auf den Drahtbericht vom 29. 4. 1941, Nr. 1328 zur Kenntnis übersandt. 
Kooperation zwischen dem Deutschen Institut und dem AA nicht immer reibungslos und das AA hatte mitunter eine zu große Selbständigkeit seiner Pariser Dienststellen zu beklagen 55 .

Um deutsche Gastspiele im besetzten Paris zu verhindern, besaß das RMVP in Berlin etliche Möglichkeiten der Einwirkung. Immerhin lag in Deutschland die Verwaltung und Organisation des Kulturlebens sowie die Vermittlung von Künstlern weitestgehend in den Händen des RMVP und seiner Nebenstellen. An der Vermittlung von Künstlern in das Ausland waren neben der Theater und Musikabteilung des Propagandaministeriums auch dessen Auslandsabteilung, die Auslandsstelle für Theater sowie die Auslandsstelle für Musik beteiligt. Die deutschen Theater dürften wenig Interesse daran gehabt haben, sich generell mit dem RMVP aufgrund eines einmaligen Pariser Gastspiels zu überwerfen. Um seine Position durchzusetzen, mußte Abetz deshalb zu einem Mittel greifen, das die Einflußmöglichkeiten des Propagandaministers wirksam außer Kraft setzen konnte, und zwar zu einer sogenannten Führerentscheidung. Tatsächlich gelang Abetz im Mai 1941 mit Hilfe eines von Hitler angeordneten Gastspiels der Berliner Staatsoper in Paris eine grundlegende Wendung zu seinen Gunsten im Streit um die Gastspiele. Die Propaganda Abteilung wurde erst über die Veranstaltung informiert. Sie schrieb dem RMVP, sie habe erfahren, die Botschaft plane ein Gastspiel der Berliner Staatsoper in Paris und wolle wissen, ob die Entscheidung Goebbels vom 19. A pril nun hinfällig geworden sei ${ }^{56}$. Die Antwort lautete, das Gastspiel solle zwar auf Anordnung des Führers erfolgen, die grundsätzliche Haltung des Propagandaministers bleibe jedoch unverändert ${ }^{57}$. Abgesehen davon, daß Abetz für die Genehmigung des prestigeträchtigen Gastspiels hinter dem Rücken von Goebbels direkt bei Hitler interveniert hatte, war auch für dessen Durchführung die Beteiligung des RMVP nicht vorgesehen ${ }^{58}$. Wie eigenständig der deutsche Botschafter hier agiert hatte, zeigt sich in der Tatsache, daß er das AA ebenfalls nicht über seine Pläne informiert hatte. Dieses beschwerte sich bei der Botschaft über ihr zu selbständiges Vorgehen, denn nur durch Zufall erfuhr das AA in Gesprächen mit der Berliner Staatsoper von dem bereits fest eingeplanten Pariser Gastspiel. Allerdings war das AA nicht nur über den Mangel an Information verärgert. Der Einsatz der Berliner Staatsoper als nach Meinung des AA repräsentativster deutscher Bühne sollte zunächst nur in den Ländern erfolgen, die Deutschland besonders nahestanden. Das Gastspiel sollte „den Charakter einer besonderen Auszeichnung für das damit bedachte Land dokumentie-

Ibid. DBP, Epting, Fernschreiben für Botschafter Abetz, z.Zt. AA, Telegramm Nr. 1328, 29. 4. 1941.

55 MiCHELs, Das Deutsche Institut, S. 108.

56 BAB, 50.01-506, Prop.Abt. an RMVP, Meldung 25007, 12. 5. 1941.

57 Ibid. RMVP, Abt. Th., Schlösser an Prop.Abt., 16. 5. 1941.

58 Ibid. RMVP, Abt. Th., Schlösser an Goebbels, Betr. Gastspiel Staatsoper Berlin in Paris, 6. 5. 1941. 
ren“59. Aus diesem Grunde hätte, so das AA, man damit bis zu einem Friedensschluß mit Frankreich warten wollen. Obgleich Abetz der Initiator des Gastspiels war, vermutete das AA zu diesem Zeitpunkt noch, der Abschluß des Vertrages sei allein auf die Aktivitäten der KDF zurückzuführen und wollte wissen, ob die Botschaft über diese Planung informiert gewesen sei ${ }^{60}$. Die kurze Antwort Eptings verwies lediglich darauf, daß das Gastspiel auf ausdrücklichen Wunsch des Führers erfolge und deswegen die Bedenken des AA wohl hinfällig sein dürften ${ }^{61}$. Als sich das AA daraufhin aktiv an den Vorbereitungen des Gastspiels beteiligte, zeigte sich erneut, daß die Kooperation mit der Botschaft und dem Deutschen Institut nicht immer reibungslos ablief. Als in Paris bereits sämtliche Mitglieder der Staatsoper für die Aufführungen probten, war dort erst ein verspätetes Schreiben des AA mit Informationen über die genaue Zusammenstellung des Ensembles eingetroffen. Da die Botschaft mit einer Werbung für das Gastspiel aber Tage vorher hatte beginnen müssen, waren die Informationen des AA zu spät eingetroffen. Auf diese Fehlplanung verwies Epting, als das AA zu einem späteren Zeitpunkt erneut Klage über die Selbständigkeit ihrer Pariser Stellen führte ${ }^{62}$.

Für Goebbels bedeutete die Durchsetzung dieses Gastspiels nicht nur eine Niederlage, weil er grundsätzlich dagegen war, sondern auch weil sein Ministerium bis zu dem Zeitpunkt bei Auslandsgastspielen mit der Berliner Staatsoper regelmäßig zusammengearbeitet hatte. Als Schlösser Anfang Mai diese Planung zufällig zu Ohren kam, setzte er sich mit Heinz Tietjen, dem Intendanten der Berliner Staatsoper, in Verbindung. Jener beteuerte, er habe Hitler mehrfach auf die bisherige gute Zusammenarbeit mit dem RMVP bei Auslandsgastspielen aufmerksam gemacht. Der habe zu verstehen gegeben, daß es sich nur um eine Ausnahme handele, da Abetz besondere finanzielle Mittel für dieses Gastspiel zur Verfügung ständen. In seinem Bericht an Goebbels resümierte Schlösser: „Ob, nachdem Abetz sich für seine Pläne nunmehr unter Umgehung unseres Hauses direkt der Sanktion des Führers zu bedienen wußte, eine Einwirkung denkbar ist, entzieht sich meiner Beurteilung "63. Tatsächlich bedeutete dies, daß aufgrund der Entscheidung durch Hitler keine Einwirkung auf die Durchführung des Gastspiels mehr möglich war, es sei denn jener änderte seine Meinung. Goebbels, der offenbar erst durch diesen Bericht Schlössers von dem Vorhaben der Botschaft unterrichtet wurde, unternahm keinen Versuch, sein Ministerium nachträglich an den Planungen zu beteiligen. Über die Haltung, die er zu diesem Gastspiel einnahm, heißt es: „Der Minister hält es trotz der Genehmigung durch den Füh-

59 PA-AA, 1380, Kult 12 Nr. 3, AA Kolb Kult K an Bot., 24. 4. 1941.

60 Ibid.

61 Ibid. DBP, Epting an AA, 6. 5. 1941.

62 PA-AA, 1368, Kult 2 Nr. 1a, DBP, Schleier an AA, Durchschlag als Konzept, Betr. Kult K 3278 vom 26.6. 1941 .

63 BAB, 50.01-506, RMVP, Abt.Th., Schlösser an Goebbels, Betr. Gastspiel Staatsoper Berlin in Paris, 6. 5. 1941. 
rer für falsch und wird in diesem Sinne beim Führer vorstellig werden" 64 . Sollte eine solche Intervention tatsächlich stattgefunden haben, so scheint sie keineswegs erfolgreich gewesen zu sein, denn die Berliner Staatsoper reiste schließlich auf Einladung des Deutschen Instituts mit Chor, Orchester und sämtlichen Dekorationen nach Paris. Dort gastierte sie etwa eine Woche lang in der Pariser Nationaloper. Das Auswärtige Amt in Berlin und die Deutsche Botschaft Paris waren die Hauptorganisatoren ${ }^{65}$.

Offizieller Anlaß des Gastspieles war der Erwerb des Hauses, in dem Richard Wagner vor hundert Jahren zum ersten Mal in Paris gewohnt hatte; Käufer war die Stadt Paris. Das deutsche Operngastspiel sollte gleichsam eine Antwort auf diese kulturpolitische Geste der Franzosen sein ${ }^{66}$. Die Staatsoper gab am 18. und 20. Mai Mozarts „Entführung aus dem Serail“. Eine Aufführung von Wagners „Tristan und Isolde“ in Bayreuther Besetzung legten die Veranstalter auf den 22. Mai als Wagners Geburtstag sowie den 25. Mai; es dirigierte Herbert von Karajan, Ehrengast war Winifred Wagner. Angeblich sollen sich die deutschen Künstler angesichts der Bedeutung des Auftrages durch Hitler mit besonderer Begeisterung eingesetzt haben und das Gastspiel wurde als eines der schönsten der Staatsoper angesehen ${ }^{67}$. Germaine Lubin, die als einzige französische Interpretin mitwirkte, war als Wagner-Sängerin bekannt und soll mit Winifred Wagner „eng befreundet" ${ }^{48}$ gewesen sein. Hitler persönlich hatte sie eingeladen, bei den Bayreuther Festspielen mitzuwirken; ihr 24jähriger Sohn wurde auf seinen Befehl hin aus der deutschen Kriegsgefangenschaft beurlaubt. Über ihre Mitwirkung als Isolde in „Tristan und Isolde“ unter Karajan bemerkte ein Mitarbeiter des Deutschen Instituts, sie habe ihre Rolle sogar in der Wehrmachtsvorstellung gesungen, obgleich sie mehrere Drohbriefe von französischer Seite erhalten hatte ${ }^{69}$. Bei einem Empfang in der Deutschen Botschaft trafen sich, wie es in einem Artikel der vom Deutschen Institut publizierten Deutsch-französischen Monatshefte (DFMH) heißt, „eine große Anzahl französischer und deutscher Persönlichkeiten mit Frau Winifred Wagner und den Künstlern

64 Ibid. RMVP, Gutterer an Leiter Abt.Th., 7. 5. 1941.

65 Insgesamt soll Abetz für die Veranstaltungen deutscher Gastspiele in Paris übrigens 30-40 Millionen Reichsmark ausgegeben haben; siehe CCDR, L'Emprise allemande, Presse, Anhang V, S. XIV.

66 BAB, 50.01-506, RMVP, Abt.Th., Schlösser an Goebbels, Betr.: Gastspiel Staatsoper Berlin in Paris, 6. 5. 1941. Siehe auch AN, AJ40 1001-7, Prop.St., Gr.Kult.Th., Aktennotiz für den Gruppenleiter, 24. 5. 1941. Drewniak mißt den Gründen für das Gastspiel der Staatsoper in Paris eine zu weitreichende politische Bedeutung bei: „sie hingen mit der politischen Vorbereitung des Überfalls auf die Sowjetunion zusammen und zielten auch auf Frankreichs Stellung im Krieg gegen England" (DREWNIAK, Das Theater, S. 114).

67 AN, AJ40 1001-7, Prop.St., Gr.Kult.Th., Aktennotiz für den Gruppenleiter, 24. 5. 1941.

68 PA-AA, 1379, Kult 12 Nr. 2, DIP, Bremer, Aufzeichnung für Schleier, 13. 11. 1941. Laut Bremer war zudem Pétain mit Germaine Lubin befreundet.

69 Ibid. 
der Staatsoper“. Die Resonanz der Aufführung beim französischen Publikum soll gut gewesen sein ${ }^{70}$. Als Höhepunkt bezeichnete der Artikel ein Konzert der Berliner Staatskapelle im Palais de Chaillot, das ebenfalls Karajan dirigierte: „Das Konzert rief Beifallskundgebungen hervor, wie sie tatsächlich in Paris in einem Konzertsaal noch nicht vorgekommen sind"71. Abgesehen davon, ob dieses Gastspiel nun tatsächlich ein derartig großer Erfolg deutscher Kulturpropaganda war oder nicht, vermittelte die kollaborierende Pariser Presse zumindest diesen Eindruck und dies schien Abetz zusätzlich in seiner Position in der Frage der Gastspiele zu bestärken. Nach diesem Etappensieg setzte sich der deutsche Botschafter erneut beim AA dafür ein, in Berlin auf eine Einigung mit dem RMVP hinzuwirken. Er drängte das AA zu einer besseren Regelung seiner Kompetenzen, zumal die Entscheidung Hitlers, so seine Argumentation, ja gezeigt hätte, daß seine Position von diesem persönlich gedeckt würde ${ }^{72}$.

Das prestigeträchtige Gastspiel der Staatsoper hatte zur Folge, daß Goebbels nun seinerseits ähnliche Veranstaltungen plante und hier in eine Art kulturpropagandistischen Wettstreit mit der Gegenseite trat. Letztere erhoffte sich dagegen eine bessere Kooperation mit dem RMVP sowie eine endgültige Regelung des Streits um den Aufgabenbereich der Kulturpropaganda. In einem Schreiben der kulturpolitischen Abteilung des AA an das RMVP heißt es, "nach den deutschen Bühnenerfolgen in Paris während der letzten Spielzeit" ${ }^{73}$ begrüße man die Absicht des Propagandaministeriums, in der nächsten Spielzeit beste deutsche Opern- und Schauspielbühnen nach Paris zu entsenden. In dem Brief wurde darum gebeten, das RMVP möge wie im übrigen Ausland im Einvernehmen mit dem AA handeln und die Propaganda Abteilung zu laufendem Kontakt mit der Botschaft veranlassen. Zudem meinte das AA: „Es wäre zu begrüßen, wenn über die Frage, welche deutsche Stelle in Frankreich künstlerische Veranstaltungen vor Franzosen durchzuführen hat, baldigst eine grundsätzliche Entscheidung herbeigeführt würde" 74 . Das Gastspiel der Berliner Staatsoper im Mai 1941 bedeutete einen entscheidenden Wendepunkt in der Entwicklung der Streitigkeiten um die Gastspielfrage zwischen RMVP und AA sowie den Pariser Dienststellen. Während die Propaganda Abteilung auf Goebbels Weisung vorher eher eine Politik der Sabotage betrieben hatte trat sie nun gleichsam in einen kulturpropagandistischen Wettlauf mit dem Deutschen Institut und der Botschaft.

Noch im Mai 1941 erteilte Goebbels den Auftrag für ein aufwendiges Operngastspiel, das als Gegenschlag für die Aufführungen der Staatsoper dienen sollte. Die Abteilung Theater im RMVP und die Propaganda Staffel sollten Aufführungen des Deutschen Opernhauses Berlin, der Charlotten-

70 Die Berliner Staatsoper in Paris, in: DFMH 5-6 (1941) S. $192 \mathrm{f}$.

71 Ibid.

72 PA-AA, 1380, Kult 12 Nr. 3, Abetz an AA, 11.6. 1941.

73 PA-AA, 1379, Kult 12 Nr. 2, AA, Kult K, Wüster an RMVP, 8. 9. 1941.

74 Ibid. 
burger Oper, mit der "Lustigen Witwe“ für Mitte Juli im besetzten Paris organisieren ${ }^{75}$. Allerdings ließ sich die Berliner Inszenierung der „Lustigen Witwe" letztlich nicht auf die Bühnenverhältnisse der Pariser Nationaloper übertragen. Stattdessen schlug das RMVP die „Fledermaus“ vor. Das Bühnenbild dieser Aufführung war leichter zu transportieren und einfacher an die Pariser Bühnenverhältnisse anzupassen. Trotzdem waren die Vorbereitungen sehr aufwendig. Allein für den Transport der Dekorationen benötigte das RMVP zehn Eisenbahnwagen sowie einen kompletten Sonderzug für Mitwirkende und Personal, insgesamt 320 Personen $^{76}$. Deswegen mußte das Gastspiel, das zunächst für den Juli 1941 geplant war, aufgrund der Transportlage auf den Anfang der Spielzeit 1941/42 verschoben werden ${ }^{77}$. Goebbels hatte sich also aus pragmatischen Gründen sowohl mit der Wahl eines anderen Stückes und auch eines anderen Termins einverstanden erklären müssen. Trotz dieser praktischen Hindernisse war das RMVP darauf bedacht, nur Gastspiele bester Qualität nach Paris zu bringen. Der Grund hierfür war nun nicht nur das in den Augen der deutschen Funktionsträger so anspruchsvolle Pariser Publikum, sondern auch der Konkurrenzkampf der deutschen Dienststellen. Schlösser betonte Goebbels gegenüber, in jedem Falle dürfe das Gastspiel nicht gegenüber dem der Staatsoper Berlin abfallen ${ }^{78}$. Mit dem Gastspiel der Berliner Staatsoper hatte Abetz also auch einen Maßstab für die Qualität deutscher Opernaufführungen in Paris gesetzt. Im September 1941 gastierte unter hohem Aufwand die Charlottenburger Oper im Thêâtre National de l'Opéra mit sieben Aufführungen der „Fledermaus“ von Johann Strauß. Drei Vorstellungen waren ausschließlich für die Wehrmacht gedacht und vier öffentlich. Insgesamt rund 400 Personen waren hierfür von Berlin nach Paris gereist und die Organisation kostete das RMVP 281 510,27 Reichsmark ${ }^{79}$. Die Resonanz in der Pariser Presse war positiv. Daß Goebbels trotzdem grundsätzlich immer noch tendenziell gegen derartige Veranstaltungen in Paris eingestellt war, zeigt sich in seiner Anweisung an die deutsche Presse, „aus internen Gründen "80 solle keine Propaganda für dieses Ereignis betrieben werden. Der Grund, weshalb Goebbels den Auftrag zu diesem Gastspiel erteilt hatte, war vor allem der Streit um den Aufgabenreich der Kulturpropaganda. Deshalb interessierte die Organisatoren abgesehen von der Rezeption des Gastspiels bei Pariser Publikum und Presse vor allem dessen Bedeutung für den Konkurrenzkampf der deutschen

75 BAB, 50.01-506, RMVP, Abt.Th., Lang an Major Titel, RMVP, 29. 5. 1941.

76 Ibid. RMVP, Abt.Th., Keppler an Goebbels, 16. 6. 1941.

77 Ibid. RMVP, Staatssekretär Gutterer an Leiter Abt.Th., Betr.: Gastspiel Dt. Opernhaus in Paris, 20. 6. 1941.

78 Ibid. RMVP, Abt.Th., Schlösser an Goebbels, 9. 7. 1941.

79 Ibid. RMVP, Abt.Th., Schlösser an Goebbels, 18. 2. 1942.

80 BAB, 50.01-705, RMVP, Abt.Th., Schlösser an Staatssekretär Gutterer, RMVP, 8. 9. 1941; siehe auch BAB, 50.01-705, RMVP, Ministeramt, Frowein an Leiter Abt.Th., Betr.: Gastspiel des Deutschen Opernhauses in Paris, 13. 9. 1941. 
Dienststellen. Schlösser und Lang, die anläßlich der Aufführungen von Berlin nach Paris gereist waren, besprachen mit ihren Pariser Kollegen die Stellung der Propaganda Staffel gegenüber der Deutschen Botschaft. Sie waren sich darüber einig, daß die Propaganda Staffel im Verlauf des vergangenen Jahres gleichsam an Boden gewonnen habe und sie „in kulturpolitischer Hinsicht als unbedingt führend "81 gesehen werden müsse. Diese Aussage ist freilich weit übertrieben, wenn man bedenkt, daß das Charlottenburger Gastspiel vom September 1941 bisher die einzige von der Staffel organisierte gröBere Aufführung dieser Art war; konkrete Vorarbeiten zu weiteren kulturpropagandistischen Aktivitäten im Bereich des Theaters und der Musik liefen bei der Staffel erst im September/Oktober 1941 langsam an ${ }^{82}$.

Nach seiner Rückkehr aus Paris berichtete Schlösser Goebbels, die Propaganda Staffel habe sich dank der Tätigkeit des Sonderführers Lucht gegenüber der Botschaft und dem Deutschen Institut sehr gut durchgesetzt. Er selbst habe in Paris mit Schleier und Epting - Abetz war nicht anwesend über die Frage der Kompetenzen der deutschen Dienststellen gesprochen. Nach Ansicht des AA blieben die militärischen Stellen im Gegensatz zur Botschaft nur vorübergehend in Frankreich. Aus diesem Grunde wollte das AA bereits jetzt die einzige für die Theaterbespielung in Paris zuständige Dienststelle sein. Schlösser dagegen vertrat die Position, solange sich deutsches Militär in Frankreich befände, sollten Theatergastspiele in erster Linie der Unterhaltung deutscher Truppen dienen und in Verbindung damit auch der kulturpolitischen Aufgabe nutzen. Schlösser warf dem Institut und der Botschaft vor, sie hätten sich eigenmächtig mit deutschen Theaterleitern in Verbindung gesetzt und dort Verwirrung hervorgerufen. Er plädierte für zukünftige Zusammenarbeit und beharrte auf den Ansprüchen des RMVP: „Deutlich habe ich zum Ausdruck gebracht, daß der von der Gegenseite gewünschte ,Totalitätsanspruch' zur Zeit nicht realisierbar sei" ${ }^{\text {"83. Trotz dieser }}$ Streitigkeiten konnte Schlösser bei den Pariser Dienststellen allerdings auch gemeinsame Positionen feststellen. Nach einer Unterredung mit dem Pariser Beauftragten der KDF kam er zu dem Schluß, sämtliche Stellen seien sich darüber einig, daß diese kulturelle Arbeit fortgesetzt und „auf lange Sicht fundiert werden müsse "84. Diese Übereinstimmung dürfte auch darin begründet gewesen sein, daß alle deutschen Dienststellen den Wunsch hatten, die Wichtigkeit der deutschen Kulturpolitik - und damit des eigenen Arbeitsgebietes $-\mathrm{zu}$ verteidigen.

Im Sommer 1941 verschärfte sich der Konkurrenzkampf der deutschen Dienststellen. Die Propaganda Staffel versuchte sogar, konkrete Planungen für Gastspiele oder andere Kulturveranstaltungen, die ursprünglich vom

81 AN, AJ40 1001-7, Prop.St., Gr.Kult.Th., ohne Titel, 25. 9. 1941.

82 Ibid. Schreiben des RMVP, Referent Dr. Lang an die Prop.St., Gr.Kult.Th. vom 2. 10.

1941. Diese Vorbereitungen sollen später noch näher erläutert werden.

83 BAB, 50.01-506, RMVP, Abt. Th., Schlösser an Goebbels, 8. 10. 1941.

84 Ibid. 
Deutschen Institut initiiert worden waren, an sich zu reißen. Ende Juli 1941 beklagte sich Epting hierüber bei Abetz, der zu diesem Zeitpunkt in Berlin weilte. Der für bildende Künste zuständige Referent Ehmsen hatte Epting mitgeteilt, die Propaganda Staffel wolle die seit längerem geplante BrekerAusstellung nun durchführen. Laut Ehmsen hatte die Staffel vom Präsidenten der Reichskammer der bildenden Künste, Prof. Adolf Ziegler, und dem RMVP hierzu den Auftrag erhalten. Allerdings war das Deutsche Institut bereits mit der Organisation dieser Ausstellung befaßt. Epting bat um Intervention des AA, damit die Ausstellung von seiner Dienststelle durchgeführt würde, was letztlich auch der Fall war ${ }^{85}$. Abetz war über derartige Vorgänge wenig erfreut und versuchte seinerseits, gegen die Aktivitäten der Propaganda Staffel vorzugehen. Als effizientes Mittel setzte das AA hier die Verweigerung der Ausreiseerlaubnis von Mitarbeitern des RMVP ein. Wer von Berlin nach Paris reisen wollte, mußte dies zunächst beim AA beantragen. Im April 1941 beklagte das RMVP während einer Sitzung der Auslandsabteilung, das AA habe wiederholt bei Ausreisen von Mitarbeitern des RMVP bewußt Schwierigkeiten bereitet ${ }^{86}$. Im Juli 1941 ersuchten die RMVP-Mitarbeiter Lang und Götze beim AA um die Erlaubnis für eine Reise nach Paris. Sie wollten bei der Staffel Paris mit Lucht über deutsche Theater- und Operngastspiele für die bevorstehende Saison 1941/42 verhandeln und insbesondere den Etat für Auslandsgastspiele und Austauschgastspiele festlegen ${ }^{87}$. In Abetz Auftrag bat Schleier das AA, beide Anträge abzulehnen. Abetz vertrat den Standpunkt, Gastspiele seien ausschließlich Angelegenheit der Botschaft und des Deutschen Instituts. Planungen durch andere Dienststellen hielt er schlicht für überflüssig8 ${ }^{88}$. Das AA genehmigte diese Reise schließlich unter der Bedingung, daß die betreffenden Personen sich vor ihrer Abreise mit der kulturpolitischen Abteilung im AA in Verbindung setzten um den Zweck der Reise vorher mit dem AA abzusprechen. Ferner sollten sie in Paris mit der Deutschen Botschaft „Fühlung halten" 89 . Abetz nahm hier eine rigorosere Haltung als das AA ein. Die Propaganda Staffel war in ihrem Bestreben, die Planungen kleinerer Gastkonzerte fortan allein für sich zu reservieren, ebenfalls sehr aktiv. So erteilte sie einer größeren französischen Konzertdirektion, der Association artistique, die Erlaubnis, deutsche Künstler nach Frankreich zu verpflichten, allerdings „nur in Zusammenarbeit mit der Propaganda Staf-

85 PA-AA, 1379, Kult 12 Nr. 2, DBP, Epting an AA (auch an Abetz z.Zt. AA), Fernschreiben Nr. 2221, 25. 7. 1941.

86 BAB, 50.01-705, RMVP, Abt. Ausland, Protokoll der Sitzung am 8. 4. 1941 beim Leiter A, Referent Dotti, 17. 4. 1941.

87 PA-AA, 1379, Kult 12 Nr. 2, AA, Garben an DBP, Telegramm Nr. 3785, 25. 7. 1941; eine Bleistiftnotiz auf diesem Dokument lautet: „Bis Rückkehr Botschafter zurückstellen".

88 Ibid. DBP, Schleier an AA, Telegramm Nr. 2257, auf Drahterlaß 3785 vom 25. 7. u. 2241 vom 26. 7., 29. 7. 1941.

89 Ibid. AA, Garben an DBP, Telegramm Nr. 3999, Auf Drahtbericht 2257, 14. 8. 1941. 
fel" 90 . Allein die Staffel beauftragte diese Agentur mit der Durchführung von Konzerten. Hierbei schlug sie die deutschen Künstler der Association artistique vor, das RMVP lud sie offiziell nach Paris ein. Epting beschwerte sich beim AA, diese Agentur, in der sich die französischen Konzertagenturen Dandelot, Kiesgen und Valmalète zusammengeschlossen hatten, würde mit der Bevorzugung durch die Staffel eine Art Monopolstellung erhalten. Vor dem Kriege sollen sich aber die genannten Agenturen keineswegs um die Vermittlung deutscher Künstler gekümmert haben. Nach Epting sollte die Besatzungsmacht die Agenturen bevorzugen, die sich bereits vor dem Kriege um die Vermittlung deutscher Künstler bemüht hätten ${ }^{91}$. Der wirkliche Grund für Eptings Beschwerde waren freilich die Aktivitäten der Staffel, die das Institut an der Veranstaltung eigener Gastkonzerte hindern wollte.

Die Propaganda Staffel versuchte im Sommer 1941, die Durchführung einer vom Deutschen Institut geplanten Mozart-Woche zu übernehmen. Als dies scheiterte, bemühte sich das RMVP, die Veröffentlichungen von Berichten des DNB über diese Veranstaltung in der Deutschen Presse zu verhindern ${ }^{92}$. Gerade am Beispiel der Mozart-Woche wird deutlich, wie stark hier die Kompetenzstreitigkeiten in den Vordergrund traten. Am Abend der ersten Veranstaltung, am 13. Juli 1941, berichtete Epting an Sellschopp, den Leiter der Außenstelle für Musik in Berlin, daß die Mozart-Woche mit einem Konzert des Berliner Kammerorchesters im Hofe des Palais Royal mit über 200 Zuhörern nun begonnen hatte und bisher ein großer Erfolg war. Diese Nachricht gab Sellschopp an die Musikabteilung im RMVP weiter. Die Reaktion des Referenten war folgende: „Ob das Konzert ein Erfolg war, interessiert mich nicht, mich interessiert lediglich wieweit die Propaganda Staffel

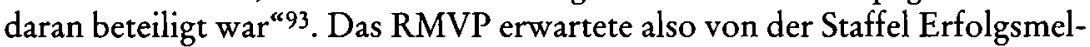
dungen, die Interessen deutscher Kulturpropaganda traten hinter Aspekten des Konkurrenzkampfes zurück.

Während die Deutsche Botschaft die alleinige Zuständigkeit für kulturpropagandistische Veranstaltungen für sich beanspruchte, kritisierte sie zudem vehement die von der Propaganda Abteilung bzw. Staffel durchgeführten Konzerte und Gastspiele. Am 29. August und 2. September 1941 gaben die Berliner Philharmoniker unter Dirigent Eugen Jochum auf Einladung der Propaganda Staffel im Théâtre national du Palais de Chaillot ein öffentliches Konzert. Die französische Konzertagentur Association artistique hatte die Vorbereitungen übernommen. Epting berichtete an das AA, die Propaganda Staffel sei nicht auf Plakaten und in der Presse sondern nur in Einladungen an

90 Ibid. AA, Kult K, Kolb an DBP, 22. 8. 1941.

91 Ibid. DBP, Epting an AA, Betr.: Kult K vom 22. 8. 1941, 9. 9. 1941.

92 Ibid. Siehe auch PA-AA, 1142, Kult 12 Nr. 3, DBP, Schleier an den Gesandten Bergmann über Dr. Schwarzmann, AA, 28. 7.1941.

93 PA-AA, 1142, Kult 12 Nr. 3, Schleier an AA, Betr.: Einstellung des Propagandaministeriums gegenüber der vom DIP. veranstalteten Mozartwoche, 5. 8. 1941; siehe bei Michels, Das Deutsche Institut, S. 133. 
deutsche und französische Gäste als Organisator in Erscheinung getreten. Er kritisierte, daß nur wenige Vorankündigen in der Presse erschienen waren, obgleich seiner Ansicht nach die Propaganda Staffel stetigen Einfluß auf die Pariser Presse ausübte. Laut Epting waren die Konzerte nur ausverkauft, weil das Pariser Publikum sich ohnehin für Musikveranstaltungen interessiere und die Logen mit geladenen Gästen der deutschen Dienststellen besetzt gewesen waren. Epting bemängelte vor allem die geringe Teilnahme französischer bekannter Persönlichkeiten; er habe dort nur Fernand de Brinon und Jacques Benoist-Méchin gesehen. Seiner Ansicht nach, war auch der Beifall geringer als dies sonst bei Konzerten mit deutscher Musik der Fall war. Abgesehen von der Auswahl des Dirigenten, die er ebenfalls nicht gut hieß, entsprach laut Epting das Programmheft inhaltlich nicht den Anforderungen, „die an eine Vertretung deutscher kultureller Interessen im Ausland gestellt werden müssen"94. Das in einem "geschraubten Propagandastil" verfaßte Heft, wirke in der französischen Übersetzung besonders lächerlich und sei wenig überzeugend. Vor allem mit einem Artikel über die „Eroica“ von Beethoven habe die Propaganda Abteilung die Grenzen des sogenannten guten Geschmacks verletzt ${ }^{95}$. Epting weigerte sich, den Artikel an die französische Presse weiterzugeben. Weiter empörte er sich: „Kulturpolitisch untragbar ist es aber, wenn die deutsche Musik Bachs gleichsam ein Lob bekommt, weil sie an slawische Volksmusik wie die von Smetana und Dvorak erinnert"96. Nicht nur organisatorisch, sondern auch bezüglich der Inhalte der Kulturpropaganda warf er der Staffel Inkompetenz vor.

Diese sparte ihrerseits ebenfalls nicht mit Kritik an Eptings Arbeit. So warf sie ihm im Frühjahr 1941 vor, seine kulturelle Aktivität sei allein auf propagandistische Augenblickserfolge ausgerichtet und verfolge keine zielbewußte Linie, „in der die für die Kulturpropaganda des Neuen Deutschlands maßgeblichen Gesichtspunkte berücksichtigt ${ }^{\text {"97 }}$ wären. Diese Kritik hatte die Staffel im Zusammenhang mit den Unstimmigkeiten um die von Epting angeblich initiierte Planung einer Aufführung der "Josephslegende" von Richard Strauß durch Serge Lifar mit seinem Ballett-Ensemble geübt. Wegen der alttestamentarischen Geschichte erschien dieses Werk der Staffel wenig zur „Hebung des Ansehens des neueren deutschen Musikschaffens“98 in $\mathrm{Pa}$ ris geeignet. Das Stück war zwar nach einem Verbot wieder auf deutschen Bühnen erlaubt, aber deswegen nach Ansicht der Staffel für Paris noch lange

94 PA-AA, 1380, Kult 12 Nr. 3, DIP, Bökenkamp an AA, Betr.: Konzert der Berliner Philharmoniker in Paris, 3. 9. 1941.

95 Ibid. Es ist denkbar, daß dieser Artikel folgendes erwähnte: Beethoven hatte die Partitur der „Eroica“ zunächst Napoleon gewidmet, nach der französischen Besetzung von Wien und Berlin die Widmung jedoch wieder revidiert.

96 Ibid.

97 PA-AA, 1368, Kult 2 Nr. 1a, Prop.St., Staffelführer Paltzo an Schleier, DBP, 17. 4. 1941.

98 Ibid. 
nicht geeignet. Immerhin habe man die "Josephslegende“ dem deutschen Publikum erst nach „acht Jahren kultureller Ausrichtung" ${ }^{\text {"99 }}$ wieder vorführen können. Epting bestritt allerdings, der Initiator der Planungen zu sein und wies die Vorwürfe der Staffel mit einem Verweis auf die nationalsozialistisch ausgerichtete Politik der Botschaft zurück: „Die Deutsche Botschaft und die ihr angeschlossenen Dienststellen führen ihre Aufgaben ausschließlich nach nationalsozialistischen Gesichtspunkten, unter Berücksichtigung der besonderen Mentalität der Franzosen und auf lange Sicht geplant durch “100. Epting betonte also, daß sein Institut nationalsozialistisch geprägte Kulturpropaganda betrieb, wobei es paradoxerweise gleichzeitig die angeblichen Eigenheiten des Pariser Publikums berücksichtigte. Wie dies möglich gewesen sein soll, bleibt unklar und wird auch aus den Aktivitäten des Instituts nicht ersichtlich. Zudem waren die Vorstellungen von einer nationalsozialistisch geprägten Kulturpropaganda offenbar eher diffus. War das „Eroica“-Konzert der Berliner Philharmoniker inhaltlich nationalsozialistische Kulturpropaganda oder nur eine von der Staffel ungeschickt durchgeführte Veranstaltung? Hatte wiederum Epting tatsächlich die Planungen zur "Josesphslegende" initiiert und damit inhaltlich unerwünschte deutsche Kulturpropaganda betrieben? Die Kontrahenten im Kampf um den Aufgabenbereich der Kulturpropaganda warfen sich gegenseitig vor, eine nicht genügend nationalsozialistisch geprägte Kulturpolitik zu betreiben. Gleichzeitig mußten beide Dienststellen jedoch auch auf den Erfolg der Veranstaltungen abzielen und versuchen, das Pariser Publikum von der Qualität deutscher Kultur zu überzeugen.

Besonders im Herbst 1941 bemühte sich die Propaganda Staffel vermehrt um Theatergastspiele; so plante sie Aufführungen des Preußischen Staatsschauspiels unter der Leitung von Intendant Gustaf Gründgens von Oktober bis Dezember 1941 mit "Faust I“ von Johann Wolfgang von Goethe101. Gründgens hatte angeblich starkes Interesse an der Idee eines Pariser Gastspiels gezeigt, doch wollte er damit warten, bis die Frage eines künstlerischen Austauschs mit Frankreich geklärt war ${ }^{102}$. Angesichts des durch Goebbels verhängten strikten Verbotes französischer Werke auf deutschen Bühnen war dies relativ unwahrscheinlich. Zum gleichen Zeitpunkt plante auch das Deutsche Institut eine Pariser Aufführung mit Goethes „Faust I“ durch das Stadttheater Bochum. Das RMVP verweigerte jedoch die Zustimmung zu diesem

\footnotetext{
99 Ibid.

100 Ibid. DBP, Schleier an Staffelführer Paltzo, 19. 4. 1941.

101 BAB, 50.01-705, RMVP, Referent Cunz an Leiter Abt.Th., Betr.: Bespielung von Paris in der Spielzeit 1941/42, 19. 9. 1941; ibid. Abt.Th., Lang an Abt. Ausland, 27. 10. 1941.

102 BAB, 50.01-292, RMVP, Leiter Abt.Th. an Lang, 30. 6. 1941. Gründgens wollte, wenn französische Stücke wieder in Deutschland gespielt werden können, Werke von Marcel Pagnol und "Cyrano von Bergerac" von Edmond Rostand aufführen sowie die

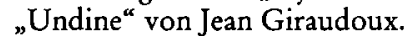


Gastspiel unter dem Vorwand, daß bereits das Preußische Staatsschauspiel mit diesem Stück in Paris gastieren werde ${ }^{103}$. Erneut beschwerte sich das RMVP beim AA darüber, daß dessen Pariser Stellen eigenständig planten und direkt mit Theatern in Deutschland über Gastspiele verhandelten ${ }^{104}$. Die zentrale Planung der Gastspiele sollte demnach allein zentral vom RMVP geplant werden, doch wurde dieser Wunsch in der Folge nicht zur Realität.

Das Arbeitsabkommen zwischen AA und RMVP im Herbst 1941 sowie ein Befehl des OKH im Sommer 1942 sollten zu einer vorläufigen Beilegung der Kompetenzstreitigkeiten führen. Die Zuständigkeit für den Arbeitsbereich der Kulturpropaganda ging allein auf die Deutsche Botschaft und auf das ihr angeschlossene Deutsche Institut über. Da sich die Überleitung der Aufgabenbereiche von der Propaganda Staffel auf die Botschaft über mehrere Monate hinzog, verfolgte die Staffel auch weiterhin bereits angelaufene Planungen ${ }^{105}$. Trotzdem gab es nach einem Bericht der Theaterabteilung im RMVP noch keine grundsätzliche Entscheidung über deren Durchführung. Goebbels hatte in der Frage der Gastspiele eine grundsätzliche Rückfrage über Reichsleiter Martin Bormann bei Hitler gestellt. Dessen Entscheidung sollte zunächst abgewartet werden ${ }^{106}$. Goebbels war demnach immer noch nicht von der Notwendigkeit deutscher Gastspiele in Paris überzeugt und sah vor allem mit dem Abschluß des Arbeitsabkommens seinen Einfluß auf die deutsche Kulturpropaganda und somit auch die Gastspieltätigkeit in $\mathrm{Pa}$ ris schwinden. Der Propagandaminister hoffe, daß Hitler sich nachträglich noch gegen deutsche Gastspiele im besetzten Paris entschied. Allerdings ließ dessen Antwort auf sich warten. Noch Mitte November erinnerte der Leiter der Theaterabteilung Goebbels an die Rückfrage und bat darum, bei Bormann erneut nachzuhaken. Die deutschen Bühnen, die in Paris gastieren sollten, drängten bei der Theaterabteilung auf einen Entschluß107. Offenbar reagierte Hitler auf Goebbels Ansinnen keineswegs wie dieser gehofft hatte, denn in der Folge waren weiterhin deutsche Ensemble-Gastspiele auf Pariser Bühnen zu sehen. Goebbels Rückfrage bei Hitler führte allerdings dazu, daß sich die Planungen der Staffel stark verzögerten und die Zeit zur Vorberei-

103 PA-AA, 1379, Kult 12 Nr. 2, RMVP, Keppler an AA, Betr.: Gastspiel der Münchner Kammerspiele in Paris, auf Kult K. 5261 vom 26. 9. 1941, Abschrift, 13. 10. 1941.

104 Ibid.

105 BAB, 50.01-705, RMVP, Referent Cunz an Leiter Abt.Th., Betr.: Bespielung von Paris in der Spielzeit 1941/42, 19. 9. 1941; ibid. Abt.Th., Lang an Abt. Ausland, 27. 10. 1941. Nach den Plänen der Propaganda Staffel sollte die Staatsoper München unter der Leitung ihres Intendanten Clemens Krauß Ende Januar 1942 nach Paris kommen. Die Volksbühne Berlin unter Generalintendant Eugen Klöpfer war für März 1942 vorgesehen, und im Spätherbst 1942 sollten weitere Aufführungen der Staatsoper München mit einer Richard Strauß-Woche in Paris folgen.

106 BAB, 50.01-705, RMVP, Abt.Th. an Abt. Ausland, 12.11. 1941; ibid. 50.01-506, RMVP, Lange an Gutterer, 30.10. 1941; BAB, 50.01-506, RMVP, Keppler an Krauß, 3. 12.1941.

107 BAB, 50.01-507, RMVP, Leiter Abt.Th. an Goebbels, 19. 11. 1941. 
tung der Gastspiele zu knapp wurde und diese nicht mehr durchgeführt werden konnten.

Die Initiativen zu Gastspielen waren jedoch nicht allein auf den Kompetenzstreit der konkurrierenden Dienststellen zurückzuführen. Im Sommer 1941 - zu einem Zeitpunkt, als sich der kulturpropagandistische Wettstreit der deutschen Dienststellen auf seinem Höhepunkt befand - ergriff der Intendant der Münchner Staatsoper, Clemens Krauß die Initiative zu einem Gastspiel in Paris. Im Mai 1941 hatte er im Zusammenhang mit dem von Hitler befohlenen Umbau der Staatsoper, vom diesem den Auftrag erhalten, diese Oper zu einem sogenannten Spitzeninstitut auszubauen. Dementsprechend hatte Goebbels eine besondere Förderung dieses Hauses angeordnet ${ }^{108}$. Krauß wollte den Auftrag Hitlers auf ganz besondere Art in die Praxis umsetzen, und zwar mit Hilfe prestigeträchtiger Gastspiele in größeren europäischen Städten. Diese sollten seinem Hause ein europäisches Renommee verschaffen und Paris sollte als wichtige Kulturmetropole Europas den Anfang bilden. Seine Pläne eröffnete der Intendant dem RMVP im Juli 1941. Das Richard Strauß-Fest, das für den Juli 1942 in München vorgesehen war, sollte demnach zu Beginn der Theatersaison 1942/43 in Paris wiederholt werden. Unter anderem war hier auch nach der Uraufführung in München ein Gastspiel mit der neuen Strauß-Oper, dem „Capriccio“, vorgesehen, deren Text von Krauß stammte. Der Komponist sollte dabei persönlich in Paris anwesend sein. Probleme machten, wie Krauß einräumte, allerdings die technischen Beschaffenheiten der Pariser Oper, da dort keine Drehbühne vorhanden war. In München sollte deswegen eine Drehbühne gebaut werden, falls das RMVP das nötige Material zur Verfügung stellten konnte. Krauß verteidigte sein aufwendiges Vorhaben im RMVP mit dem Hinweis, die Strauß-Woche in Paris wäre „eine künstlerische Angelegenheit ersten Ranges und von hervorragender propagandistischer Wirkung " ${ }^{109}$, zumal der Komponist in Paris eine große Anhängerschaft besitze und Krauß dort bereits mehrfach erfolgreich dirigiert habe. Auf Wunsch der Propaganda Staffel erklärte Krauß sich bereit, zusätzlich zu einem früheren Zeitpunkt, Ende Januar 1942, ein Paris-Gastspiel zu geben. Für die Aufführungen im Januar schlug er selbst den „Parsifal“, „Don Carlos“ und „Fidelio“ vor. Für den Anschluß plante er sogar eine Operntournee nach Spanien und Portugal ${ }^{110}$. Die aufwendigen Vorschläge sowie die Idee von Krauß, ausgerechnet mit Hilfe von europaweiten Gastspielen aus der Münchner Staatsoper ein sogenanntes Spitzeninstitut zu machen, dürften Goebbels kaum zugesagt haben. Abgesehen von deren finanziellem Aufwand, spiegelten die Planungen des Münch-

$108 \mathrm{BAB}, 50.01-400$, RMVP, Abt.Th. an Abt. Personal, Betr.: Münchner Staatsoper, 31. 5. 1941.

109 BAB, 50.01-398, RMVP, Lange an Leiter Abt.Th. u. Regierungsrat Lang, Betr.: Auslandsgastspiele der Münchner Staatsoper, 2. 7. 1941.

110 BAB, 50.01-398, RMVP, Lange an Leiter Abt.Th. u. Regierungsrat Lang, Betr.: Auslandsgastspiele der Münchner Staatsoper, 2. 7. 1941. 
ner Intendanten auch Anerkennung und Respekt vor Paris als einer kulturellen Metropole wider.

Im November 1941 sandte die Intendanz der Münchner Staatsoper einen Kostenvoranschlag für das vom 24. Januar bis 1. Februar 1942 geplante Gastspiel mit Aufführungen von Wagners „Walküre“, der „Verkauften Braut“ und dem „Rosenkavalier" nach Berlin. Demnach sollten während zehn Tagen 32 Solisten, 24 Solorepetitoren, einige Soufleure sowie 123 Orchestermitglieder, 89 Chormitglieder, 34 Ballettmitglieder, 51 Statisten, 54 Techniker und anderes Personal - insgesamt 444 Personen - nach Paris fahren. Die Kosten hierfür schätzte Krauß auf rund 332800 Reichsmark. Darin waren allerdings weder die Kosten für die Unterbringung noch der in München entstehende Ausfall an Einnahmen mit eingerechnet ${ }^{111}$. Da sich anschließend die Planungen aufgrund der oben erwähnten Rückfrage bei Hitler hinzogen, stellte Krauß dem RMVP schließlich ein Ultimatum mit der Bitte, es möge doch bis zum 10. Dezember eine endgültige Entscheidung treffen. Ohnehin war die Finanzierung des Gastspiels noch unklar. Die Staatsoper selbst besaß keine Sondermittel für derartige Vorhaben und erwartete eine Unterstützung des RMVP, auch was die Frage des Transports sowie die Unterbringung der Beteiligten in Paris anbelangte ${ }^{112}$. Trotz Ablauf des Ultimatums erhielt die Münchner Staatsoper jedoch noch keine Antwort, worüber Krauß sehr verärgert war ${ }^{113}$. Als Grund für eine Absage des Gastspiels wurden schließlich die Transportschwierigkeiten genannt. Die Theaterabteilung im RMVP vermerkte Anfang Dezember, es sei unmöglich, für Ende Januar für vier oder fünfhundert Menschen einen Sonderzug nach Paris zur Verfügung zu stellen ${ }^{114}$. Zudem war Krauß mit den Planungen der für den Sommer angesetzten Strauß-Festwoche und der Übernahme der Salzburger Festspiele ausgelastet, was die geplanten Auslandsgastspiele unmöglich machte ${ }^{115}$. Die Initiativen für Pariser Gastspiele waren also keineswegs Teil einer zentralen, kulturpropagandistischen Linie und sie waren auch nicht allein ein Instrument innerhalb des Kompetenzstreites der deutschen Dienststellen. Sie konnten, wie die Vorschläge des Münchner Intendanten zeigen, auch in persönlichen Initiativen, in dem Streben der jeweiligen deutschen Theaterintendanten nach einem europäischen Renommee begründet sein. Krauß war daran sehr gelegen und trotz der sich verändernden Weltkriegslage, der wachsenden Transportschwierigkeiten sowie der Materialknappheit verfolgte er sogar noch im

111 BayHStA, MK 40993, Intendanz der Bayerischen Staatsoper an Theo Lang, RMVP, Betr:: Gastspiel der Bayerischen Staatsoper in Paris, 25. 11. 1941.

112 Ibid.

113 BAB, 50.01-506, RPA Wien, Lange an Keppler, RMVP, Abt.Th., 2. 12. 1941.

114 BAB, 50.01-507, RMVP, Abt.Th., Lang, Vermerk, Gastspiel der Staatsoper München in Paris Ende Januar 1942, 5. 12. 1941.

115 BAB, 50.01-506, RMVP, Clemens Krauß, Intendant der Münchner Staatsoper, an Schlösser, RMVP, 6. 1. 1942; ibid. Schlösser an Krauß, Berlin 16. 2. 1942. Aus diesem Grund mußte auch ein für Ende März vorgesehenes Gastspiel der Münchner Staatsoper in Rom ausfallen. 
Frühjahr 1944 völlig unrealistische, gleichsam an Größenwahn grenzende, Vorschläge zu Gastspielen in Paris, worauf später noch eingegangen werden soll.

Die Planungen der Deutschen Botschaft waren nicht weniger aufwendig angelegt als die Vorschläge des Münchner Intendanten. Im Frühjahr/Sommer 1941 setzte sie sich mit dem Deutschen Institut vergeblich für ein Gastspiel des Wiener Burgtheaters und der Wiener Staatsoper ein. Nach Baldur von Schirach waren für das Scheitern der Pläne vor allem Transportschwierigkeiten verantwortlich. Epting war jedoch von einer Sabotage durch das RMVP überzeugt ${ }^{116}$. Im November 1941 verhandelte Abetz erneut mit Schirach über Paris-Gastspiele des Burgtheaters. Nach dem Arbeitsabkommen zwischen RMVP und AA mußte der Botschafter nun nicht mehr mit der direkten Vereitelung seiner Pläne durch das RMVP rechnen, das jedoch immer noch Möglichkeiten zur Einflußnahme besaß. Immerhin hielt es in Deutschland die zentrale Lenkung des Kulturlebens in der Hand. Auf Anregung von Abetz sandte ihm Schirach Gastspielvorschläge und betonte, die Veranstaltungen müßten die größten bisher im Ausland gezeigten deutschen Gastspiele werden ${ }^{117}$. Die Wiener Staatsoper sollte mit ihrer Neueinstudierung des „Fidelio“ unter der Leitung Wilhelm Furtwänglers in einer Inszenierung von Lothar Müthel und in Bühnenbildern von Caspar Neher in der Pariser Oper in bester Besetzung spielen. Ebenfalls in einer Inszenierung Müthels waren Aufführungen des Wiener Burgtheaters mit Goethes "Torquato Tasso" an der Comédie-Française geplant, ebenfalls mit guten Schauspielern"18. Gleichzeitig war im Palais de Chaillot die "Antigone" von Sophokles in einer Inszenierung Müthels vorgesehen, während die Wiener Oper gemäß einer angeblichen Anregung de Brinons den "Figaro" unter der Leitung von Carl Böhm im Trianon geben sollte ${ }^{119}$. Auch diese Planungen wurden niemals umgesetzt. Verwirklicht wurde im Frühjahr 1942 dagegen eine Gastspiel-Initiative der Propaganda Staffel, die am 14., 15., 17. und 18. April ein Gastspiel des Münchner Staatsschauspiels mit Goethes „Iphigenie in Delphi“ an der Comédie-Française organisierte. Das deutsche Ensemble gab zwei öffentliche und zwei geschlossene Aufführungen für die Wehrmacht. Die

116 PA-AA, 1379, Kult 12 Nr. 2, Reichsstatthalter in Wien, von Schirach an Abetz, 16. 5. 1941; ibid. DBP, Epting an von Schirach, über AA, 9. 6. 1941; ibid. AA, Kolb an DBP, (Reichsstatthalter Wien, Kaufmann an Botschafter Abetz), Telegramm Nr. 3340, 21. 6. 1941; ibid. DBP, Epting an AA, Telegramm Nr. 209, 21. 1. 1941; ibid. AA, Hirzel, an Abetz, DBP, Telegramm Nr. 4091, 22. 8. 1941; ibid. DBP, Epting an Schleier, 29. 8. 1941; ibid. Abetz an AA, Telegramm Nr. 2588, 30. 8. 1941.

117 PA-AA, 1379, Kult 12 Nr. 2, Reichsstatthalter in Wien, von Schirach an Abetz, DBP, 10. 11. 1941.

118 Ibid. Horst Caspar war für die Titelrolle, Ewald Balser als Antonio und Raoul Aslan als Herzog vorgesehen.

119 Ibid. Die Aufführungen sollten vier Tage dauern. Schirach wollte die in Wien durch die zeitweise Schließung des Theaters anfallenden Kosten übernehmen. Für den in Paris entstehenden Aufwand sollte die Deutsche Botschaft aufkommen. 
Entscheidung und Planung für die Veranstaltung war sehr langwierig und hatte sich seit Herbst 1941 hingezogen. Die Stückauswahl erfolgte in enger Verbindung mit dem Spielplan der französischen Gastbühne, denn die Schauspielertruppe der Comédie-Française führte das gleiche Werk in eigener Inszenierung auf. Auf das Gastspiel sowie die vergleichende Rezeption der deutschen und französischen Aufführungen in der Pariser Presse soll in den Ausführungen zu Erfolgen und Mißerfolgen deutscher Kulturpropaganda noch näher eingegangen werden ${ }^{120}$. Im Anschluß an dieses Gastspiel berichtete die Staffel stolz über die vielfältigen Begleitveranstaltungen und den angeblichen Erfolg bei Pariser Publikum und Presse ${ }^{121}$. Allerdings war ihr dies im Konkurrenzkampf mit der Botschaft nur noch von wenig Nutzen, da im Sommer 1942 das Arbeitsgebiet der Kulturpropaganda offiziell an die Botschaft übergehen sollte, was mit dem Abkommen zwischen RMVP und AA vom Herbst 1941 längst entschieden war.

Goebbels, der sich in der Pariser Gastspielfrage der von Abetz vertretenen Position notgedrungen angeschlossen hatte, wurde im Frühjahr 1942 durch die Ereignisse während eines Gastkonzertes der Berliner Philharmoniker im Süden Frankreichs in seiner ursprünglich ablehnenden Haltung erneut bestätigt. Er persönlich hatte das Orchester damit beauftragt, im Rahmen einer Spanien-Tournee mit zwei zusätzlichen Konzerten in der unbesetzten Zone Frankreichs zu gastieren. Die Durchführung lag in den Händen der Zweigstelle der Deutschen Botschaft in Vichy ${ }^{122}$. Am 17. und 18. Mai 1942 spielten die Philharmoniker dirigiert von Clemens Krauß in Marseille und Lyon. Es waren die ersten deutschen Konzerte in der Südzone Frankreichs ${ }^{123}$ und beide waren alles andere als ein Erfolg deutscher Kulturpropaganda. Bei dem Konzert in Marseille verbreitete sich nach der Pause Tränengas im Theater, so daß die Zuschauer der ersten Ränge ihre Plätze verlassen mußten. Das Orchester spielte allerdings den Berichten nach unverdrossen weiter und zum Ende des Konzertes war der Saal angeblich wieder voll besetzt. Die Besucher sollen starken Beifall gezollt haben, angeblich um ihre Empörung über den Zwischenfall zu demonstrieren ${ }^{124}$. Während in Marseille Zivilpolizei den Saal gesichert hatte, erhielt das darauffolgende Konzert in Lyon aufwendige-

120 Siehe Kapitel III. 1.3. dieser Arbeit.

121 BAB, 50.01-705, RMVP, Abt.Th. an Abt. Ausland, 12.6. 1942.

122 PA-AA, 1215, Kult 12 Nr. 2, RMVP, Graf Calice, e.o.Inf.III2392, Vermerk, 30. 3. 1942.

123 PA-AA, 1216, Kult 12 Nr. 3, DBP, Epting an Zweigstelle der Deutschen Botschaft in Vichy, 24. 2. 1942. (Abschrift)

124 BAB, R55/714, RMVP, Berliner Philharmonisches Orchester, Westermann an RMVP, Bericht über die Konzerte der Berliner Philharmoniker in Marseille und Lyon am 17. und 18. 5. 1942, 21 5. 1942. Sehr positiv klingt der Bericht des Konsulats in Marseille, siehe PA-AA, 1380, Kult 12 Nr. 3, Deutsches Generalkonsulat Marseille, Spiegel an DBP, Betr.: Konzert des Berliner Philharmonischen Orchesters in Marseille, 18.5. 1942. Siehe auch PA-AA, 1215, Kult 12 Nr. 2, DBP, Rabuse an Epting, Bericht über die Konzerte in Lyon und Marseille, 19. 5. 1942. 
ren Schutz. Dies war nicht allein aufgrund der Vorkommnisse in Marseille geschehen, denn schon beim Kartenverkauf für das Lyoner Konzert hatte es Probleme gegeben. Laut Bericht der Philharmoniker kauften angeblich Juden und Kommunisten, vor allem aber Studenten, nahezu sämtliche Karten innerhalb weniger Stunden auf, um Interessenten am Konzertgang zu hindern. Daraufhin erklärte die französische Präfektur den Vorverkauf für ungültig und ließ ihn wiederholen. Unter Vorzeigen des Personalausweises durfte jeder Konzertgänger nur jeweils eine Karte erstehen, vorausgesetzt er war älter als 25 und kein Student. Hiermit wollte die französische Präfektur eine erneute Sabotage des Kartenvorverkaufs ausschließen. Am Vormittag des Konzertes wurden schließlich Flugblätter verteilt, die sich an die Lyoner Bevölkerung richteten ${ }^{125}$ :

Pendant que 1500000 des nôtres déperissent dans les camps allemands, alors que 200000 tombes sont à peine recouvertes, à l'heure même ou l'on fusille encore nos frères, les bourreaux nous provoquent chez nous: ça, Lyonnais, nous ne le tolérerons pas! Tous Salle Rameau, lundi 20 heures. Les Boches de Berlin ne joueront pas ${ }^{126 !}$

Damit das Konzert trotzdem möglichst reibungslos ablaufen konnte, postierte die Polizei- und Stadtpräfektur am Abend des Konzertes im Umkreis des Theaters uniformierte Polizisten. Die Zufahrtsstraßen zu dem Konzertsaal sperrte die Polizei schon Stunden vor Beginn des Konzertes. Vor den Straßensperren standen Ansammlungen von Menschen, die laut johlten, Flugblätter verteilten und die Marseillaise sangen. Die Demonstrationen gingen auch während des Konzertes weiter ${ }^{127}$. Nach einem Bericht der Leitung der Berliner Philharmoniker soll das Polizeiaufgebot peinlich gewirkt haben ${ }^{128}$. Dr. Georg Rabuse, ein Mitarbeiter des Deutschen Instituts, war der Ansicht, die starken Sicherheitsmaßnahmen hätten die Unruhen mit verschuldet. Durch die Polizeikordons, die mit Überfall- und Rettungsautos an den für den Verkehr gesperrten Straßen gestanden hätten, so Rabuse, wäre lange vor Beginn des Konzertes der Eindruck einer Belagerung geschaffen worden, was die Demonstrationen geradezu herausgefordert hätte. Die Besucher des Konzertes, die versuchten, durch die Absperrungen zu kommen,

$125 \mathrm{BAB}, \mathrm{R} 55 / 714$, Berliner Philharmonisches Orchester, Westermann an RMVP, Bericht über die Konzerte der Berliner Philharmoniker in Marseille und Lyon am 17. und 18. 5. 1942, 21. 5. 1942. PA-AA, 1216, Kult 12 Nr. 3, Bericht Dr. Haitingers, dem Vertreter der Zweigstelle der Botschaft in Vichy, über das Konzert der Berliner Philharmoniker in Lyon, Juni 1942.

126 PA-AA, 1216, Kult 12 Nr. 3, Bericht Dr. Haitingers, dem Vertreter der Zweigstelle der Botschaft in Vichy, über das Konzert der Berliner Philharmoniker in Lyon, Juni 1942.

127 BAB, R55/714, Berliner Philharmonisches Orchester, Westermann an RMVP, Bericht über die Konzerte der Berliner Philharmoniker in Marseille und Lyon am 17. und 18. 5. 1942, 21. 5. 1942. PA-AA, 1216, Kult 12 Nr. 3, Bericht Dr. Haitingers, dem Vertreter der Zweigstelle der Botschaft in Vichy, über das Konzert der Berliner Philharmoniker in Lyon, Juni 1942.

128 Ibid. 
wären unter Rufen wie „à bas les boches“129 ausgepfiffen worden; angeblich war das Publikum von dem Konzert selbst begeistert. Dieser vermeintliche Erfolg ist allerdings wenig erstaunlich, wenn man bedenkt, daß ein Großteil der Besucher wie in Marseille geladene Gäste waren. Die Zweigstelle der Deutschen Botschaft in Vichy erhielt im Anschluß an das Lyoner Konzert für seine Einladungen französische Dankeskarten, welche die Hoffnung zum Ausdruck brachten, der kulturelle Austausch zwischen Frankreich und Deutschland möge zu einer Verbesserung der deutsch-französischen Beziehungen beitragen ${ }^{130}$. Die darauffolgenden Konzerte der Philharmoniker im besetzten Teil Frankreichs verliefen dagegen ruhig. In Paris gab das Orchester einige Konzerte für die Wehrmacht und das Rote Kreuz sowie ein sogenanntes Werk-Konzert in einer französischen Rüstungsfabrik. Ein öffentliches Konzert im Théâtre national du Palais de Chaillot am 23. Mai 1942 soll angeblich so erfolgreich gewesen sein, daß Krauß beim Schlußapplaus sich sieben Mal zeigen mußte ${ }^{131}$.

Die Vorkommnisse bei den Konzerten der Berliner Philharmoniker in Marseille und Lyon müssen Goebbels besonders geärgert haben, zumal es als bestes deutsches Orchester als Aushängeschild des Dritten Reiches galt und offizielles Orchester für kulturpropagandistische Zwecke im Ausland war. Zudem hatte das Orchester sowohl vor dem Krieg als auch zu Beginn der Besatzung mit regelmäßigem Erfolg in Paris gastiert, häufig im Zusammenhang mit Tourneen nach Spanien und Portugal. Auch in der Folge war dies nicht anders. Am 10. September 1943 gaben die Philharmoniker ein Konzert in Bordeaux unter der Leitung von Hans Knappertsbusch, am 14. September gastierten sie in der Pariser Oper und am 15. September im Palais de Chaillot. Alle drei Konzerte waren öffentlich. Knothe berichtete an das AA, die Veranstaltungen der Philharmoniker gehörten in Paris inzwischen zu den Höhepunkten des regen Musiklebens. In Bordeaux hätten die Philharmoniker eine besonders gute Aufnahme von den französischen Behörden und der Bevölkerung erfahren ${ }^{132}$. Die Abrechnungen dieser Konzerte bestätigen durchaus den Eindruck, daß die Philharmoniker Erfolge zu verzeichnen hatten. Im Regelfall mußten die Kosten für deutsche kulturpropagandistische Veranstaltungen von den Organisatoren getragen werden, während beispielsweise die Konzerte der Philharmoniker vom 14. September und 15. September einen Überschuß von 31880 Francs ergaben ${ }^{133}$.

129 PA-AA, 1215, Kult 12 Nr. 2, DBP, Rabuse an Epting, Bericht über die Konzerte in Lyon und Marseille, 19.5. 1942.

130 PA-AA, 1216, Kult 12 Nr. 3, Zweigstelle Vichy an Botschaft, Berliner Philharmonisches Konzert in Lyon, 2. 6. 1942; in der Anlage befindet sich ein Bericht Dr. Haitingers über das Konzert.

131 PA-AA, 1380, Kult 12 Nr. 3, DIP, Epting an AA, Telegramm Nr. 2222, 27. 5. 1942;

PA-AA, 1380, Kult 12 Nr. 3, DBP, Abetz an AA, Telegramm Nr. 1595, 24. 5. 1941

132 PA-AA, 1114, Kult 12 Nr. 3, DBP, Knothe an AA, 24. 9. 1943.

133 PA-AA, 1113, Kult 12 Nr. 3, DBP, Knothe an AA, 22. 2. 1944. 
Gleichwohl ordnete Goebbels aufgrund der Vorkommnisse in Marseille und Lyon im Mai 1942 an, „daß künftig jeder Kulturaustausch für das unbesetzte Frankreich verboten" 134 werde; deutsche Kulturveranstaltungen im besetzten Frankreich könnten zwar weiter stattfinden, seien jedoch an eine vorherige Genehmigung durch den Propagandaminister gebunden. Auch nach dem Abkommen zwischen AA und RMVP war damit der Konkurrenzstreit keineswegs beigelegt. Obgleich offiziell der Aufgabenbereich der Kulturpropaganda im besetzten Frankreich auf die Deutsche Botschaft übergegangen war, sollte nach Goebbels Anordnung immer erst dessen Einverständnis eingeholt werden. In der Folge waren es allerdings weniger Anordnungen oder Verbote, welche die Durchführung deutscher Gastspiele in Frankreich verhinderten. Vielmehr waren die praktischen Möglichkeiten vor allem für größere Ensemble-Gastspiele mehr und mehr eingeschränkt. $\mathrm{Zu}$ den Transportschwierigkeiten kam auch die fortschreitende Knappheit an Material für Bühnenbilder sowie der kriegsbedingte Mangel an Künstlern und technischen Mitarbeitern der deutschen Bühnen hinzu. Im Juni vermerkte Knothe in einem Bericht an das AA, aufgrund der starken Inanspruchnahme des gesamten deutschen Kunstapparates sei die kulturpropagandistische Betreuung Europas sehr schwierig ${ }^{135}$. Dementprechend standen die Gastspielvorhaben gegen Ende 1942, vor allem aber in den Jahren 1943/ 44, im Zeichen der praktischen Gegebenheiten. Generell ist hier eine Tendenz zu pragmatischen Gastspielplanungen, kleineren Gastspielen einzelner Künstler, vor allem von Musikern und Sängern, zu beobachten. Trotzdem fanden noch einige wenige größere Gastspiele deutscher Ensembles statt, die in den Augen der Besatzer das unerschütterliche Vertrauen in das angeblich siegreiche deutsche Reich symbolisieren sollten.

\subsection{Gastspiele als Demonstration des „deutschen Vertrauens in die Zukunft": 1943-1944}

Aus einem Tätigkeitsbericht der Botschaft über deutsche Kulturveranstaltungen vom Mai 1942 bis Juli 1943 geht hervor, daß Theatergastspiele in diesem Zeitraum wie in den vorangegangenen Jahren vor allem an Transportschwierigkeiten gescheitert sind. Der Schwerpunkt der Arbeit lag daher auf kleineren Musikgastspielen, die zunehmend in der französischen Provinz stattfanden. Das Deutsche Institut führte zusammen mit der Organisationsabteilung der Botschaft 21 öffentliche Konzerte in Paris, 10 im Deutschen Institut, 40 Konzerte in der Provinz, 29 Vorträge in Paris und 48 in der Provinz durch. An sogenannten gesellschaftlichen Veranstaltungen richtete es 39 größere Empfänge, 47 Frühstücke, 13 Abendessen und 12 Tee-Empfänge aus.

134 BAB, R55/714, RMVP, Gutterer an Abteilungsleiter und Generalreferenten der RKK, 26. 5. 1942.

135 BAB, 50.01-519, DBP, Knothe an AA, Durchdruck für RMVP, 24. 6. 1943. 
Insgesamt nahmen daran 7600 Personen teil. In der französischen Provinz organisierten die jeweiligen DWI zunehmend mehr Konzerte, weil diese Veranstaltungen dort oft die einzigen kulturellen Ereignisse waren. Der Erfolg solcher Bemühungen schien angesichts des stark auf Paris und die größeren Städte konzentrierten Kulturlebens gesichert zu sein. Das Deutsche Institut hielt die französische Provinz für einen kulturell „unbestellten Acker“136, den es zu bewirtschaften galt. Die in dem Bericht erneut erwähnten Transportschwierigkeiten waren dafür verantwortlich, daß Operngastspiele nun vor allem in bescheidenerer Form, mit einzelnen Sängern und Dirigenten, durchgeführt wurden. Während das Berliner Opernhaus im September 1941 noch mit großem Aufwand in Paris gastiert hatte, erschien es im Dezember/ Januar 1943 dort nur mehr mit einigen Künstlern, um in einer Aufführung des "Rosenkavalier" in der Pariser Oper mitzuwirken. Am 4. Januar 1943 berichtete Knothe dem AA über den Erfolg des Rosenkavalier-Gastspiels und schlug dem AA weitere Planungen vor. Diese spiegeln eine vorwiegend nach pragmatischen Gesichtspunkten ausgerichtete Tendenz wieder. Sie richteten sich nach dem von deutscher Seite beeinflußten Repertoire der Pariser GroBen Oper sowie danach, ob die Werke gesprochenen Dialog enthielten. Freilich war eine vollständig gesungene Oper eher vorzuziehen, da der Text für das französische Publikum ohnehin unverständlich war. Nach Meinung Knothes sollte die angeblich veraltete Interpretation der Opernwerke durch französische Ensembles durch "markante deutsche Gastspiele“137 aufgefrischt werden. Eine derartige Auffrischung war hier als Aktualisierung im nationalsozialistischen Sinne gemeint. Knothe hielt dies vor allem deswegen für wünschenswert, weil ein Großteil der Besucher der Großen Oper Angehörige der Wehrmacht waren. Des weiteren hielt Knothe angeblich in Ermangelung guter französischer Orchesterleiter an der Pariser Oper einen Einsatz deutscher Dirigenten für unbedingt notwendig. Seine Planungen sahen zwei Wagner-Opern - die "Walküre“ und den "Fliegenden Holländer" sowie die „Salomé" von Richard Strauß vor. In allen Fällen sollten möglichst die Hauptrollen mit Sängern aus Deutschland besetzt werden. Bis auf den Dirigenten wurde der Rest den französischen Gastgebern überlassen. Außerdem schlug Knothe eine Wiederaufnahme von Pfitzners "Palestrina" vor. Während die Gastspiele einzelner Künstler im Vergleich zu denen ganzer Ensembles kulturpropagandistisch gesehen nur unvollständig sein konnten, weil sie die sogenannte typisch deutsche Aufführung nicht widerspiegelten, sollten sie trotzdem so gut als möglich eine Propagierung der Kultur des nationalsozialistischen Deutschland darstellen. Die Aufführung der „Walküre“

136 PA-AA, 1141 a, Kult 11 Nr. 4, DIP, Epting an Schleier, DBP, Arbeitsbericht Mai 1942-Juli 1943.

137 BAB, 50.01-519, Knothe, DBP an AA, Betr.: Gastspiele deutscher Künstler in der Pariser Großen Oper, 4.1.1943. Im Anschluß an den Bericht Kult Nr. 25/43 4.1.1943 über die Ergebnisse und Erfahrungen des „Rosenkavalier“-Gastspieles deutscher Künstler in der Pariser Oper. 
kam, so Knothe, der Nachfrage des französischen Publikums nach WagnerStücken mit einer „den neueren deutschen Intentionen im wesentlichen entsprechenden " 138 Inszenierung des Werkes nach. Knothe hob zudem hervor, diese Planungen würden nur wenig Vorbereitung benötigen.

Im Frühjahr 1943 fanden zur Feier des 130. Geburtstages Wagners, am 22. Mai 1943, und des 50jährigen Jubiläums der Erstaufführung dieses Stükkes in Frankreich drei Aufführungen der „Walküre“ mit deutschen Gästen in der Großen Oper in Paris statt ${ }^{139}$. Während der Vorbereitungen zu diesen Aufführungen arbeitete der zuständige Mitarbeiter des Botschaft, Fritz Piersig, auch weiterhin mit seinen ehemaligen Kollegen von der Staffel zusammen. So holte er beispielsweise über seinen ehemaligen Vorgesetzten Lucht zunächst einmal das grundsätzliche Einverständnis des RMVP für dieses Gastspiel ein. Lucht leitete inoffiziell den Vorschlag an die Theaterabteilung im RMVP weiter, die kurz darauf die Zustimmung des Ministeriums mitteilte ${ }^{140}$. Erst danach sandte die Botschaft an das AA eine offizielle Anfrage, die an das RMVP weitergeleitet wurde ${ }^{141}$. Im Anschluß an die Aufführungen der "Walküre" Mitte Mai 1943 berichtete die Botschaft über die Resonanz der Aufführungen nach Berlin. Die Propaganda Abteilung tat dies ebenfalls, obgleich sie offiziell nicht mehr mit Fragen der Kulturpropaganda befaßt war. Das Gastspiel wurde demnach angeblich "mit großer Begeisterung" aufgenommen. Die Presse lobte die stimmliche Leistung Hilde Konetznys (Sieglinde), die Regie Georg Hartmanns und die Orchesterleitung Rudolf Krasselts. Die französischen Künstler, unter anderem Hélène Bouvier als Fricka, sollen sich, wie die Propaganda Abteilung betonte, gut in die Aufführung eingepaßt haben ${ }^{142}$. Jeder Sänger sang seine Partie in der eigenen Sprache, was eine französische Zeitung zu dem Titel "Wotan et Fricka se sont donné la réplique sans se comprendre" veranlaßte ${ }^{143}$. Auf ähnliche Verständigungsprobleme spielte ein Bericht der Auslandsstelle für Theater an das RMVP an. Demnach soll Hartmann die Vorbereitungs- und Probenarbeit mit den französischen Künstlern in Paris als mühevoll, aber angeblich auch harmonisch empfunden haben ${ }^{144}$. Hier klingt an, daß diese Form von Gast-

$138 \mathrm{BAB}, 50.01-519$, DBP, Knothe an AA, Betr.: Gastspiele deutscher Künstler in der Pariser Großen Oper, 4. 1.1943.

139 PA-AA, 1142, Kult 12 Nr. 2, Knothe an AA, 24. 6. 1943.

140 BAB, 50.01-519, Prop.Abt., Gr.Kult., Lucht an Lang, RMVP, Abt.Th., 22. 1. 1943. 141 Ibid. AA an RMVP, 27. 1. 1943.

142 Ibid. Prop.Abt., Bericht über den Monat Mai 1943. BAB, 50.01-519, Serge Moreux, „La Walkyrie“ à l'Opéra, in: La Gerbe, 3. 6. 1943; ibid. Raoul BRUNEL, „La Walkyrie“ de Richard Wagner, in: L'CEuvre, 2./3. 6. 1943; ibid. Heinrich STROBEL, Pariser Walküren Jubiläum, Eine deutsch-französische Aufführung in der Grossen Oper, in: Pariser Zeitung, 20. 5. 1943.

143 PA-AA, 1142, Kult 12 Nr. 2, Pour le cinquantennaire de la Walkyrie Allemands et Français chantent à l'Opéra, Wotan et Fricka se sont donné la réplique sans se comprendre, in: Toute la Vie, 27. 5. 1943.

144 BAB, 50.01-519, Auslandsstelle für Theater, Berlin Charlottenburg, Götze an 
spielen im Vergleich zu Gastspielen ganzer Ensembles nicht vollkommen unproblematisch war. So betonte Knothe sogar in seinem offiziellen Bericht, der Erfolg der Aufführungen sei selbstverständlich nicht so groß gewesen wie bei Gastspielen von Ensembles ${ }^{145}$. Die auf Gastsänger und Dirigenten reduzierten pragmatischen Varianten waren demnach kulturpropagandistisch gesehen weniger wünschenswert als aufwendige Ensemblegastspiele. Diese Beobachtungen Knothes spiegelten allerdings eher dessen Vorstellungen wider als die tatsächliche Rezeption des französischen Publikums.

Zu diesem Zeitpunkt plante die Botschaft Aufführungen der „Salomé" mit Künstlern der Münchner Staatsoper, die Ende Oktober 1943 stattfinden sollten. Weil Clemens Krauß zeitweise „an höherer Stelle“ 146 in Ungnade gefallen war, belegte man ihn mit einer sogenannten Auslandssperre, die bald darauf jedoch wieder aufgehoben wurde. Im Dezember 1943 bat Knothe deshalb das AA um eine Wiederaufnahme der Planungen für das Gastspiel147. Inzwischen hatte Krauß allerdings selbst beim RMVP Vorschläge für Ensemble-Gastspiele der Münchner Staatsoper in Paris gemacht. Seine aufwendigen Planungen stellten nun angesichts der veränderten Weltkriegslage und der damit einhergehenden Mangelsituation in Deutschland wie in den besetzten Gebieten ein absurdes und illusorisches Unterfangen dar. Seine Vorschläge resultiertem zum Teil daraus, daß es Krauß gelungen war, bei Hitler einen Sonderstatus der Münchner Staatsoper zu erreichen. Auf Befehl Hitlers sollte die Münchner Staatsoper als besonders leistungsfähige Institution trotz der allgemein schwierigen Lage im Reich aufrechterhalten werden. Angesichts Materialknappheit und Personalmangels, da viele Mitarbeiter deutscher Bühnen eingezogen wurden, war dieser Status von vitalem Interesse für die Münchner Oper und ihre Angestellten. Die seiner Ansicht nach notwendigen Maßnahmen, um aus seinem Opernhaus eine besondere Institution zu machen, besprach Krauß Anfang November 1943 im RMVP mit Bormann sowie dem Leiter der Musikabteilung, Dr. Heinz Drewes und dem Opernreferenten der Theaterabteilung, Dr. Lange. ${ }^{148} \mathrm{Krauß}$ hielt an seiner ursprüng-

Abt.Th., RMVP, Betr:: Walküre-Aufführungen in der Großen Oper in Paris, 31. 5. 1943.

145 PA-AA, 1142, Kult 12 Nr. 2, DBP, Knothe an AA, 24. 6. 1943.

146 PA-AA, 1215, Kult 12 Nr. 2, DBP, Gerlach an AA, Für Kult Pol K., Telegramm Nr. 5609, 21. 8. 1943; BAB, 50.01-519, DBP an RMVP, über AA, Schnellbrief, 30. 8. 1943 (telefonisch an Abt.Th. mitgeteilt am 28. 8. 1943). PA-AA, 1215, Kult 12 Nr. 2, AA an DBP, Kult Pol K1 5151, Betr.: Salomé-Gastspiel in Paris, 17. 9. 1943. Übrigens war auch Peter Kreuder für Auslandsgastspiele zeitweise nicht zugelassen: PA-AA, 1113, Kult 12 Nr. 3, AA, Schattenfroh an DBP, 16. 4. 1944. PA-AA, 1113, Kult 12 Nr. 3, Editions Continental, an Prop.Abt., Ref.Musik, 4. 3. 1944.

147 PA-AA, 1215, Kult 12 Nr. 2, Knothe an AA, Telegramm Nr. 7888, 17. 12. 1943. Bezug auf Drahtberichte Nr. 5609 v. 21. 8., 6184 vom 17. 9., Erlaß vom 17. 9. Kult Pol K1 Nr. 5151. Knothe erwähnt darin die Aufhebung der sogenannten Auslandssperre von Krauß.

148 BAB, 50.01-398, RMVP, Abt. Musik, Drewes an Goebbels, Betr.: Besprechung mit Clemens Krauß über Planungen der Münchner Staatsoper, 9. 11. 1943. 
lichen Initiative fest, der Münchner Staatsoper vor allem mit Hilfe großer Ensemble-Gastspiele im Ausland ein europäisches Renommee zu verschaffen. Er betonte, daß dies das einzige Mittel sei, den guten Ruf des Hauses zu bewahren. Gastspiele im Inland, so Krauß, würden nur Anlaß zu Vergleichen geben, zumal überall die gleichen Stücke auf dem Spielplan ständen. Er bestand zudem auf der Entsendung des kompletten Ensembles, da er nur hiermit den besonderen Stil der Münchner Aufführung zeigen könne. Spielen sollte das Ensemble in sogenannten Reisedekorationen, die eigens dafür angefertigt werden sollten. Angesichts des Aufwands wollte er sich auf wenige, langfristig geplante Gastspiele in europäischen Großstädten beschränken. Paris sollte auf Wunsch des Intendanten unbedingt am Anfang stehen. Drei Wochen lang - vom 23. März bis zum 15. April - wollte Krauß dort unbekannte Strauß-Werke aufführen und anschließend in Brüssel sowie in Krakau, Budapest, Lember und Sofia gastieren. Das RMVP sollte die Herstellung der Dekorationen unterstützen und ihm zudem Götze, einen der Mitarbeiter der Abteilung Theater, dem Intendanten zur Seite stellen, da dessen bisheriger Assistent eingezogen worden war ${ }^{149}$.

Mit diesen Vorschlägen rief Krauß freilich Erstaunen und heftigen Widerspruch bei den Abteilungen Theater und Musik im RMVP hervor. Diese betonten angesichts der erheblichen Materialprobleme sämtlicher deutscher Theater, wäre eine besondere Materialzuteilung für die Herstellung der Dekorationen nur durch einen sogenannten Führerbefehl möglich. Krauß benötigte zudem für den Transport nach Paris Eisenbahnwaggons für mehrere hundert Personen und etliche Dekorationen. Als Leiter der Theaterabteilung meinte Schlösser hierzu nur trocken, er sei „in besseren Zeiten Augenzeuge derartiger Völkerwanderungen" $" 150$ gewesen und habe allein deswegen „schwerste Bedenken“. Am heftigsten protestierte er dagegen, daß Götze Krauß assistieren sollte, weil viele Mitarbeiter des RMVP eingezogen waren und der Wegfall Götzes die Arbeit der Theaterabteilung in Frage stellen würde. Schlösser betonte, Gastspiele mit einigen guten Sängern der Münchner Staatsoper, vielleicht zu einem Zeitpunkt, an dem die Berliner Philharmoniker ohnehin auf Tournee in den Westgebieten gingen, wären eher wünschenswert und vor allem leichter zu realisieren ${ }^{151}$. Goebbels gab auf die Anfrage Schlössers zwar seine "grundsätzliche Zustimmung " 152 zu einem Gastspiel der Münchner Staatsoper in Paris, allerdings war er keineswegs bereit, auf die konkreten Forderungen des Intendanten einzugehen. Die Auslandsgastspiele der Oper sollten „den propagandistischen Erfordernissen entspre-

149 Ibid.

150 BAB, 50.01-398, RMVP, Schlösser an Goebbels, 9. 11. 1943.

151 Ibid.

152 BAB, 50.01-507, Abt.Th., Schlösser an Goebbels, 6. 12. 1943; ibid. Abt.Th., Lang an Götze, Auslandsstelle für Theater, Betr.: Gastspiel der Staatsoper München in Paris, 15. 12. 1943. 
chend ${ }^{\star 153}$ geplant werden. Die hierzu vom RMVP gewährte Unterstützung sollte der anderer prestigeträchtiger Institutionen wie die Berliner Philharmoniker entsprechen. Trotzdem gestaltete Krauß seine Planungen kaum weniger anspruchsvoll. Im Dezember 1943 schlug er ein vierwöchiges Gastspiel mit der "Walküre“, „Tristan und Isolde“, dem „Fliegenden Holländer" von Wagner und dem „Rosenkavalier“ sowie der „Salomé" von Strauß vor. Die Auswahl der Werke hatte er nun danach gerichtet, welche Dekorationen bereits bei der Pariser Oper vorhanden waren. Außerdem plante er die „Ägyptische Helena“, „Verklungene Feste“ oder „Capriccio“, jedoch nur, falls die Pariser Oper dazu bereit wäre, neue Dekorationen anzufertigen, um eines dieser in Paris bisher unbekannten Werke herauszubringen. Erneut befürwortete Krauß die Anfertigung von Reisedekorationen. Die Zahl des für die Zeit vom 15. Mai bis 15. Juni 1944 geplanten Gastspiels notwendigen Personals belief sich auf insgesamt 325 Personen. Am 10. Juni 1944 sollte in Paris mit der Aufführung eines Werkes von Richard Strauß der 80. Geburtstag des Komponisten gefeiert werden. Die Transportfrage gedachte der Intendant, in mehrfachen kleineren Teiltransporten zu lösen ${ }^{154}$. Das RMVP reichte diese Vorschläge im Januar 1944 an das AA und die Deutsche Botschaft weiter. Doch erfuhr jene kurz nach Eingang der Anfrage auf indirektem Wege vom RMVP, daß "gewisse Schwierigkeiten "155 in Berlin eingetreten waren, weshalb sie in Paris keine Verhandlungen mit der Oper aufnahm. Als im März 1944 immer noch die Zustimmung Goebbels fehlte, setzte sich zur Wiederaufnahme der Besprechungen nun das Reichspropagandaamt München mit Krauß in Verbindung. Anschließend betonte es gegenüber dem RMVP, der Intendant erwarte immer noch die Zustimmung des Ministers zu seinen Vorschlägen und habe vor, danach mit seinem Freund Jacques Rouché, dem Leiter der Pariser Oper, zu sprechen. Angeblich wollte Krauß nun doch mit sämtlichen Dekorationen nach Paris reisen. Lang gab zu bedenken, daß "nachdem das Gastspiel vom Führer gewünscht wird“ ${ }^{156}$, unbedingt festgestellt werden müsse, ob es technisch durchführbar sei. Einige Wochen später, Mitte März, stellte das RMVP die Planungen für das Gastspiel schließlich ein, da Krauß erklärte, die Vorbereitungszeit sei nach den Verzögerungen in der laufenden Spielzeit nun zu kurz geworden ${ }^{157}$.

153 BAB, 50.01-398, RMVP, Ministeramt, Hamel an Leiter Abt. Musik und Abt.Th., Betr.: Besprechung mit Clemens Krauß über Planungen der Münchner Staatsoper, 12. 11. 1943.

154 BAB, 50.01-507, Auslandsstelle für Theater, Götze, Bericht über eine Dienstreise nach München, 22. 12. 1943.

155 PA-AA, 1215, Kult 12 Nr. 2, AA an DBP, Betr.: Deutsche Gastspiele in Paris, 15. 1. 1944 (Brief RMVP vom 6. 1. 1944); Ibid. DBP an AA, Betr.: Deutsche Gastspiele in Paris, 18. 4. 1944.

156 BAB, 50.01-507, RMVP, Abt.Th., Lang, Vermerk, 1. 3. 1944.

157 Ibid. Lang an Ministerialdirektor Dr. Naumann, Ministeramt, Betr.: Gastspiel der Staatsoper München in Paris, 17. 3. 1944. 
Die Absage dürfte im RMVP angesichts der aufwendigen Pläne des Intendanten auf Erleichterung gestoßen sein. Zu einem Zeitpunkt, da deutsche Städte bombardiert wurden, die deutschen Truppen an der Ostfront mehr und mehr Niederlagen erlitten und nur wenige Monate vor der Landung der Alliierten in der Normandie legte Krauß noch Planungen für Operngastspiele in Paris vor, die in ihrem Aufwand sämtliche bisher durchgeführten Gastspiele überstiegen hätten. Und obwohl Goebbels offizielles Einverständnis auf sich warten ließ, so stießen diese absurden und unrealistischen Planungen des Intendanten offenbar sowohl beim RMVP als auch bei Hitler zumindest auf eine gewisse Zustimmung. Prestigeträchtige Aufführungen im besetzten Paris sollten den dort stationierten Soldaten sowie dem französischen Publikum weiterhin die Illusion eines angeblich siegessicheren Deutschlands vorgaukeln. Obgleich die obigen Planungen nicht realisierbar waren, zog das RMVP ihre Durchführung doch ernsthaft in Erwägung. Die Initiativen des Intendanten der Münchner Staatsoper fußten nicht in erster Linie auf Motiven der Kulturpropaganda. Krauß wollte damit vor allem seinem Haus ein europäisches Renommee verschaffen, damit die sogenannte Kriegswichtigkeit der Staatsoper erhöhen und diese mitsamt der verbliebenen Mitarbeiter erhalten. Die Anziehungskraft der Kulturmetropole Paris war hier groß, denn Paris sollte der erste Gastspielort sein. Derartige Planungen konnten also sowohl auf persönlichen Motiven des jeweiligen Intendanten beruhen, als auch in dem Wunsch der beteiligten Dienststellen, mit Hilfe einer intakten Kulturpolitik die militärischen Niederlagen zu kontrastieren, begründet sein. Nicht alle Initiativen scheiterten so vollständig wie jene des Münchner Intendanten. In den Kriegsjahren 1943 und 1944 wurden tatsächlich noch deutsche Gastspiele in Paris realisiert.

Im Oktober 1943 führte Heinrich George mit dem Schillertheater in der Comédie-Française den „Richter von Zalamea“ von Pedro Calderon de la Barca auf. Die Auswahl eines spanischen Autors für eine Veranstaltung deutscher Kulturpropaganda zeigt einmal mehr, wie planlos die Umsetzung der deutschen Kulturpropaganda war. Der Vorschlag zu der Gastspielreise war von George ausgegangen, weil das Gebäude des Schillertheaters durch Bombenangriffe beschädigt und das Ensemble nun gleichsam obdachlos war. Es lag in Georges Interesse, möglichst schnell ein neues Wirkungsfeld in und auch außerhalb Berlins zu finden, allein um die eigenen Mitarbeiter vor dem Einzug an die Front zu bewahren und das Theaterensemble aufrechtzuerhalten. Übrigens hatte sich bereits während des Frankreichfeldzuges 1939 der Hinweis auf die Bedeutung des Schillertheaters für Berlin sowie der Vorschlag einer Gastspielreise als geeignetes Mittel erwiesen, das Personal des Schillertheaters in Berlin zu belassen. Der Oberbürgermeister von Berlin hatte sich damals bei Goebbels dafür eingesetzt, man möge nicht zu viele Mitarbeiter des Schillertheaters einziehen, weil das Theater wesentlich für die Aufrechterhaltung des Berliner Kulturlebens sei und sich bald auf eine von George vorgeschlagene erfolgversprechende Gastspielreise begeben 
wolle ${ }^{158}$. Mit dem Verweis auf das Prestige der Gastspielreisen, konnte die sogenannte Kriegswichtigkeit eines Theaters erhöht werden. Goebbels erklärte sich angesichts der Tatsache, daß das Gebäude des Schillertheaters erst um die Jahreswende 1943/44 wieder bespielbar sein würde, mit einer Gastspielreise des Ensembles in die besetzten Westgebiete einverstanden. Die Verhandlungen um die Stückauswahl zogen sich allerdings länger hin ${ }^{159}$. Daß die Wahl für eine Aktion deutscher Kulturpropaganda letztlich auf das Stück eines spanischen Autors fiel bedarf einer Erklärung.

Zum Verständnis des Auswahlprozesses ist es wichtig, einen Exkurs in vorangegangene Gastspielplanungen des Schillertheaters, insbesondere der intensiven Verhandlungen über die Auswahl von Theaterstücken zwischen George und Goebbels zu unternehmen. Es war nicht das erste Mal, daß George sich mit dem "Richter von Zalamea“ auf eine Gastspielreise begab. Das Stück gehörte zum gängigen Repertoire des Schillertheaters und hatte sich bereits mehrfach bei Gastspielreisen ins Ausland bewährt. George unternahm 1938 mit dem "Richter von Zalamea" eine erfolgreiche Reise in den Norden, unter anderem nach Helsingfors und Stockholm (Oslo, Riga und Kopenhagen $)^{160}$. Goebbels hätte damals die Auswahl eines deutschen Stükkes bei weitem vorgezogen 161 . Welche Gründe mögen den Propagandaminister bewogen haben, diesem Stück trotzdem zuzustimmen? Die Antwort hierauf findet sich in den gut dokumentierten Verhandlungen um eine weitere Gastspielreise des Schillertheaters im Jahre 1940. Das Schillertheater sollte in mehreren Städten des Balkans gastieren. Die Initiative hierzu ging abgesehen von George generell auch von den deutschen Dienststellen im Osten, d.h. vom AA und der AO der NSDAP aus ${ }^{162}$. George schlug den "Richter von Zalamea" mit der Begründung vor, daß sich keiner der anderen Klassiker des aktuellen Repertoires für eine Gastspielreise ins Ausland eignete. Für dieses Stück aber besaß das Theater geeignete Bühnenbilder, die sich leicht transportieren und an die verschiedenen Bühnen im Ausland anpassen ließen. Außerdem war eine qualitativ gute Besetzung der Rollen möglich, ohne den gesamten Spielbetrieb in Berlin unterbrechen zu müssen, was einen Ausfall an Einnahmen bedeutet hätte. Nach Goebbels Ansicht sollten bei Gastspielen im Ausland jedoch nur deutsche Werke gespielt werden. George begegnete diesem Argument mit der Begründung, das Stück stamme zwar von einem spanischen Autor, doch handele es sich hier nicht um eine reine Übersetzung, sondern um eine Neudichtung von Wilhelm Scholz.

$158 \mathrm{BAB}, 50.01-290$, Berliner Oberbürgermeister in Vertretung an Goebbels, Berlin 4. 1.1939.

159 BAB, 50.01-291, Schlösser, Vermerk für Lang, 28. 9. 1943.

$160 \mathrm{BAB}, 50.01-290$, Berliner Oberbürgermeister in Vertretung, an Goebbels, Berlin 4. 1.1939.

161 BAB, 50.01-503, RMVP, Abt.Th., Schlösser an Goebbels, Betr.: Gastspielreise Heinrich George - Balkan, 27. 3. 1940.

162 Ibid. 
Diese, so George, sei „ganz in deutsche Ausdrucksform und Charakterwerte" 163 umgewandelt. Das Thema des Bauern, der um seine Ehre kämpfe, sei gerade in den bäuerlich geprägten Staaten des Balkans sehr lebendig. Die Hauptgestalt erscheine dem "tapferen Bauernadel der jugoslawischen Länder" als nahe verwandt. George fügte hinzu, er habe bisher mit diesem Stück bei Auslandsgastspielen in zehn verschiedenen Ländern Erfahrungen sammeln können und sei der Meinung, daß es sich aufgrund des moralischen und politischen Inhalts gut für Auslandsgastspiele eigne ${ }^{164}$. Schlösser, der Georges Argumentation zu verteidigen suchte, fügte dem hinzu, George werde als „vollblütige Künstlernatur" 165 mit den Aufführungen sicherlich Erfolg haben, was die Aufführung eines spanischen Autors in deutscher Nachdichtung wett mache. Nicht nur Goebbels, sondern auch die kulturpolitische Abteilung das AA stimmte aufgrund der Stückauswahl der Gastspielreise letztlich nur widerwillig zu ${ }^{166}$. Schließlich mußte George die Gastspielreise auf zwei Aufführungen am 25. und 26. Mai 1940 allein in Budapest beschränken, da die Verhandlungen zwischen Schillertheater und RMVP zu lange gedauert hatten; George war zu diesem Zeitpunkt aufgrund der Aufnahmen für Veit Harlans "Jud Süß" wenig disponibel. Das Schillertheater erhielt zwar gute Pressekritiken, wie die deutsche Gesandtschaft aus Budapest berichtete, doch soll demnach der Erfolg nicht den Erwartungen des Ensembles entsprochen haben. Zudem kritisierte die Gesandtschaft die Auswahl eines spanischen Stückes und betonte, daß diese auch beim ungarischen $\mathrm{Pu}$ blikum Erstaunen hervorgerufen habe ${ }^{167}$. Ungeachtet dieser Kritik schlug George gleich im Anschluß an die Gastspielreise dem RMVP vor, auf der Budapester Margarethen-Insel William Shakespeares "Was ihr wollt" aufzuführen. Schlösser leitete die Anfrage nicht an Goebbels weiter und gab George zur Antwort, wenn Shakespeare auch in Deutschland zugelassen sei, so sei dessen Aufführung durch ein deutsches Ensemble im Ausland jedoch völlig ausgeschlossen. Im Ausland würde sicherlich niemand verstehen, weshalb ein deutsches Ensemble, ausgerechnet einen englischen Autor spiele und dies zu einer Zeit des Kampfes gegen England. Schlösser betonte, daß sowohl er als auch Goebbels stärkste Bedenken gegen den „Richter von Zalamea“ hat-

163 BAB, 50.01-503, Schiller Theater der Reichshauptstadt, Intendant, Heinrich George an Schlösser, RMVP, 2. 4. 1940.

164 Ibid.

165 BAB, 50.01-503, RMVP, Abt.Th., Schlösser an Goebbels, Betr.: Gastspielreise Heinrich George - Balkan, 27. 3. 1940.

166 Ibid. Vermerk, Schlösser zur Kenntnis, Betr.: Gastspielreise Heinrich George, 11. 5. 1940.

167 BAB, 50.01-503, Deutsche Gesandtschaft Budapest, von Erdmannsdorf an AA, Inhalt: Gastspiel des Schillertheaters, Durchdruck, 4. 6. 1940. Sie war der Ansicht, klassische deutsche Bühnenstücke wie der "Prinz von Homburg“, "Minna von Barnhelm“ oder der „Urfaust“ eigneten sich besser für eine Aufführung in Budapest. 
ten, weil es sich um einen ausländischen Autor handelte. Nur weil die Durchführung des Gastspiels gefährdet war, wurden diese zurückgestellt ${ }^{168}$.

Der "Richter von Zalamea" war demnach zwar für das Schillertheater ein erprobtes Stück für Gastspielreisen im Ausland, trotzdem wurde es von Goebbels keineswegs gewünscht. Ob die von George genannten pragmatischen Gründe für die Stückauswahl der Wahrheit entsprachen oder inwieweit für ihn eher seine persönlichen Wünsche und Vorlieben ausschlaggebend waren, sei hier dahingestellt. Als George 1943 erneut mit Goebbels um die Auswahl für die Gastspielreise verhandelte, versuchte der Intendant, durch geschicktes Taktieren seine Vorstellungen durchzusetzen, denen offenbar keine ideologischen, sondern allein persönliche Präferenzen zugrunde lagen. Interessant ist ferner, daß sich Goebbels so intensiv um Detailfragen wie die Auswahl von Stücken für Auslandsgastspiele kümmerte. 1943 schlug George dem Reichsdramaturgen Schlösser zunächst inoffiziell Friedrich von Schillers "Kabale und Liebe", mit dem er bereits 1941 in Paris gastiert hatte, sowie Gerhart Hauptmanns "Swedenhjelms“ vor. Da George wußte, daß Goebbels generell aufgrund der sogenannten Englandstellen gegen „Kabale und Liebe" eingestellt war, wollte er im Falle der Ablehnung Schillers "Fiesko" geben. Schlösser leitete diese Anfragen absichtlich nicht an Goebbels weiter. Er war der Meinung, die Vorschläge seien besser durchzusetzen, wenn George sich gleichzeitig zur Bespielung der ausgebombten, umquartierten Theater in Berlin und des Renaissance Theaters äußerte. George wollte hierfür zwar Pläne einreichen, betonte jedoch, daß ihm besonders die Auslandsgastspielreise am Herzen lag 169. Neben „Kabale und Liebe“ dürfte auch der "Swedenhjelms" nicht auf Goebbels Zustimmung gestoßen sein. Beispielsweise hatte sich das Referat Kulturpresse im RMVP 1940 bei Goebbels beschwert, das Stück stelle in der Inszenierung von George den Beruf des Journalisten überzogen lächerlich dar. Die „Borniertheit und Hilflosigkeit " ${ }^{\prime 170}$ des dargestellten Journalisten sei übertrieben und damit für die schreibende Zunft beleidigend. Da deutsche Theaterstücke im Ausland in Goebbels Augen Deutschland positiv darstellen sollten, ist seine Ablehnung des Stückes wenig verwunderlich. George war sich über die Schwierigkeit der Durchsetzung seiner Wünsche bewußt, zumal die Stückauswahl auch für die Spielpläne im Inland nicht einfach war. Stücke auszuwählen, die nicht Gefahr liefen, Anstoß zu erregen und verboten zu werden, war für die Intendanten schwierig 171 . Schließlich schlug George im September 1943 in einer

168 BAB, 50.01-503, RMVP, Schlösser an George, 29. 5. 1940.

169 BAB, 50.01-290, RMVP, Abt.Th., Vermerk, 24. 9. 1943.

170 Ibid. RMVP, Abt.Dt.Presse an Schlösser, 25. 6. 1940.

171 Hierüber hat sogar Schlösser einmal bei Goebbels Klage geführt. Der Reichsdramaturg berichtete, daß in den Kreisen der deutschen Künstler mit wachsender Besorgnis beobachtet werde, wie wenig deutsche Stücke noch zur Aufführung übrig blieben. Die deutschen Theater dürften nicht auf ein Mindestmaß meist langweiliger aber politisch einwandfreier Stücke reduziert werden. Die Intendanten hatten ihm gegenüber immer 
Unterredung mit dem Propagandaminister offiziell den „Richter von Zalamea" und Heinrich von Kleists "Zerbrochenen Krug" vor, womit Goebbels sich einverstanden erklärte. Geplant waren zwei umfangreiche Gastspielreisen, in Städten Ost-, West- und Südeuropas ${ }^{172}$. Nur wenig später brachte George gegenüber Schlösser jedoch seine wirklichen Wünsche vor: Er bevorzuge die südliche Gastspielreise, weil er für eine Reise von Posen bis Oslo kein geeignetes Stück im Repertoire habe. In den meisten Städten habe er bereits mit dem "Richter von Zalamea“ gastiert. George schlug vor, neben Kleists „Zerbrochenem Krug", Hauptmanns „Fuhrmann Henschel“ oder „Veland der Schmied“ geben zu wollen. Nach Meinung Schlössers hatten diese Vorschläge jedoch wenig Aussicht auf Erfolg173. Immerhin waren „Fuhrmann Henschel“ und „Veland der Schmied“ wie andere Stücke Hauptmanns von seiten der Nationalsozialisten als zu "depressiv" bezeichnet worden und schienen damit wenig geeignet, im Ausland für das nationalsozialistische Deutschland zu werben ${ }^{174}$. Schließlich zog George auch den „Zerbrochenen Krug" als Vorschlag zurück, weil das Stück aufgrund der Sprachschwierigkeiten nicht geeignet sei. George betonte, die Geschichte beruhe vor allem auf der inneren Entwicklung der Hauptfigur, des Richters Adam; ein ausländisches Publikum könne das Stück daher nur schwer verstehen. Schlösser betonte, George habe in der Unterredung mit Goebbels nicht gewagt, den „Fuhrmann Henschel“ vorzuschlagen. George schlage Goebbels das Stück nun „in Form einer verschämten Geburtstagsbitte ${ }^{\alpha 175}$ vor. Schlösser schrieb weiter, er kenne und teile Goebbels Einstellung zu dem frühnaturalistischen Werk Hauptmanns, der als Autor jedoch im Ausland recht bekannt sei. Nach Ansicht der Auslandsstelle für Theater habe gerade der „Fuhrmann Henschel“ besonders in Spanien Aussichten auf Erfolg. Außerdem habe George vorgeschlagen, er könne eventuell den Fuhrmann auch eher humorig darstellen, wobei dieser Art der Inszenierung aufgrund des Werkes Grenzen gesetzt sind. Im Falle einer Ablehnung des „Fuhrmann Henschel“, würde George „Kabale und Liebe“ vorziehen, wobei er die England betreffenden Stellen kürzen könne. Ansonsten wollte George, so

wieder erklärt, daß somit jegliche Experimentierfreudigkeit unterbunden würde, die jedoch unentbehrlich für ein blühendes Kulturleben sei; siehe BAB, 50.01-235, RMVP, Abt.Th., Schlösser an Goebbels, 23. 12. 1940.

172 BAB, 50.01-291, RMVP, Schlösser, Vermerk für Lang, 28. 9. 1943. Vorgesehen war eine Reise nach Posen, Danzig, Königsberg, Riga, Helsinki, Stockholm und Brüssel, und eine weitere nach Essen, Köln, Gladbach, Rheydt, Brüssel, Antwerpen, Den Haag, Paris, Barcelona, Madrid und Lissabon.

173 Ibid.

174 BAB, 50.01-235, RMVP, Abt.Th., Schlösser an Gobbels, Betr.: Gerhart Hauptmann, 4. 7. 1942. Schlösser berichtet, der "Fuhrmann Henschel" sei vor etwa anderthalb Jahren von Angehörigen der NSDAP als „zu depressiv“ bezeichnet worden. Zu „Veland der Schmied“ siehe BAB, 50.01-507, RMVP, Ministeramt, Regierungsrat Hamel, an Leiter Abt.Th., Betr.: Auslandsgastspiele des Schiller-Theaters, 18. 12. 1943.

175 BAB, 50.01-291, RMVP, Abt.Th., Schlösser an Goebbels, Betr.: Auslandsreisen des Schillertheaters, 30.9.1943. 
Schlösser, nur die südliche Reiseroute mit dem „Richter von Zalamea“ durchführen ${ }^{176}$. George hatte zunächst also seine wirklichen Wünschen gegenüber Goebbels zurückgehalten und versuchte nun zu taktieren, um dessen Zustimmung für die eigenen Vorschläge zu erhalten. Der Propagandaminister lehnte jedoch die Aufführung des „Fuhrmann Henschel“" „ganz entschieden“ 177 ab, ebenso hielt er „Kabale und Liebe“ für ungeeignet. So fiel die Wahl schließlich auf den „Richter von Zalamea“, der in Goebbels Augen im Vergleich zu den anderen genannten Stücken wohl eher das geringere Übel als das bevorzugte Theaterstück deutscher Kulturpropaganda im Ausland darstellte. Erstaunlicherweise zog er die Auswahl eines nicht-deutschen Autors einer Aufführung der angeblich zu depressiven Stücke Hauptmanns im Ausland vor. Die Politik der deutschen Kulturpropaganda war hier mit der Aufführung eines spanischen Autors alles andere als kohärent, zumal ausgerechnet der „Fuhrmann Henschel" sogar auf Betreiben der Propaganda Staffel im Februar 1943 zu Ehren des 80. Geburtstags Hauptmanns im Pariser Théâtre de l'Odéon gespielt wurde, worauf später noch eingegangen wird 178 .

Trotz Goebbels Entscheidung für die südliche Gastspielroute wurde diese nicht in vollem Umfang durchgeführt. Das AA zeigte in bezug auf Spanien und Portugal als Gastspielorte Skepsis ${ }^{179}$. Die deutschen Gesandtschaften in Lissabon und Madrid meinten, daß die fehlenden deutschen Sprachkenntnisse die Gastspiele zu einem hohen finanziellen und propagandistischen Wagnis machten. So wurde die Tournee, die übrigens auch der Betreuung der deutschen Truppen diente, schließlich verkürzt. Das deutsche Theater in Lille bereitete die Aufführungen in Lille, Brüssel, Antwerpen, Gent und Paris vor; unter anderem stellte es auch die Dekorationen her. Weitere Stationen der Reise waren Bordeaux und Nancy ${ }^{180}$. Das Gastspiel des Schillertheaters in Paris im Oktober 1943 war also Station einer Tournee, die vor allem aus pragmatischen Gründen Goebbels Zustimmung gefunden hatte. Die Entscheidung hierzu wurde ebensowenig wie die Auswahl des Stückes aus rein kulturpropagandistischen Motiven getroffen. Für Paris waren zunächst sogar nur drei Vorstellungen vor Truppen der Wehrmacht vorgesehen, bis das RMVP bei der Deutschen Botschaft in Paris anfragte, ob auch eine Aufführung vor französischen Publikum in der Comédie-Française möglich wäre ${ }^{181}$. Die Botschaft war damit einverstanden, betonte jedoch, die öffentliche Vorstellung müsse vor geladenen Gästen stattfinden. Ein nur einmaliges

\author{
176 Ibid. \\ 177 Ibid. 50.01-291, RMVP, Ministeramt, Dr. Naumann an Schlösser, Betr.: Auslands- \\ reisen des Schillertheaters, 2. 10. 1943. \\ 178 Siehe Kapitel III. 1.3. dieser Arbeit. \\ 179 BAB, 50.01-291, RMVP, Schlösser an Leiter Abt. Ausland, 2. 10. 1943. \\ 180 Ibid. RMVP, Abt.Th., Schlösser an Goebbels, Betr.: Gastspielreise des Schiller- \\ theaters, 6. 10. 1943. \\ 181 PA-AA, 1142, Kult 12 Nr. 2, AA, Schattenfroh an DBP, 10. 10. 1943.
}


Auftreten des Schillertheaters könne ansonsten die dem künstlerischen Ereignis entsprechende Resonanz nicht sichern. Um einem etwaigen Reinfall vorzubeugen, bestand das Publikum der öffentlichen Aufführung schließlich vor allem aus geladenen Gästen der Botschaft, angeblich den „führenden geistigen und künstlerischen Pariser Kreisen "182. Außerdem waren im Zuschauerraum Schüler der Sprachkurse des Deutschen Instituts sowie GermanistikStudenten der Sorbonne, denen die Botschaft Einladungen geschickt hatte ${ }^{183}$. Im Anschluß an das Gastspiel lobte die Botschaft die reibungslose Organisation, die gemeinsam mit der KDF und dem Deutschen Theater Lille erfolgt war ${ }^{184} . \mathrm{Da}$ in Paris die Vorstellung nicht wirklich öffentlich gewesen war, übernahm die Botschaft die dafür entstandenen Kosten, die sich insgesamt auf 83498 Francs beliefen, davon erhielt die Comédie-Française 61098 Francs zur Erstattung ihrer Kosten ${ }^{185}$. Obwohl es sich hier um ein Ensemble-Gastspiel handelte, war dies im Vergleich zu anderen Planungen eher kostengünstig. Für das Jahr 1943 sollte es das einzige deutsche Theatergastspiel in Paris bleiben.

Die Botschaft und das Institut konzentrierten ihre Anstrengungen zu diesem Zeitpunkt vorwiegend auf kleinere Kulturveranstaltungen, vor allem auf Konzerte mit deutschen Musikern in Paris und auch vermehrt in der französischen Provinz. Die kulturpolitische Abteilung des AA hatte allgemein dem Wunsch zu mehr sogenannter Aktivpropaganda und Kulturpropaganda Ausdruck verliehen, was Schleier als besonders wichtig für die Südzone Frankreichs erschien. Seiner Ansicht nach war die Einflußnahme auf die öffentliche Meinungsbildung gerade dort sehr wichtig. Allerdings bedauerte er gegenüber dem AA, daß dies bisher aus Mangel an Mitarbeitern nicht möglich sei ${ }^{186}$. Sowohl das AA als auch die Deutsche Botschaft hielten weiterhin an möglichst umfangreichen Aktivitäten deutscher Kulturpropaganda im besetzten Frankreich fest, wenn dies auch aufgrund materieller Schwierigkeiten immer problematischer wurde. Generell stellte sich im Zuge des totalen Krieges jedoch mehr und mehr die Frage nach der weiteren Bedeutung dieser Politik und somit auch die Frage nach dem Sinn und Zweck der Arbeit der mit kulturpolitischen Aufgaben befaßten Dienststellen in Paris. Angesichts der Tatsache, daß mehr und mehr Mitarbeiter der deutschen Dienststellen Paris verlassen mußten und eingezogen wurden, war diese Frage permanent präsent. Die deutschen Funktionsträger hatten aus rein persönlichen Gründen ein vitales Interesse an der Fortführung der deutschen Kulturpolitik in

182 Ibid. DBP, Gerlach an AA, Kult Pol K Nr. 6040/43, 19. 10. 1943.

183 Ibid. (und BAB, 50.01-291), DBP, Knothe an AA, Betr.: Gastspiel des Berliner Schillertheaters am 3. 11. 1943 in Paris, 31. 1. 1944.

184 Ibid.

185 PA-AA, 1142, Kult 12 Nr. 2, DBP, Knothe an Abetz, über Gerlach, Aufzeichnung, 10. 12. 1943 .

186 PA-AA, 1136a, Kult 1, DBP, Schleier an AA, Betr.: Verstärkung der kulturpolitischen Arbeit, Durchdruck, 20. 10. 1943. 
Frankreich, die gleichzeitig jedoch mehr und mehr an Bedeutung verlor. Die wirtschaftlichen und propagandistischen Interessen des kriegführenden Deutschland und damit die Ausbeutung der besetzten Gebiete sowie die Maßnahmen zur sogenannten Endlösung der Judenfrage traten in den letzten beiden Jahren der Besatzung in Frankreich mehr und mehr in den Vordergrund. Auch das AA bestand jedoch auf der Notwendigkeit der Fortführung der deutschen Kulturpolitik und somit auch der Kulturpropaganda. Im Februar 1944 sandte das AA ein Rundschreiben an alle Gesandtschaften eine "grundlegende Stellungnahme" 187 , die eine offizielle Argumentationshilfe für den Fall bildete, daß die kulturpolitische Arbeit im Ausland in Frage gestellt würde. Der Leiter der kulturpolitischen Abteilung, Franz Alfred Six, schrieb in diesem Sinne, angesichts des totalen Krieges stelle sich die Frage nach der Wichtigkeit der Weiterführung der kulturellen Arbeit und somit die Frage, ob diese Kulturarbeit „kriegswichtig“ und weiterhin gerechtfertigt sei. Häufig werde diese Frage gedankenlos verneint, wobei es sich um eine Verkennung der Bedeutung der Kulturarbeit für die Gesamtpolitik des Reiches handelte. Hauptsächlich nannte er zwei Gründe, die nach seiner Ansicht eine möglichst uneingeschränkte Weiterführung der Kulturarbeit notwendig machten:

1.) Die kulturelle Betätigung allgemein wie die Unterhaltung kultureller Sammelpunkte in Form der Schulen, wissenschaftlichen Institute usw. ist der sichtbare Ausdruck unserer Zuversicht und unseres Vertrauens in die Zukunft. Vorübergehende militärische Rückschläge und ein dadurch bedingtes Absinken der Stimmung machen die Aufrechterhaltung der kulturpolitischen Positionen nicht etwa weniger wichtig, sondern wichtiger.

2.) Die kulturelle Betätigung ist eine Arbeit auf lange Sicht. Sie duldet keine Unterbrechung, andernfalls würden gewisse Jahrgänge des Fremdvolkes, insbesondere des akademischen Nachwuchses, für die kulturell-formende Beeinflussung unsererseits ausfallen. Ein Versäumnis, das sich später in der Gesamtpolitik als Verlust auswirkte und nicht mehr aufzuholen sein würde ${ }^{188}$.

Six führte weiter an, die französische Kulturpolitik der Vergangenheit sei der beste Beweis dafür, daß es möglich sei, durch kulturpolitische Arbeit grundlegende politische Veränderungen herbeizuführen. Als Beispiel führte er südosteuropäische Staaten an, in denen es Frankreich mit Hilfe seiner Kulturpolitik gelungen sei, die führende Schicht politisch für sich zu gewinnen, obgleich sie vorher nach Deutschland orientiert waren. Eine langfristig angelegte Kulturpolitik im Ausland durfte nach Six nicht unterbrochen werden, auch wenn die Belastung für Deutschland durch den Krieg besonders groß sei. Gerade um das Vertrauen des nationalsozialistischen Deutschland in die Zukunft zu dokumentieren, sollte demnach die kulturelle Arbeit fortgeführt werden ${ }^{189}$.

187 PA-AA, 1115a II, D.Kult 1 Nr. 1, AA, Six an DBP, 8. 2. 1944.

188 Ibid.

189 Ibid. 
Dementsprechend schickte das AA einen Monat später, im März 1944, wie im vorangegangenen Jahr an alle Gesandtschaften Vorschläge für deutsche Kulturveranstaltungen im Bereich von Theater, Musik und Ausstellungen. Die Listen von möglichst besten Künstlern, die das AA beilegte, entsprachen grundsätzlich den Vorschlägen vom Vorjahr. Das AA meinte zwar einschränkend, durch die Kriegsereignisse, vor allem die Luftangriffe, müßten eventuell Änderungen vorgenommen werden, doch Grundgedanke bleibe folgender: Der Einsatz deutscher Künstler sollte möglichst auch in gefährdeten Gebieten geschehen, ähnlich wie auch die Truppenbetreuung an der Front. Die Gesandtschaften in luftgefährdeten Gebieten - dazu gehörte auch Frankreich - müßten unbedingt diesen Grundsatz beachten. Was Theatergastspiele anbelangte, so war das AA der Meinung, daß in jedem Falle auch in Zukunft größere Gastspiele mit geschlossenen Ensembles oder Orchestern stattfinden sollten, falls die Transportlage es zuließ $\mathrm{e}^{190}$. Zu diesen Vorschlägen gehörten auch Konzertreisen der Wiener Philharmoniker nach Spanien und Portugal, was generell auch eine Zwischenstation in Paris einschloß. Weiterhin empfahl das AA das Gewandthausorchester unter Paul Schmitz. Als Gastdirigenten für Paris schlug es insbesondere Hermann Abendroth, Staatskapellmeister Herbert von Karajan, Karl Schuricht, Eugen Jochum und Hans Schmidt-Isserstedt vor. An geeigneten Solisten nannte es unter anderem Walter Gieseking, Wilhelm Kempff, Elly Ney und Fritz Heitmann ${ }^{191}$. In den Aufstellungen der tatsächlich durchgeführten Veranstaltungen der Jahre 1942 und 1943 findet sich ein Großteil der genannten Namen wieder ${ }^{192}$. Ende 1943 und im Frühjahr 1944 waren die Botschaft und das Deutsche Institut in Paris sowie die Deutschen Institute in der Provinz weiterhin besonders darum bemüht, angesichts der deutschen militärischen Niederlagen nun erst recht weiterhin Kulturpropaganda in Frankreich zu betreiben. Die Pariser Stellen beklagten sich allerdings im Januar 1944 beim AA, es würden nicht genügend deutsche Künstler nach Paris gesandt, um den Bedarf der Botschaft zu decken. Diese teilte vorwurfsvoll mit, es hätten deswegen in der gesamten französischen Provinz nur dreißig Konzerte vom 1. Oktober 1943 bis zum 29. Februar 1944 stattfinden können. Um aber den Ansprüchen der deutschen Stellen in ganz Frankreich gerecht zu werden, müßten monatlich mindestens drei Ensembles an je zehn verschiedenen Orten spielen. Das AA müsse das RMVP unbedingt auf die Dringlichkeit einer intensiven künstlerischen Betreuung hinweisen, damit regelmäßig mehr deutsche Ensembles und Künstler zu Veranstaltungen nach Frankreich gesandt würden ${ }^{193}$. Hier zeigt sich, daß die

190 Ibid. AA an DBP (an alle Gesandtschaften und Bot.), Kult pol. Fü. St. 894/44, Betr.: Planung 1944/45, Theater, Musik, Ausstellungen, 2. 3. 1944.

191 Ibid. Anlage; ferner sollten die Münchner Philharmoniker unter Oswald Kabaster sowie das Kammerorchester von Benda eventuell im Rahmen einer Wehrmachtstournee auch öffentliche Konzerte in der französischen Provinz geben.

192 Siehe dazu SCHWARTZ, Musikpolitik, S. 55-78.

193 PA-AA, 1113, Kult 12 Nr. 3, DBP, von Kutzschenbach an AA, Betr.: Konzertveran- 
alleinige Zuständigkeit der Botschaft für den Aufgabenbereich der Kulturpropaganda zunehmend an Bedeutung verlor. Das RMVP war zuständig für die zentrale Verteilung der deutschen Künstler, die immerhin auch in Deutschland die Bevölkerung unterhalten sollten. Im Zuge des fortschreitenden Künstlermangels bestimmte vor allem das RMVP, welche deutschen Künstler in Paris auftraten. Die Beschwerden der Botschaft stießen in Berlin dennoch auf offene Ohren. Die Musikabteilung im RMVP sagte bald darauf Bemühungen zu, um diesen Zustand zu ändern. Die ersten Resultate machten sich laut Piersig im April 1944 bemerkbar. Auch für Mai und Juni gab es demnach ein kulturpropagandistisches Programm ${ }^{194}$. Dieses umfaßte vor allem kleinere Gastkonzerte einzelner deutscher Musiker. Für den März 1944 war sogar ein Gastspiel der Hamburger Staatsoper in Paris geplant worden, das jedoch nicht stattfand. Die Idee hierzu war entstanden, als sich 1943 ein sogenanntes Wehrbetreuungsensemble der Hamburger Staatsoper in Paris befunden hatte. Die Botschaft hatte den Vorschlag befürwortet und insbesondere eine Aufführung des von der Hamburger Oper vorgeschlagenen "Freischütz“ als „kulturpolitisch für sehr erwünscht" gehalten. Dagegen erschien ihr, als im Frühjahr 1944 die Hamburger Aufführung des „Xerxes“ von Händel zur Sprache kam, letzterer für Paris als ungeeignet. Die Botschaft bat jedoch die Staatsoper, sich mit der Stückauswahl direkt an das RMVP zu wenden ${ }^{195}$. Auch Mitte Mai 1944, nach einer erneuten Anfrage des Hamburger Bürgermeisters C.V. Krogmann, verwies ihn Abetz abermals an das RMVP. Er versicherte lediglich, die Botschaft würde sich freuen, wenn die Hamburger Staatsoper in Paris gastierte ${ }^{196}$. Abetz, der noch 1941 hart um seine alleinige Zuständigkeit für Gastspiele in Paris gekämpft hatte, verwies nun die Hamburger Oper zur Entscheidung an das RMVP. Der Kompetenzstreit zwischen den deutschen Dienststellen wurde in den Jahren 1943/44 allmählich durch die sich verschlechternde Kriegslage endgültig entschieden. In Deutschland herrschte Künstlermangel und das RMVP übernahm die zentrale Verteilung dieser Kräfte. Die Planungen der Botschaft vom März 1944 zeigen ebenfalls, daß das RMVP stark darin einbezogen war. Der zuständige Mitarbeiter bei der Botschaft, Piersig, stand als ehemaliger Angehöriger der Propaganda Staffel stets in direkter Verbindung mit der Auslandsstelle für Theater im RMVP. Damit hielt er den vorgeschriebenen Dienstweg über das AA nicht ein. Obwohl die Realisierung deutscher Gastspielpläne laut Piersig durch die schwierige Elektrizitätsversorgung in Paris immer schwieriger

staltungen in Paris und der französischen Provinz im Winterhalbjahr 1943/44, 1. 4. 1944.

194 Ibid. DBP, Piersig, Aufzeichnung, 14. 4. 1944; die Aufzeichnung nahm bezug auf den Bericht des DIP Kult 1321/44 vom 1. April 1944 betr. Konzertveranstaltungen in der Provinz im Winterhalbjahr 43/44.

195 Ibid. DBP, Gerlach, über AA an Bürgermeister C.V. Krogmann, Hamburg, Paris 4. 3. 1944.

196 Ibid. DBP, Abetz an Krogmann, 19. 5. 1944. 
wurde, sollten die Münchner Kammerspiele entweder den „Urfaust“ oder Gotthold Ephraim Lessings „Emilia Galotti“ Anfang Mai 1944 im Théâtre de l'Odéon aufführen. Die Finanzierung sollten die deutschen Dienststellen in Paris übernehmen ${ }^{197}$. Da das Gastspiel aus spielplantechnischen Gründen von den Kammerspielen abgesagt wurde, verhandelte Piersig kurzfristig mit dem Staatlichen Schauspielhaus Hamburg. Dieses schlug Gotthold Ephraim Lessings "Minna von Barnhelm“ und Friedrich Hebbels „Gyges und sein Ring" vor. Das AA wurde über diese Verhandlungen erst nach deren Abschluß unterrichtet ${ }^{198}$. Die Wahl fiel auf das letztgenannte Stück, eine Entscheidung, die laut Intendant Staatsrat Karl Wüstenhagen aufgrund von organisatorischen Gründen getroffen wurde ${ }^{199}$.

So gastierte das Hamburger Schauspielhaus mit dem Stück vom 19. bis 31. Mai 1944 in Frankreich. In Paris fanden am 19., 20., 23. April und 4. Mai vier öffentliche Vorstellungen im Théâtre de l'Odéon statt; eine weitere Aufführung gab das Ensemble ebenfalls vor französischem Publikum am 31. Mai in Bordeaux. Vor Angehörigen der Wehrmacht spielte die Truppe am 22. Mai in Fontainebleau sowie am 26., 29. und 30. Mai in Bordeaux. Abetz hatte für diese Gastspiele einen Zuschuß von 800000 Francs genehmigt, wovon jedoch nur 395000 Francs in Anspruch genommen wurden. Die Veranstalter in Bordeaux betonten, wie gut dort die Zusammenarbeit von KDF, Propaganda Staffel und Deutschem Institut gewesen sei ${ }^{200}$. Auch für Paris lassen sich keinerlei Anzeichen für eine schlechte Kooperation der deutschen Dienststellen finden. Die Deutsche Botschaft meldete an das AA in Berlin, die Aufführungen müßten „als ein gewichtiger und nachdrücklicher kulturpropagandistischer Erfolg gewertet werden"201. Das Theaterreferat war der Ansicht, das Gastspiel habe bei Publikum und Presse ein anerkennendes Echo gefunden 202. Obgleich die Aufführungen öffentlich waren, versandte die Botschaft zahlreiche Einladungskarten an die ihr nahestehenden französischen Kreise und Teilnehmer der Sprachkurse des Deutschen Institut. Die geladenen Gäste sollten den Erfolg der Veranstaltung sichern, zumal für die Werbung etwa durch Plakate zu diesem Zeitpunkt der Besatzung immer weniger

197 BAB, 50.01-519, RMVP, Auslandsstelle für Theater, Götze an Lang, Vermerk, Betr. Gastspiel der Kammerspiele München in Paris, 22. 3. 1944.

198 Ibid. Auslandsstelle für Theater, Götze an Lang, Vermerk, 15. 4. 1944.

199 Ibid. Staatliches Schauspielhaus Hamburg, Generalintendant Staatsrat Karl Wüstenhagen an Schlösser, RMVP, 7. 6. 1944.

200 PA-AA, 1215, Kult 12 Nr. 2, DBP an AA, Betr. Gastspiel des Staatlichen Schauspielhauses Hamburg in Frankreich, 10. 7. 1944.

201 Ibid.

202 AN, AJ40 1001-7, Bericht über den Monat Mai 1944, 31. 5. 1944. Schon mit der Aufführung von Hebbels „Maria Magdalena“, das im Februar und September 1943 im Théâtre de l'Odéon gespielt wurde, war das Theaterreferat zufrieden gewesen. Goldmann lobte im September diese französische Inszenierung; AN, AJ40 1001-7, Prop.Abt., Gr.Kult.Th., Tätigkeitsbericht, 29. 9. 1943. 
Mittel zur Verfügung standen ${ }^{203}$. Die Pariser Zeitung schrieb über das Gastspiel, es habe vor vollbesetztem Hause eine warmherzige Aufnahme gefunden:

Die Wirkung eines solchen Werkes in so gelungener Aufführung erschöpft sich nicht in wenigen Minuten eines freudigen und dankbaren Beifalls. Sie geht in die Tiefe, sie verlangt ihre Zeit und sie wirkt in der Zeit. [...] Diese Schauspielertruppe kam aus einer deutschen Großstadt, die mit am schwersten durch die Bombenangriffe getroffen ist. Diese Hamburger Schauspieler haben das Elend der Zerstörungen an sich selbst und ihren Nächsten erfahren ${ }^{204}$.

Allerdings wird dieses letzte deutsche Theatergastspiel im besetzten Paris mit seinen gerade vier deutschsprachigen Aufführungen ebenso wie die übrigen Gastspiele wohl kaum Einfluß auf das Pariser Publikum im Sinne deutscher Kulturpropaganda gehabt haben, zumal ein erheblicher Teil geladene Gäste waren. Vor allem aber zeigt der Inhalt des Programmheftes die Widersprüchlichkeit der Vorstellungen der Besatzungsmacht über die Inhalte deutscher Kulturpropaganda. Die Veranstalter betonten im Programmheft den starken Bezug von Hebbels Leben und Werk - insbesondere von „Gyges und sein Ring“ - zu Frankreich. Hebbel verbrachte in den Jahren 1843 bis 1844 längere Zeit in Paris. Er betonte in seinen Tagebüchern, dort habe er viele Anregungen erhalten und denke dankbar an den Aufenthalt zurück. Das Programmheft zum Pariser Gastspiel druckte einige seiner Tagebuchauszüge ab. Darin schreibt Hebbel, er würde sich gerne ein Leben lang in Paris aufhalten. Nur mit Entsetzen denke er an seine bevorstehende Abreise nach Rom. Paris werde immer der Mittelpunkt seiner Wünsche bleiben: „Lebe wohl du schöne herrliche Stadt, die mich so gastfreundschaftlich aufnahm! Empfange meinen wärmsten Segen! Blühe länger als alle Städte der Welt zusammengenommen"205! Zudem, so der Text des Programmheftes, lehne sich Hebbel mit "Gyges und sein Ring" im Gegensatz zu seinen anderen Werken ausdrücklich an die französische klassische Tragödie an. Zu seinen Lebzeiten habe er vergeblich auf eine Aufführung des Stückes an der Comédie-Française gehofft. Dieser Traum sei nun endlich wahr geworden ${ }^{206}$. Die ausdrückliche Betonung des französischen Einflusses auf Hebbel und dessen Bewunderung für Paris entsprach wohl kaum den Vorstellungen deutscher Kulturpropaganda, die eigentlich demonstrieren sollte, wie höherstehend die deut-

203 PA-AA, 1215, Kult 12 Nr. 2, DBP, Piersig u. Knothe an AA, Betr.: Gastspiel des Staatlichen Schauspielhauses Hamburg in Frankreich, 10. 7. 1944. Die Schauspielerin Maria Wimmer hielt als Begleitprogramm zum Gastspiel eine Goethe-Lesung vor den Sprachschülern des Deutschen Instituts.

${ }_{204}$ BN-BA, Albert BUESCHE, Gyges und sein Ring im Odéon, Geschichtsdrama in geschichtlicher Situation, in: Pariser Zeitung, 23. 5. 1944. Wüstenhagen wurde von folgenden Schauspielern begleitet: Maria Wimmer, Helga Goering, Agathe Poschmann, Stig von Nauckhoff, Erich Rauschert und Helmut Gmelin.

${ }^{205} \mathrm{BAB}, 50.01-519$, Programmheft zum Gastspiel des Hamburger Staatsschauspiels mit Hebbels "Gyges und sein Ring“ in Paris, Juni 1944. (zweisprachig)

206 Ibid. 
sche Kultur sei. Die Tagebucheintragungen Hebbels konnten dem französischen Zuschauer eher Anlaß zum Stolz auf die eigenen kulturellen Leistungen geben. Der gesamte Tenor des Heftes zielte keineswegs auf eine Werbung für die sogenannte höherstehende deutsche Kultur ab. Zwar wollten die Dienststellen deutsche Kulturpropaganda betreiben, doch zeigt sich in der Umsetzung dieser Politik, daß sie sich dabei auch nach den Wünschen bzw. der Mentalität des französischen Publikums richteten. Die Berücksichtigung der französischen Zuschauer zeigt den Respekt vor der französischen kulturellen Ausstrahlungskraft, der sich hier mit der Angst vor eventuellen Mißerfolgen deutscher Kulturpropaganda verband. Gleichzeitig diente diese Art deutscher Kulturpropaganda auch dem vor allem von Institut und Botschaft verfolgten Ziel, der französischen Seite einen deutsch-französischen Kulturaustausch vorzugaukeln, ganz im Sinne einer Politik der Kollaboration. An den Aspekt, daß dieses Stück von Hebbel am Vorbild des französischen Theaters gewachsen war, knüpfte auch Intendant Wüstenhagen an, als er Schlösser im RMVP berichtete. Er äußerte sich besonders zufrieden darüber, den engen Bezug Hebbels zu Frankreich deutlich gemacht zu haben. Seine Gespräche mit französischen Journalisten, so Wüstenhagen, hätten die gute Auswahl des Stückes bestätigt. Die Presse habe sogar Bühnenbild und Inszenierung des Hamburger Staatsschauspiels mit französischen Aufführungen ähnlicher Werke verglichen und dies oft zum Nachteil der französischen Theater. Während der Aufführungen seines Ensembles habe „andachtsvolle, lautlose Stille geherrscht" 207 und am Ende hätte das Publikum für Pariser Verhältnisse ungewöhnlich stark Beifall geklatscht.

Die Deutsche Botschaft maß dem Gastspiel darüber hinaus angesichts der Kriegslage eine symbolische Bedeutung bei. Im Juli 1944 berichtete die Botschaft an das AA, wie beeindruckend es gewesen sei, ein deutsches Ensemble auf der Bühne zu sehen, das aus einer besonders durch Luftangriffe betroffenen Stadt komme. Abschließend heißt es:

Das Gastspiel des Staatlichen Schauspielhauses Hamburg hat erwiesen, daß in Frankreich Darbietungen erlesener deutscher Ensemblekunst jederzeit sachliches Interesse, ernsthafte Anerkennung und ehrlichen Erfolg finden. Auf diesem Wege, d.h. mit Darbietungen wertvoller deutscher Werke in innerlich sauberer Inszenierung, bieten sich künstlerisch-kulturell ergiebige Möglichkeiten für die Durchsetzung deutscher Kunst in Frankreich 208 .

Kurz nach Landung der Alliierten in der Normandie und nur einen Monat vor der Befreiung von Paris sprach die Botschaft hier also noch zuversichtlich vom angeblichen Erfolg deutscher Kulturpropaganda. Vor dem Hintergrund der Niederlagen der deutschen Armee an der Ostfront sollten die Aufführungen des Staatsschauspiels die angebliche Stärke und Siegesgewißheit

207 BAB, 50.01-519, Staatliches Schauspielhaus Hamburg, Generalintendant Staatsrat Karl Wüstenhagen an Schlösser, RMVP, 7. 6. 1944.

208 Ibid. 
Deutschlands dokumentieren. Im Gegensatz zum ersten deutschen Theatergastspiel im besetzten Paris im Frühjahr 1941, sollten diese Aufführungen nicht mehr den militärischen Sieg Deutschlands über Frankreich durch einen kulturellen Sieg komplettieren. Vielmehr sollten sie nun die militärischen Niederlagen an der Ostfront vergessen machen und den Glauben an die siegreiche Zukunft des nationalsozialistischen Deutschlands dokumentieren. Diese Sichtweise charakterisiert insgesamt die letzten kulturpropagandistischen Bemühungen im Bereich der Gastspiele. Als die Berliner Philharmoniker im Juni 1944 eine Tournee nach Spanien unternahmen, gastierte das Orchester am 12. Juni in Paris. Unter der Leitung des Dirigenten Hans Knappertsbusch gab man ein öffentliches Konzert im Théâtre national du Palais de Chaillot. Das Konzert wurde nach den Berichten der Botschaft angeblich ein künstlerischer und auch politischer Erfolg. Es war ausverkauft und mehrere hundert Besucher sollen keinen Einlaß mehr bekommen haben. Wegen des Fliegeralarms war der Beginn um eine Stunde verzögert worden. Das Publikum, das zu vier Fünfteln aus Franzosen bestanden haben soll, wartete den Alarm demnach geduldig ab. Angeblich sollen Dirigent und Orchester anschließend so stark gefeiert worden sein, daß das Publikum eine Zugabe erzwang, obgleich inzwischen die letzte Metro fuhr. Demnach soll sich das französische Publikum anschließend freiwillig zu Fuß auf den Heimweg begeben haben. In diesem Augenblick, so die Botschaft, habe das Konzert der Philharmoniker eine "wertvolle Kundgebung für absolutes deutsches Vertrauen in weitere Entwicklung der Lage" 209 dargestellt und in diesem Sinne bei den Franzosen eine starke Wirkung gehabt. Diese Einschätzung dürfte von der Realität jedoch weit entfernt gewesen sein, da zu dem Zeitpunkt der Großteil der Pariser Bevölkerung eher auf die ersehnte Libération wartete. Dem Konzert der Philharmoniker mag zwar tatsächlich ein gewisser Erfolg beschieden gewesen sein, doch dürfte dieser in keinem Zusammenhang mit einem Vertrauen der französischen Bevölkerung in den Sieg der keineswegs beliebten deutschen Besatzungsmacht gestanden haben. Auf das obige Konzert weist auch der letzte kulturpolitische Bericht des Deutschen Instituts vom Juni 1944 hin. Dieser zieht ein Resümee der kulturpolitischen Arbeit in Frankreich. Demnach soll die in diesem Bereich in den Jahren 1943/44 gewonnene Stellung erhalten geblieben sein. Weiter heißt es: „Daß auf dem rein kulturpolitischen Sektor auch nach der Invasion noch Erfolge möglich sind, hat das Konzert der Philharmoniker unter Knappertsbusch erwiesen, das unter erschwerenden Umständen einen vollen Erfolg gebracht hat “210. Dementsprechend war das Deutsche Institut darauf bedacht, auch jetzt noch die "volle Bereitschaft zur rein kulturpolitischen Arbeit" aufrecht zu erhalten. Der Bericht sah sogar noch Planungen für die Zukunft vor. Demnach wollte 
das Institut versuchen, kulturpolitisch auf den Süden Frankreichs stärkeren Einfluß zu nehmen. Die kulturpolitische und propagandistische Arbeit wollte das Institut in Frankreich dezentralisieren, indem die Referenten in der südlichen Zone mehr materielle Unterstützung und Selbständigkeit erhielten ${ }^{211}$. Auch hier beklagte sich das Institut erneut, aus Berlin seien nicht genügend Künstler gesandt worden, so daß der Bedarf nicht gedeckt werde. Die weiteren Planungen sahen vor, vor allem die bisher in Frankreich weniger bekannte deutsche Musik wie Werke von Anton Bruckner, Max Reger, Hans Pfitzner und Werner Egk zu fördern. Zu Theateraufführungen heißt es nur allgemein, auch deutsche Theatergastspiele könnten bei erstklassigen Aufführungen in Zukunft wirkungsvoll sein ${ }^{212}$. Freilich handelt es sich hier um einen offiziellen und deswegen in einem zuversichtlichen Ton gehaltenen Tätigkeitsbericht an das AA. Ob die Mitarbeiter der Botschaft und des Instituts tatsächlich diese doch eher illusorischen Ansichten teilten, ist zweifelhaft. In diesem Bericht klingt allerdings auch eine Rechtfertigung der eigenen Tätigkeit an. Er will den Leser Glauben machen, in Frankreich habe die Besatzungsmacht im Grunde genommen auf dem „rein kulturpolitischen Sektor" - also nicht auf dem militärischen - durchaus gesiegt; trotz der militärischen Niederlage habe die deutsche Kulturpropaganda das französische Publikum von der Qualität der deutschen Kultur, symbolisiert durch das Konzert der Philharmoniker, auch jetzt noch überzeugen können.

Die vorangegangenen Ausführungen zu deutschen Gastspielen im besetzten Paris haben gezeigt wie stark die Kulturpolitik in diesem Bereich von Kompetenzstreitigkeiten bestimmt war, während Inhalte und Umsetzung der Kulturpropaganda keiner klaren Linie folgten. Die sogenannte Pariser Gastspielfrage war bereits zu Beginn der Besatzung Gegenstand eines Streites zwischen den deutschen Dienststellen in Paris, vor allem aber zwischen Botschafter Abetz und Propagandaminister Goebbels. Während Abetz mit prestigeträchtigen deutschen Gastspielen eine Art deutsch-französischen Kulturaustausch $z$ wischen vorgeblich gleichberechtigten Partnern propagieren wollte, nahm Goebbels aus mehreren Gründen eine entgegengesetzte Haltung ein. Große Pariser Gastspiele der besten deutschen Ensembles stellten in seinen Augen eine Art Anerkennung und Respekt vor dieser Stadt als einer Kulturmetropole dar. Darüber, daß im Falle von Gastspielen nur die besten deutschen Künstler nach Paris reisen sollten, waren sich jedoch alle Dienststellen einig. Dieser Grundsatz galt generell für Auslandsgastspiele und ganz besonders für Paris. Gegensätzliche Positionen äußerten sich auch in der Auswahl der Stücke; im Falle des Gastspiels des Schillertheaters mit "Kabale und Liebe" war Goebbels aufgrund der Passagen, die England betrafen, strikt gegen dieses Stück, während Deutsche Botschaft und Institut propagierten, das Werk Schillers sei von den Ideen Rousseaus beeinflußt und so- 
mit Ausdruck eines deutsch-französischen Kulturaustauschs. Das von Abetz durch direkte Intervention bei Hitler durchgesetzte, ebenso aufwendige wie prestigeträchtige Gastspiel der Berliner Staatsoper in Paris brachte eine Wende in der sogenannten Gastspielfrage. Goebbels sah sich vor vollendete Tatsachen gestellt und schickte nun die Propaganda Staffel in eine Art kulturpropagandistischen Wettstreit. Diese war als Dienststelle vor Ort prinzipiell eher für Gastspiele eingestellt und hätte diese in Konkurrenz mit dem Deutschen Institut gerne selbst initiiert; aufgrund der strikten Haltung von Goebbels hatte es jedoch vor allem nur die Aktivitäten des Deutschen Instituts in diesem Bereich sabotiert. Nach der Wende im Streit um die Gastspiele bemühte sich auch die Staffel verstärkt um Theater- und Operngastspiele. Im Jahr 1941 verschärfte sich so der Konkurrenzkampf der deutschen Dienststellen. Die Kulturpropaganda wurde nun vor allem zu einem Instrument innerhalb dieses Kampfes, hinter dem die Ziele deutscher Kulturpropaganda zurücktraten. In dieser Phase beobachteten die Dienststellen kritisch die Aktivitäten der Gegenseite und warfen sich gegenseitig vor, die Inhalte der Kulturpropaganda richteten sich zu wenig nach nationalsozialistischen Gesichtspunkten, sie seien kulturpropagandistisch ungeschickt oder gar falsch. Das Deutsche Institut betonte hier, es verfolge eine nationalsozialistische Kulturpropaganda, die sich gleichzeitig nach der Mentalität der Franzosen richte. Mit der offiziellen Beilegung des Streites im Herbst 1941 und im Sommer 1942 ging der Aufgabenbereich der Kulturpropaganda zwar an die Deutsche Botschaft und das Institut über, doch versuchte die Propaganda Staffel auch weiterhin, in diesem Bereich aktiv zu werden.

Die Initiativen zu Paris-Gastspielen dienten aber nicht nur als Instrument innerhalb des Kompetenzstreites der Dienststellen, sondern konnten auch von den Intendanten deutscher Theater ausgehen. Die aufwendigen Planungen von Clemens Krauß mit seiner Münchner Staatsoper zeigen, daß in den Augen deutscher Intendanten die Situation der Besatzung durchaus auch als günstige Gelegenheit begriffen wurde, endlich einmal in der Kulturmetropole Paris zu spielen. Krauß wollte seinem Haus mit Hilfe von Auslandsgastspielen ein europäisches Renommee verschaffen und dafür erschienen ihm Paris-Gastspiele als besonders geeignet. Die Gastspiele sollten in diesem $\mathrm{Zu}-$ sammenhang auch dazu dienen, das eigene Haus als besonders erhaltenswert und somit als „kriegswichtig“" erscheinen zu lassen, was aufgrund der sich verändernden Kriegslage gerade in den Jahren 1943/44 immer bedeutsamer wurde. Viele Mitarbeiter an deutschen Theatern wurden eingezogen; in Deutschland herrschte Künstlermangel, bzw. die Künstler wurden gerade jetzt - vor allem in Goebbels Augen - mehr und mehr an der Heimatfront benötigt, um die Bevölkerung bei Laune zu halten. Im Zeichen der veränderten Kriegslage standen auch die Gastspiele der letzten beiden Jahre der Besatzung. Statt aufwendiger Ensemble-Gastspiele entsandte das RMVP nunmehr einzelne deutsche Künstler nach Paris. Der Konkurrenzkampf zwischen den Deutschen Dienststellen in Paris wurde letztlich durch diese sich immer 
mehr verschlechternde Mangelsituation entschieden, in der das RMVP zentral die Verteilung der deutschen Künstler übernahm. Abetz, der vorher so erbittert um den Aufgabenbereich der Kulturpropaganda gekämpft hatte, verwies nun deutsche Intendanten mit ihren Gastspielwünschen an das RMVP. Das Beispiel der Gastspielreise des Schillertheaters zeigt, wie sehr nun die Kriegslage ausschlaggebend war: Das Schillertheater war zu diesem Zeitpunkt ausgebombt und Intendant George initiierte persönlich die Gastspielreise, die sein Ensemble auch nach Paris führte. Der Auswahl des Stükkes gingen zähe Verhandlungen zwischen George und Goebbels voraus. Der Propagandaminister hatte auch während der dreißiger Jahre persönlich sehr strikt in die Auswahl der Stücke für Georges Gastspielreisen eingegriffen. Nun lehnte er die von George vorgeschlagenen frühnaturalistischen, angeblich zu depressiven, Stücke Hauptmanns ebenso rigoros ab. Daß sich beide schließlich ausgerechnet mit dem "Richter von Zalamea“ auf das Stück eines spanischen Autors einigten, zeigt, wie wenig es sich hier um zielgerichtete Kulturpropaganda handelte, deren Inhalte sich etwa an nationalsozialistischen Vorstellungen orientierten. Das Stück gehörte zu den Klassikern des Spielplans des Schillertheaters und erschien Goebbels angesichts der übrigen von George vorgeschlagenen Stücke als das geringste. Übel. Die letzten Berichte der Botschaft und des Instituts über deutsche Konzerte und Theatergastspiele in Paris im Juni und Juli 1944 zeigen, daß diese Veranstaltungen nun - angesichts der aussichtslosen militärischen Lage Deutschlands - als Zeichen des Vertrauens in den angeblichen deutschen Sieg dargestellt wurden. Auf dem Gebiet der Kulturpolitik sei die Besatzungsmacht auf französischem Boden gleichsam erfolgreich gewesen. Während die Kulturpropaganda zu Beginn der Besatzung den militärischen Sieg hatte komplettieren sollen, sollte sie nun trotz der militärischen Niederlage den angeblichen „kulturellen Sieg" Deutschlands symbolisieren.

Auf die Illusion eines Kulturaustauschs, wie ihn vor allem die Deutsche Botschaft und das Deutsche Institut propagierten, zielten die Hinweise des französischen Einflusses auf die deutsche Kultur in Programmheften oder Zeitungsartikeln für deutsche Gastspiele; gerade dieser Bezug zu Frankreich sollte den Erfolg der deutschen Theateraufführungen sichern helfen. Die deutschen Dienststellen bezogen damit die Vorstellungen des in ihren Augen anspruchswollen Pariser Publikums in ihre Planungen deutscher Kulturpropaganda mit ein. Die Hinweise auf den Einfluß der französischen Kultur konnten jedoch für die französischen Zuschauer vielmehr Anlaß zum Stolz auf die eigene Kultur sein als die angeblich hohen Leistungen der deutschen Kultur anpreisen. Dieser Aspekt hatte die Botschaft, wie bereits erwähnt, sogar an dem kulturpropagandistischen Erfolg der gut besuchten BrekerAusstellung zweifeln lassen. Immerhin entsprachen die Skulpturen Brekers einem Bild von "nationalsozialistischer Ästhetik“, doch konnte der Hinweis auf die Beeinflussung des Bildhauers durch die französischen Schule Anlaß zum Stolz auf die französischen kulturellen Leistungen geben. Deutsche 
Kulturpropaganda konnte demnach durch die Rezeption des Publikums sogar zu französischer Kulturpropaganda werden. Eine Beantwortung der Frage nach Erfolgen und Mißerfolgen deutscher Theaterstücke in Frankreich - gemessen an den Zielen deutscher Kulturpolitik - ist vor diesem Hintergrund nicht einfach.

\subsection{Deutsche Werke im französischen Spielplan- Erfolge deutscher Kulturpolitik?}

Vor allem im Vergleich zum Bereich der Musik, wo relativ viele Veranstaltungen im besetzten Paris stattfanden, war es für die Dienststellen sehr schwierig, deutsche Theaterstücke - in französischer Inszenierung und Besetzung im Spielplan der Pariser Theater unterzubringen. Die Bemühungen hierfür setzten bei der Propaganda Abteilung erst im Frühjahr 1941 ein, weil im Herbst/Winter 1940 die Zulassungen zur Wiedereröffnung der Pariser Theater und deren Kontrolle im Vordergrund standen. Deren finanzielle Situation war schwierig. Viele Intendanten griffen zunächst auf erprobte Wiederaufnahmen zurück. Eine Inszenierung deutscher Werke aber bedeutete für die Theater ein besonderes Risiko. Die Reaktion des Publikums war kaum vorhersehbar. Weder die Besatzungsmacht noch die Theaterdirektoren konnten letztlich das mit deutschen Theaterstücken wenig vertraute Pariser Publikum dazu zwingen, die Aufführungen anzusehen. Ein Mißerfolg hätte in der für die Pariser Theater ohnehin materiell schwierigen Zeit der Besatzung den Bankrott des Hauses zur Folge haben können. Letzteres wäre für die Besatzungsmacht ausgesprochen peinlich gewesen und hätte auch nicht mit dem Ziel der Aufrechterhaltung des kulturellen Lebens in Einklang gestanden. Trotzdem wurden im Verlaufe der Besatzungszeit einige wenige deutsche Theaterstücke an Pariser Bühnen aufgeführt. Nach einer Darlegung der Bemühungen der deutschen Dienststellen, deutsche Theaterstücke in den Pariser Spielplan zu bringen, wird zu fragen sein, inwiefern diese Aufführungen als Erfolge oder Mißerfolge deutscher Kulturpropaganda zu sehen sind.

Bereits im Herbst 1940 ergriff das Deutsche Institut einzelne Initiativen zur Aufführung deutscher Theaterstücke. Der Theaterreferent Kaspar Pinette notierte im November 1940, der Leiter des Théâtre de l'Athénée, Louis Jouvet, habe ihm versichert, er sei bereit, in einigen Monaten ein deutsches Stück zu spielen; er benötige jedoch eine gute Übersetzung eines für diese Zwecke geeigneten Werkes. Das Deutsche Institut schlug „Minna von Barnhelm" von Gotthold Ephraim Lessing sowie ein Stück von Georg Büchner vor $^{213}$. Die Inszenierung eines deutschen Stückes durch Jouvet wäre im besetzten Paris sicherlich kein bedeutungsloses Ereignis gewesen. Der be-

213 PA-AA, 1379, Kult 12 Nr. 2, DBP, Aufzeichnung betreffend die Pariser Theaterpläne unter Bezugnahme auf den Erlaß Kult K 7082, Kaspar Pinette, 7. 11. 1940. (Am 7. 11. 1940 als Anlage von Epting an AA geschickt) 
rühmte Regisseur und Schauspieler hatte zusammen mit Gaston Baty, Charles Dullin und Georges Pitoëff im Jahre 1927 das Cartel gegründet, das dem damals nicht subventionierten théâtre d'art helfen sollte, der Konkurrenz des Boulevardtheaters zu widerstehen. Seit der Übernahme des Théâtre de l'Athenée 1934 hatte er dort vor allem Werke von Giraudoux aufgeführt, die nun verboten waren; Giraudoux hatte sich seit 1939 in seiner Funktion als Leiter des Commissariat général à l'Information der anti-deutschen Propaganda gleichsam schuldig gemacht. Die Bereitschaft Jouvets, ein deutsches Stück aufzuführen, war jedoch nur vorgetäuscht. Er beabsichtigte mit seinem Ensemble eine Tournee in die französische Provinz, vor allem in den unbesetzten Teil Frankreichs zu unternehmen, wofür er eine Ausreiseerlaubnis und somit die Zustimmung der Deutschen Botschaft benötigte. So versprach Jouvet schließlich, nach seiner Rückkehr Kleists „Käthchen von Heilbronn“ zeigen zu wollen und begab sich mit seiner Truppe auf die Reise ${ }^{214}$. Nach einigen Aufführungen unternahm das Ensemble eine Tournee in die Schweiz und reiste ohne Wissen der Deutschen Botschaft in Paris direkt nach Lateinamerika weiter. In Buenos Aires äußerte sich Jouvet in einem Interview mit einer argentinischen Zeitung deutschfeindlich, wie die dortige Deutsche Botschaft berichtete. In Paris vermutete das Deutsche Institut allerdings, die den Deutschen grundsätzlich feindlich gesinnte argentinische Presse habe die Äußerungen Jouvets falsch wiedergegeben und wollte ihn nach seiner Rückkehr zur Rechenschaft ziehen ${ }^{215}$. Jouvet kehrte mit seinem Ensemble nicht mehr in das besetzte Paris zurück.

Durch geschicktes Taktieren entgingen offenbar auch andere Direktoren den Vorschlägen der deutschen Dienststellen, deutsche Stücke aufzuführen. Im März 1941 berichtete das Deutsche Institut, Gaston Baty, der Leiter des Thêâtre Montparnasse, beschäftige sich mit deutschen Theaterstücken. AuBerdem sei die Leiterin des Théâtre des Ambassadeurs, Alice Cocéa, mit der Bitte an das Institut herangetreten, man möge ihr zur Aufführung einige passende deutsche Stücke vorschlagen. Das Institut nannte ihr die Komödie "Wie führe ich eine Ehe" von Axel von Ambesser, weil dieses Werk gut zum Spielplan dieses Hauses passe. Die Intendantin erwiderte jedoch, das französische Publikum sehe zur Zeit lieber ernste Stücke. Das Institut schlug Schillers „Maria Stuart“ vor ${ }^{216}$. Der Einwand Cocéas wirkt rückblickend wenig glaubwürdig, denn generell erfreuten sich Komödien wie etwa die vaudevilles in Paris während der Besatzungszeit durchaus der bisherigen Beliebtheit. Es ist zudem denkbar, daß Cocéa und Baty sich gar nicht aus eigener Initiative an das Deutsche Institut gewandt hatten, um ihr Interesse an deut-

214 Ibid. DBP, Epting an AA, 12. 3. 1941; Anlage, Bericht über die Weiterentwicklung des Theaterwinters in Paris, Kaspar Pinette (auch Lektor an der Sorbonne).

215 Ibid. DIP, Bremer an AA, 21. 11. 1941; ibid. Dokumente vom 14. 10. 1941, 20. 8. $1941 \mathrm{u}$. Zeitungsartikel.

${ }^{216}$ Ibid. DBP, Epting an AA, 12. 3. 1941; Anlage, Bericht über die Weiterentwicklung des Theaterwinters in Paris, Kaspar Pinette. 
schen Theaterstücken zu bekunden. Die Intendanten hätten solche Wünsche beiläufig etwa auf den Empfängen in der Botschaft oder im Institut äußern können - ohne die ernsthafte Absicht, deutsche Stücke aufzuführen. Letztlich spielten beide Theater keine deutschen Stücke. Als das Deutsche Institut im Juli 1941 notierte, es habe endlich einige deutsche Stücke im französischen Spielplan unterbringen können, war diese Vorfreude verfrüht. Nur eines der in dem Bericht des Instituts genannten Werke wurde später auch tatsächlich aufgeführt, es war Schillers „Don Carlos“217. Mit den vorgeschlagenen Werken folgte das Deutsche Institut weniger politischen oder ideologischen Gesichtspunkten, sondern richtete sich vorwiegend nach dem, was in Paris und an dem jeweiligen Theater möglich schien oder angeblich gewünscht wurde. Theoretisch konnte zwar Schillers „Maria Stuart“ bei entsprechender Inszenierung anti-englische Propaganda enthalten, doch entsprach der Vorschlag an Jouvet, ein Stück von Büchner aufzuführen, keineswegs nationalsozialistischen Vorstellungen von deutscher Kulturpropaganda. Büchners Werke wie „Dantons Tod“ oder „Woyzzek" waren selten in deutschen Spielplänen zu finden und insbesondere "Dantons Tod" fand bei den Nationalsozialisten keinen Beifall218. Weder das Institut noch die Deutsche Botschaft erhielten offenbar von Berlin aus konkrete Anweisungen, welche deutschen Stücke sie den Pariser Theaterdirektoren vorschlagen sollten. Die Propaganda Staffel agierte hier weniger autonom.

Im Mai 1941 heißt es in seinem Bericht über die Ergebnisse der Arbeitstagung der Kulturreferenten der Propaganda Staffeln, in Zukunft sei eine stärkere kulturpropagandistische Tätigkeit wünschenswert: „Es ist wichtig, daß den Franzosen Eindrücke und Beispiele des Kunstlebens im Dritten Reich gegeben werden, nachdem der erste Auftrag an die Propaganda Staffeln, das französische Kulturleben wieder in Gang zu bringen, als erfüllt angesehen werden kann" 219 . Das Theaterreferat stieß mit der versuchten Einflußnahme auf die Pariser Spielpläne von Anfang an auf Schwierigkeiten. In einem rückblickenden Bericht vom Februar 1942 heißt es: „Das Pariser Theaterleben lief auf vollen Touren. Der zweite Auftrag, diesen sichtbaren Erfolg zu behaupten und auszubauen, erwies sich als schwieriger als vorauszusehen war" ${ }^{\text {"220. }}$. In der Folgezeit habe das Theaterreferat mit Vorsicht bobachtet, beraten und kontrolliert, um die französische Seite „scheinbar dem Wohlgefühl einer gewissen Selbständigkeit zu überlassen, gleichzeitig aber aus seinen nationalen Schwächen für Deutschland Kapital zu schlagen"221. Während dieses Zeit-

217 Ibid. DBP, Epting an AA, Betr.: Aufführung deutscher Theaterstücke in Paris, 1. 7. 1941. Auf das Stück, den „Don Carlos“ von Schiller am Théâtre de l'Odéon, wird noch zurückzukommen sein.

218 DREWNIAK, Das Theater, S. 175, zur „Maria Stuart“ siehe S. 172.

219 AN, AJ40 1001-7, Prop.St., Gr.Kult.Th., Ergebnisse der Arbeitstagung der Kulturreferenten, 24. 5. 1941.

220 Ibid., Bericht, ohne Titel und Autor, 3. 2. 1942.

221 Ibid. 
raumes der "friedlichen Durchdringung“ habe sich das Referat verstärkt darum bemüht, "deutsche Theaterstücke in den Pariser Spielplan einzubauen, wozu die Theaterleitung des Propagandaministeriums in großzügiger Weise die Hand bot" ${ }^{222}$. Tatsächlich trieb hier vor allem das Theaterreferat die Initiativen und Maßnahmen zur Umsetzung der deutschen Kulturpropaganda voran, während ihm das RMVP in enger Abstimmung bei diesem Vorhaben half.

Im Frühjahr 1941 sollte zunächst Reichsdramaturg Schlösser im RMVP eine Liste von in Frage kommenden Stücken aufstellen. Die Entscheidung, welche Werke künstlerisch und ideologisch zu einer Verbreitung in Frankreich geeignet wären, lag beim Propagandaministerium. Offenbar glaubten die beteiligten Referenten in Paris und Berlin zunächst sogar noch an die Realisierung eines gegenseitigen Kulturaustauschs, denn das Theaterreferat erhielt die Aufgabe, bei den Pariser Theaterdirektoren und deren Verband, dem ADTP, um Vorschläge zu bitten, welche französischen Stücke nach deren Meinung für eine Aufführung in Deutschland für einen späteren Zeitpunkt in Frage kämen ${ }^{223}$. Doch die Liste Schlössers ließ auf sich warten und so bat das Theaterreferat schließlich beim RMVP einfach um die Zusendung von Textbüchern deutscher Theaterstücke. Am 2. Oktober 1941 schickte das Ministerium eine Kiste mit 174 Büchern an die Propaganda Staffel nach Paris. In dreifacher Ausführung fanden sich darin 58 Buchtitel; es waren 50 Theatertexte ausschließlich zu Werken zeitgenössischer Autoren und Sachbücher mit Titeln wie "Deutsche Dramatik der Gegenwart“ oder "Judengestalten auf der Bühne“. Neben Friedrich Forsters „Robinson soll nicht sterben “ und Gerhart Hauptmanns „Fuhrmann Henschel" sowie "Rose Bernd" fanden sich in dieser Kiste vorwiegend Stücke von neueren, auch im Reich zum Teil noch relativ unbekannten Autoren, die mehr oder weniger nationalsozialistisch geprägt waren 224 . Geeignet waren also aus der Sicht des RMVP vor allem zeitgenössische deutsche Autoren. Im Vergleich zum Deutschen Institut, das sich mit Vorschlägen von Autoren wie Kleist oder Büchner stärker daran ausrichtete, welche deutschen Stücke die Zustimmung der französischen Theaterdirektoren finden könnten, folgten die Vorschläge des RMVP eher einer ideologischen Ausrichtung. Dies bestätigt auch ein Bericht über ein Gespräch des Theaterreferenten Baumann mit Lang, der anläßlich des Gastspiels der Charlottenburger Oper im September 1941 von Berlin nach Paris gekommen war. Demnach wollte das RMVP die französischen Intendanten

222 Ibid.

223 AN, AJ40 1001-7, Prop.St., Tätigkeitsbericht, 11. 5.-18. 5. 1941.

224 Ibid. RMVP, Lang an Prop.St., Gr.Kult.Th., 2. 10. 1941; in der Anlage des Schreibens befindet sich eine Liste der Titel der nach Paris gesandten Bücher ohne Angabe von Autoren; laut Eingangsstempel erreichte das Schreiben am 14. 10. 1941 die Prop.St. $\mathrm{Zu}$ zeitgenössischen Autoren deutscher Theaterstücke siehe DREWNIAK, Das Theater, S. 211-243. Drewniak geht unter anderem auch auf die Problematik einer Eingrenzung des Begriffes „nationalsozialistischer Autor“ ein (Ibid. S. 215 f.). 
mit den deutschen Stücken vertraut machen, die zwar zu einer Aufführung weniger geeignet wären, jedoch der „Mentalität der deutschen Autoren und den kulturpolitischen Bestrebungen der Reichsdramaturgie"225 entsprächen.

Die Initiative, deutsche nationalsozialistisch geprägte Theaterstücke in den Pariser Spielplan zu bringen, ging also vor allem vom Propagandaministerium aus. Immerhin war dieses sich auch der Schwierigkeiten eines solchen Unterfangens bewußt, da diese Werke den Theaterdirektoren zunächst nur näher gebracht werden sollten. Während der gesamten Besatzungszeit waren allerdings keine Theaterstücke nationalsozialistisch beeinflußter deutscher Autoren auf Pariser Bühnen zu sehen. Im Gegensatz zum RMVP stand das Pariser Theaterreferat einer erfolgreichen Verbreitung deutscher Gegenwartsliteratur von vornherein sehr skeptisch gegenüber. Es beschwerte sich in Berlin, in der vom RMVP gesandten Bücherkiste seien nur Werke zeitgenössischer Autoren gewesen und keine Stücke aus dem klassischen Repertoire. Die deutschen Funktionsträger vor Ort gingen davon aus, daß Werke von Schiller, Kleist oder Goethe in Paris noch eher akzeptiert würden. Außerdem war das Theaterreferat von der Qualität der Werke sogenannter neuerer Autoren wenig überzeugt. Darauf spielte der Referent an, als er dem RMVP gegenüber betonte, die ersten Aufführungen deutscher Stücke im besetzten Paris sollten doch möglichst das „dramatische Schaffen Deutschlands in würdiger Form repräsentieren "226. Diese Bedenken waren sicherlich nicht unbegründet. Drewniak hat in seinem Werk zum deutschen Theater der NSZeit konstatiert, ein Großteil der zeitgenössischen Autoren hätten zwar die Spielpläne bereichert, weniger aber die dramatische Literatur. So gab es nicht viele Autoren, die qualitativ gut waren und gleichzeitig den politischen $\mathrm{Er}$ wartungen entsprachen ${ }^{227}$. Trotz der vom Theaterreferat geäußerten Kritik wurden vom RMVP in der Folge keine klassischen Theatertexte nach Paris gesandt. So stellte das Referat schließlich selbst eine Liste klassischer Werke auf, die bereits ins Französische übersetzt waren ${ }^{228}$.

Für die erfolglosen Versuche, deutsche Stücke in den Pariser Spielplan zu bringen machte das Theaterreferat unter anderem den Mangel an geeigneten Übersetzungen verantwortlich. Aus diesem Grunde wurde beschlossen, von den aus Berlin gesandten Theaterstücken Inhaltsauszüge anzufertigen und diese übersetzen zu lassen. Erst bei Interesse der Theaterleiter sollte ein Stück vollständig ins Französische übertragen werden ${ }^{229}$. Die Klage über das Fehlen von Übersetzungen ging zu Beginn der kulturpropagandistischen Bemü-

225 AN, AJ40 1001-7, Prop.St., Gr.Kult.Th., Aktennotiz für den Herrn Kommandeur, Betr.: Unterredung mit dem Leiter der Auslandsstelle für Theater des Propaganda-Ministeriums, Dr. Lang, Paris, den 9. Oktober 1941.

226 Ibid. Tätigkeitsbericht, 31. 10.-14. 11. 1941.

227 DREWNIAK, Das Theater, S. $211 \mathrm{f}$.

228 AN, AJ40 1001-7, Prop.St., Gr.Kult.Th., ohne Titel, 3. 2. 1942. (Bericht des Theaterreferats an das RMVP)

229 Ibid. Tätigkeitsbericht, 31. 10.-14. 11. 1941. 
hungen des Jahres 1941 stets einher mit der Versicherung, mehrere Pariser Theaterdirektoren hätten bereits reges Interesse an der Aufführung deutscher Werke gezeigt. Die Aussagen hierzu wirken jedoch überzogen. So behauptete das Theaterreferat beispielsweise im Mai 1941, die vermehrten Anfragen nach deutschen Stücken rührten daher, daß Ersatz für den Ausfall der verbotenen Stücke englischer und jüdischer Autoren benötigt werde; ohne den Einsatz deutscher Stücke würden die Theater nicht mehr lebensfähig erscheinen ${ }^{230}$. Trotz des Verbotes englischer und jüdischer Werke war das Pariser Theater allerdings weder lebensunfähig, noch führte dies tatsächlich dazu, daß etwa vermehrt deutsche Stücke gespielt wurden. Stattdessen standen Werke spanischer und skandinavischer Autoren auf dem Spielplan und auch Shakespeare, der ja von der Zensur nicht verboten wurde, erfreute sich besonderer Beliebtheit ${ }^{231}$. Abgesehen von den Übertreibungen in den Berichten des Referats ist davon auszugehen, daß die Theaterdirektoren zum Teil nur vorgaben, an deutschen Stücken interessiert zu sein - um dann auf die fehlenden Übersetzungen zu verweisen, die sie an der Aufführung hinderten.

Laut Frank waren bis zum Februar 1942 die Vorarbeiten für den Einsatz deutscher Stücke im französischen Spielplan geleistet. Neben einer Liste von Übersetzungen deutscher klassischer Theatertexte gab es Inhaltsangaben von 50 Stücken lebender Autoren, von denen im Februar 1942 ein Teil bereits übersetzt war ${ }^{232}$. Trotzdem sank laut Theaterreferat die Bereitschaft der Direktoren, die anfangs Interesse gezeigt hatten, deutsche Werke aufzuführen, mehr und mehr. Ein Grund hierfür war das sukzessive Verbot französischer Theaterstücke im Deutschen Reich seit 1933233. Angesichts der Tatsache, daß das französische Theater vorher ein fester Bestandteil der deutschen Spielpläne gewesen war, machte dies nun einen echten Kulturaustausch von vornherein unmöglich. Nach Einschätzung des Theaterreferenten Frank hatte es anfangs nicht an Entgegenkommen der Theaterdirektoren gefehlt, allerdings nicht aufgrund höherer politischer Einsicht sondern universalistischer, „übervölkischer" Vorstellungen vom „Wesen der Kunst" ${ }^{234}$. Danach habe sich jedoch das Mißtrauen der Theaterdirektoren vertieft, die nicht einsähen, weshalb sie deutsche Stücke aufführen sollten, während französische Bühnenliteratur an deutschen Theatern verboten sei. Zudem hatte nach Mei-

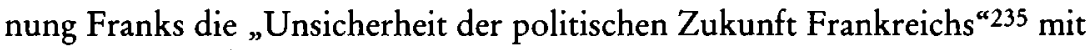
zu dieser vorsichtigeren Haltung beigetragen.

230 Ibid. Tätigkeitsbericht, 25. 5.-31. 5. 1941.

231 Ibid. Tätigkeitsbericht, 29. 5. 1942; Bericht über den Monat April 1943.

232 Ibid. ohne Titel, 3. 2. 1942. (Bericht des Theaterreferats an das RMVP)

${ }^{233} \mathrm{Zu}$ dem Verbot bzw. den wenigen französischen Autoren auf deutschen Bühnen während des Dritten Reiches siehe bei DREWNIAK, Das Theater, S. 260-267.

${ }^{234}$ AN, AJ40 1001-7, Prop.St., Gr.Kult.Th., ohne Titel, 3. 2. 1942 (Bericht des Theaterreferats an das $\mathrm{RMVP}$ )

235 Ibid. 
Deshalb setzte sich das Pariser Theaterreferat unterstützt von der Abteilung Theater im RMVP für die Aufhebung des Verbotes französischer Stücke in Deutschland ein. Letztere stellte in dieser Angelegenheit im Herbst 1941 einen Antrag im RMVP, der jedoch abgelehnt wurde ${ }^{236}$. Dementsprechend war die Abteilung Theater des RMVP der Ansicht, man müsse sich an den Propagandaminister direkt wenden oder zumindest den Militärbefehlshaber Frankreich bitten, diese Frage bei einer nächsten Unterredung mit dem Propagandaminister aufzuwerfen ${ }^{237}$. Es ist fraglich, ob diese Intervention jemals stattgefunden hat, doch nahm Goebbels auch in der Folge hinsichtlich der Lockerung des Verbots der Aufführung von Werken französischer Autoren auf deutschen Bühnen eine strikte Haltung ein ${ }^{238}$. In den Spielplänen des Dritten Reichs waren nach 1933 nur wenige französische Werke zu finden gewesen, weil sie inhaltlich nicht zur nationalsozialistischen Ideologie paßten. Mit Ausbruch des Krieges 1939 waren sie dann vollständig von den deutschen Bühnen verschwunden. Die Aufführung des Stückes „Der Himmelspförtner" Ende 1941 in Nürnberg bildete hier eine Ausnahme. Es war von dem kollaborierenden französischen Schriftsteller und Journalisten Eugène Gerber verfaßt worden 239. In Paris gab dies dennoch Anlaß zu neuer Hoffnung. In einem Schreiben an Lang betonte Lucht, wie sehr ihm weiterhin an einer Lockerung des Verbots französischer Stücke in Deutschland gelegen war und daß er in der Aufführung von Gerbers Stück einen ersten Schritt in diese Richtung sehe ${ }^{240}$. Hier irrte Lucht, denn das Verbot französischer Theaterstücke erfuhr in der Folge so schnell keine Änderung.

Im Juni 1942 verfaßte Theaterreferent Frank eine Aktennotiz, die einen Vorstoß in Richtung auf eine Lockerung des Verbots französischer Werke in Deutschland darstellen sollte. Er kritisierte die bisher von seiner Dienststelle verfolgte Theaterpolitik, insbesondere die Politik der Kulturpropaganda. Vor allem machte er die Einseitigkeit der Kollaboration für die Probleme der deutschen Kulturpropaganda verantwortlich. Das Versprechen der Gegenseitigkeit eines Kulturaustauschs, so Frank, müsse irgendwann eingelöst werden. Nur dann hätte die Propaganda Staffel mehr Möglichkeiten, Forderungen durchzusetzen. Frank plädierte deswegen für „auflockernde Maßnahmen"241. Der französischen Seite sei eine Art kultureller Austausch vorge-

236 AN, AJ40 1001-7, Prop.St., Gr.Kult.Th., Aktennotiz für den Herrn Kommandeur, Betr.: Unterredung mit dem Leiter der Auslandsstelle für Theater des PropagandaMinisteriums, Dr. Lang, Paris, den 9. Oktober 1941.

237 Ibid. Aktennotiz, Betr.: Aufführung französischer Stücke im Reich, 22. Oktober 1941.

238 DrewnIAK, Das Theater, S. 262.

239 Ibid. S. 260-262.

240 AJ40 1002-2, Prop.St., Gr.Kult.Th., Lucht an Lang, RMVP, Abt.Th., 11. 12. 1941. Es konnte nicht ermittelt werden, ob dieses Theaterstück anschließend auch in Paris aufgeführt wurde.

241 AN, AJ40 1001-7, Prop.St., Gr.Kult.Th., Aktennotiz für Herrn Professor Arno 
gaukelt worden, indem die Besatzer anläßlich der deutschen Gastspiele in Paris betont hatten, es handele sich um den Beginn eines wechselseitigen Kulturaustauschs. Doch war jener einseitig geblieben, was sich zukünftig ändern müsse: „Durch die Möglichkeit gewisser Versprechen und Zusagen, vor allem aber auch entsprechender Maßnahmen von deutscher Seite hätte die Staffel eine propagandistisch wirkungsvolle Handhabe, die eigenen Forderungen durchzusetzen" 242 . Frank hatte seine kritische Aktennotiz an Arno Breker, den Lieblingsbildhauer Hitlers gerichtet, da er hier die Möglichkeit sah, über Breker bei Hitler selbst, im Sinne einer Lockerung des Verbots zu intervenieren. Schmidtke verbot Frank jedoch die Übergabe des Schreibens ${ }^{243}$. Diese Reaktion ist keineswegs erstaunlich, da Arno Breker mit der Deutschen Botschaft in enger Verbindung stand. Eine Ausstellung seiner Werke, die nur einen Monat vorher eröffnet worden war, hatte die Botschaft gemeinsam mit dem Deutschen Institut organisiert. Angesichts des Konkurrenzkampfes zwischen den deutschen Dienststellen war Schmidtke freilich wenig daran gelegen, Franks selbstkritische Ausführungen der Botschaft zu übergeben. Zudem hätte diese Initiative für eine Auflockerung des Verbots französischer Kultur in Deutschland bedeutet, Goebbels zu hintergehen, indem Frank sich direkt an Hitler - über die Person Brekers - wandte. Schmidtke wird daran verständlicherweise wenig Interesse gehabt haben. Weshalb hatte Theaterreferent Frank seine Aktennotiz an Breker adressiert? Trotz seiner Verbindungen zur Deutschen Botschaft war Breker eine Persönlichkeit, die außerhalb dieser Konkurrenzstreitigkeiten stand und gute Verbindungen zu Hitler hatte. Zudem war es während der Organisation der Breker-Ausstellung zu Unstimmigkeiten zwischen dem Bildhauer und der Botschaft gekommen. In einem Bericht der Botschaft an das AA heißt es, Breker habe sich beklagt, die Botschaft unterstütze ihn bei der Vorbereitung der Ausstellung nicht genügend. Angeblich gebe sich die französische Seite weit mehr Mühe; dies treffe vor allem auf Jacques Benoist-Méchin und François Lehideux zu, die Breker in Berlin besucht hatten ${ }^{244}$. Franks Idee, sich an Breker zu wenden, war also keineswegs abwegig.

Auch die Deutsche Botschaft bemühte sich ihrerseits um eine Aufhebung des Verbotes französischer Kultur in Deutschland. Das ist zumindest für den Bereich der Musik belegt, wo sich das Verbot im Jahre 1943 lockerte. Diese Entscheidung hing vor allem auch mit dem kriegsbedingten Mangel an Künstlern in Deutschland zusammen. Beispielsweise wurde der Cellist Pierre Fournier im Sommer 1943 nach Berlin eingeladen, um unter Furtwängler vom 13. bis 17. November desselben Jahres drei Cellokonzerte in

Breker, 4. Juni 42; eine Bleistiftnotiz lautet: „Abl., Übergabe von Kdtr. nicht genehmigt, Fr. 5. 6. $1942^{\circ}$.

242 Ibid.

243 Ibid.

244 PA-AA, R102960, Pol II, AA Berichtsdoppel der DBP, Schleier an Abetz in Berlin, 13. 4. 1942. 
Berlin zu geben. Die Konzertdirektion Adler in Berlin hatte diese Anfrage an die Pariser Konzertagentur Kiesgen gerichtet. Fournier nahm die Einladung an. Daraufhin erkundigte sich die Botschaft beim AA, ob zukünftig nun zumindest einige französische Musiker in Deutschland zugelassen wären ${ }^{245}$. Aus Berlin erhielt sie zur Antwort, dies treffe nur auf eine beschränkte Anzahl prominenter französischer Künstler zu, was das AA im Einvernehmen mit dem RMVP entschieden habe. Die Auswahl der Künstler sollte auf Grundlage der Beurteilung durch die Botschaft geschehen ${ }^{246}$. Die Botschaft bemühte sich kurz darauf beim AA um eine weitere Lockerung des Verbotes französischer Musik in Deutschland. Sie begründete ihre Anfrage damit, daß es zunehmend schwieriger werde, vor allem zeitgenössische deutsche Werke in den Pariser Musik-Programmen unterzubringen. Von französischer Seite werde stets erwidert, in Deutschland sei französische Kultur verboten. Für eine Lockerung des Verbotes spreche auch die Tatsache, daß der Dirigent Alfred Cortot im Vorjahr bei den Berliner Festspielen mitgewirkt habe und 1943 etwa 15 weitere Konzerte in Deutschland geben werde. Da solche Einladungen bisher propagandistisch individuell begrenzt gewesen wären, sei eine weitere Lockerung des Verbots dringend nötig. Außerdem, so die Botschaft, hätten Komponisten wie etwa Marcel Delannoy bisher ihre positive Haltung zum „neuen Deutschland“ bewiesen. Deren weitere Ausschaltung aus den deutschen Programmen erscheine gegenüber der Zulassung verschiedener Solisten als ungerecht ${ }^{247}$.

Einige Monate später fällten schließlich AA und RMVP die Entscheidung, französische Musik nun in deutschen Konzertsälen freizugeben, falls dies in begrenztem Rahmen und in besonders begründeten Fällen geschehe. Allerdings durfte nicht mehr als ein Viertel der Programmfolge französische $\mathrm{Mu}-$ sik enthalten. Auf diese Weise sollte eine „Überflutung der Konzertprogramme " 248 mit französischer Musik vermieden werden. Im Bereich des Theaters trat eine Lockerung des Verbotes ebenfalls im Jahre 1943 ein. Sogenannte Problemstücke und Werke lebender Autoren waren davon allerdings ausgenommen ${ }^{249}$. Übrigens war das Verbot für französische Opern schon im August 1942 teilweise aufgehoben worden. Clemens Krauß, der sich mehrfach darum bemüht hatte, französische Opern aufführen zu dürfen, erhielt im August 1942 vom RMVP die Nachricht, er könne nun die von ihm ge-

245 PA-AA, 1142, Kult 12 Nr. 3(4), Piersig an AA, Telegramm Nr. 5393, 11. 8. 1943.

246 Ibid. AA an DBP, 13. 8. 1943.

247 Ibid. DBP an AA, Betr.: Zulassung frz. Musik in Deutschland, 23. 8. 1943. Alfred Cortot war bereits während der dreißiger Jahre in Berlin aufgetreten, ebenso im Jahre 1942. Laut Prieberg entwickelten sich während der Okkupation auf Betreiben Piersigs Ansätze einer deutsch-französischen Musik-Kooperation; Prieberg, S. 380, 398-401. 248 Ibid. AA, Kult.Pol. an DBP, Betr.: Aufführung französischer Musik, 15. 11. 1943. 249 DREWNIAK, Das Theater, S. 263. Drewniak führt hier keinen Beleg an, sondern konstatiert: „Der elfte deutsche Farbspielfilm war sogar eine Verfilmung der Komödie ,Ein toller Tag oder Figaros Hochzeit" von Beaumarchais in der Regie von O.F. Schuh. Er wurde ganz zu Ende des Krieges in der Ufa gedreht. Der Streifen blieb unvollendet“. 
wünschte Oper „Mignon“ von Ambroise Thomas in den Spielplan aufnehmen. Auf Antrag der Abteilung Theater im RMVP habe Goebbels das Verbot französischer Opern gelockert. Die älteren Repertoire-Opern des 19. Jahrhunderts wie „Fra diavolo“ von Daniel S. E. Auber, „Die weiße Dame“ von François Adrien Boieldieu, „Mignon" und „Margarethe“ von Charles François Gounod dürften nun wieder gespielt werden. Aufführungen weiterer, vor allem zeitgenössicher Werke, wie Jules Massenets „Manon“ und „Werther", Gustave Charpentiers „Louise“, Claude Debussys „Pelleas und Melisande" sowie "Faust's Verdammnis" von Hector Berlioz benötigten eine Sondergenehmigung ${ }^{250}$. Trotz dieser Lockerung fand generell französische Kultur in der Zeit von 1940 bis 1944 in Deutschland nur sehr wenig Eingang in deutsche Spielpläne und Konzertprogramme.

Abgesehen von der Einseitigkeit des Kulturaustauschs war auch die Entwicklung der öffentlichen Meinung ein Grund für die abnehmende Kooperationsbereitschaft der Pariser Theaterdirektoren. 1942 mehrten sich die Klagen des Theaterreferats über eine mangelnde Bereitschaft der Theaterdirektoren, deutsche Stücke aufzuführen, was mit der sich verändernden Kriegslage in Verbindung gebracht wurde. Theaterreferent Frank schrieb im Dezember 1942, die abweisende Haltung der Intendanten hätte sich schon zu Beginn des Jahres gezeigt und befinde sich nun in einem kritischen Stadium. Die frühere Bereitwilligkeit sei einer „abwartenden Zurückhaltung “251 gewichen, was sich in einer stark sinkenden Besucherzahl zeige. Die Franzosen erschienen nur noch bei der Propaganda Staffel, um Beschwerden und beson-

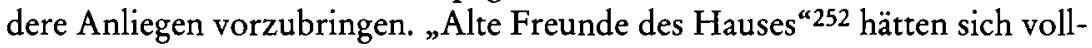
kommen zurückgezogen und kämen nur etwa um Anträge auf Sonderrationen von Kohle zu stellen. Frank berichtete weiter, das Theaterreferat habe versucht, die Deutschfreundlichkeit der Theaterdirektoren heimlich zu testen; ein französischer Strohmann hatte an Pariser Bühnen ein übersetztes deutsches Theaterstück angeboten. Der Erfolg dieser Aktion sei vollständig negativ gewesen. Die Direktoren hätten sich geweigert, obgleich sie ohne Bedenken spanische oder italienische Werke spielten und immer wieder versuchten russische oder angelsächsische Stücke in den Spielplan zu nehmen: „Es könne ihnen dies, war die Antwort, ,nach dem Sieg der Engländer' übel ausgelegt werden" 253 . Frank kritisierte die von der Staffel bisher verfolgte Politik deutscher Kulturpropaganda. Man hätte sich seiner Ansicht nach nicht „auf dem unzuverlässigen Parkett der Kollaboration“ bewegen sollen, sondern mehrere französische Theater ankaufen müssen, um von dort ausgehend deutsche Kulturpropaganda aufzubauen. Das Referat habe allerdings keine finanziellen Mittel zur Verfolgung dieses Ziels zur Verfügung gehabt.

250 BAB, 50.01-398, RMVP, Dr. Lange an Bayerische Staatsoper München, Generalintendant Clemens Krauß, 27. 8. 1942.

251 AN, AJ40 1001-7, Prop.Abt., Tätigkeitsbericht, 30. 12. 1942.

252 Ibid.

253 Ibid. 
Man habe nur reagieren können, beispielsweise durch Ausübung von Druck mittels einer verschärften Zensur. Alle durch das Referat vermittelten Sonderbegünstigungen würden gemäß eines deutschfreundlichen Verhaltens gehandelt ${ }^{254}$. Die Weltkriegslage beeinflußte entscheidend das Verhalten und die Einstellung der Theaterdirektoren gegenüber der Aufführung deutscher Werke. Die vom Theaterreferat verfolgte Politik der sogenannten friedlichen Durchdringung, die auf einer Bereitschaft zur Kollaboration basierte, war so zum Scheitern verurteilt. Es ist jedoch unklar, ob zu Beginn der Bemühungen des Referats eine solche Bereitschaft wirklich bestanden hat, wie vom Theaterreferat behauptet worden ist. Franks Bericht vom Dezember 1942 zeigt außerdem, daß das Theaterreferat im Bereich deutscher Kulturpropaganda weiterhin aktiv war, obgleich dieser Aufgabenbereich bereits an die Deutsche Botschaft übergegangen war. Offenbar war das Theaterreferat nicht bereit, diese Aktivitäten vollständig einzustellen. Der Grund hierfür lag auch darin, daß Frank befürchtete, mit dem Aufgabenbereich der Kulturpropaganda seine Arbeitsstelle in Paris zu verlieren. Im August 1942 berichtete er dem Theaterreferenten Lang beim RMVP resigniert von der Neuverteilung der Kompetenzen. In melancholischem Ton und in Erwartung seiner Versetzung an die Ostfront heißt es:

Wir haben gemeinsam gelebt und gefochten, also wollen wir uns auch gemeinsam verschicken lassen, mag in des Teufels Namen daraus werden was da wolle. [...] Die gute Zeit verrinnt, ich komme nicht weiter, obwohl ich doch wahrhaftig willens bin, die Fahne der Kulturpropaganda hochzuhalten, bis uns die Welle verschlägt ${ }^{255}$.

Etwa einen Monat später gab er Lang zu verstehen, er sei dazu entschlossen, trotz der offiziellen Abgabe des kulturpropagandistischen Auftrags auch weiterhin in diesem Bereich tätig zu werden und die Verbreitung deutscher Theaterstücke auf Pariser Bühnen voranzutreiben ${ }^{256}$. Ferner kritisierte er die kulturpropagandistische Aktivität der Botschaft.: „Die Abtrennung des Sektors Kulturpropaganda vom Aufgabenbereich der Gruppe Kultur hat auf dem Gebiet des Theaters ein merkliches Nachlassen der kulturpropagandistischen Aktivität zur Folge“257. Die Gruppe Kultur führe die bereits in Angriff genommenen Vorgänge noch zu Ende; außerdem halte er sich ebenso wie die anderen Referenten zur Beratung und Unterstützung der Botschaft bereit. Frank kritisierte weiter, der Besuch Max Halbes habe in Paris kaum Widerhall gefunden. Der 1865 geborene bekannte deutsche Dramatiker und Schriftsteller, der im Jahre 1944 verstarb, hatte auf Einladung des Deutschen Instituts im Oktober 1942 dort eine Lesung gehalten. ${ }^{258}$. Anfang November meinte Frank, die kulturpropagandistischen Belange der Theaterabteilung in

254 Ibid.

255 BAB, 50.01-519, Prop.Abt., Gr.Kult.Th., Frank an Lang, 4. 8. 1942.

256 Ibid., Frank an Lang, 11. 9. 1942.

257 AN, AJ40 1001-7, Prop.Abt., Gr.Kult.Th., Tätigkeitsbericht, 30. 10. 1942.

258 Ibid. 
Frankreich gingen nun langsam ihrem „Todesschlaf“259 entgegen. Doch im Januar 1943 betonte er wieder, das Theaterreferat bemühe sich auch weiterhin darum, deutsche Stücke in den Pariser Spielplan zu bringen. Als Folge des Krieges und des sehr guten Theaterbesuchs bestehe ein großes Interesse an der Eröffnung neuer Theater.

Das Referat ergreift die Gelegenheit, die Vergebung neuer Konzessionen von der deutschfreundlichen Haltung der Kandidaten abhängig zu machen. Auf diese Weise ist das Gespräch über den Einsatz deutscher Stücke im Pariser Spielplan wieder sehr rege geworden. [...] Es konnte nicht festgestellt werden, daß diese Chancen von der zuständigen Dienststelle der Deutschen Botschaft ergriffen worden wären ${ }^{260}$.

Frank schreibt weiter, das Referat halte sich für Beratungen in der Frage deutscher Werke auf Pariser Bühnen zur Verfügung, denn es könne sich auf zweieinhalb Jahre Beobachtung des Pariser Spielplans stützen ${ }^{261}$. Das Theaterreferat hielt die Deutsche Botschaft für unfähig die Aufgabe der Kulturpropaganda zu erfüllen und war nicht ohne weiteres bereit, eigene Aktivitäten auf diesem Gebiet gänzlich einzustellen. Noch im März 1943 hieß es in einem Bericht, man halte in kulturpropagandistischen Angelegenheiten enge Verbindung mit Knothe, dem Bevollmächtigen des RMVP bei der Deutschen Botschaft $^{262}$. Im Juni 1943 war das Referat damit beschäftigt, Inhaltsangaben deutscher Werke herzustellen, um sie angeblich interessierten Theaterdirektoren zur Auswahl vorzulegen. Allerdings zogen die Direktoren es vor, bereits übersetzte spanische oder skandinavische Stücke aufzuführen ${ }^{263}$. Das Theaterreferat blieb also lange nach Klärung der Kompetenzstreitigkeiten durch das Abkommen von AA und RMVP im Oktober 1941 im Bereich der Kulturpropaganda aktiv, während es die Arbeit der Deutschen Botschaft kritisierte.

Wie aus einem Bericht der Sipo-SD hervorgeht, sollen im Bereich der Kulturpropaganda und der Kulturpolitik alle konkurrierenden Dienststellen gleichermaßen erfolglos gewesen sein. Ein wesentlicher Grund hierfür liege generell in einer unklaren Linie bezüglich der Behandlung "kultureller Grundfragen des deutsch-französischen Verhältnisses“264, was eine unterschiedliche Politik der zuständigen Dienststellen bedingt hätte. Die Franzosen beschwerten sich über eine Einseitigkeit der Kollaboration und über die Unklarheit der Stellung Frankreichs in einem "Europa neuer Ordnung“, auch in kultureller Hinsicht. Über die Erfolge deutscher Kulturpropaganda heißt es, die deutsche Musik sei fest im Pariser Musikleben verankert: „Auf

259 BAB, 50.01/519, Prop.Abt., Gr.Kult.Th., Frank an Lang, 11. 9. 1942.

260 AN, AJ40 1001-7, Prop.Abt., Gr.Kult.Th., Tätigkeitsbericht, 29. 1. 1943.

261 Ibid.

262 Ibid. Tätigkeitsbericht, 1. 3.-30. 3. 1943.

263 Ibid. Tätigkeitsbericht, 1. 6.-30. 6. 1943.

264 BAB, R58/190, Reichssicherheitshauptamt, Chef der Sipo-SD, Amt III, SD-Berichte zu Inlandsfragen, Zur Entwicklung der deutsch-französischen Kulturbeziehungen, Geheim, Berlin, den 1. 11. 1943. 
dem Gebiete der Oper und des Schauspiels ist dagegen der eigenartige Tatbestand eingetreten, daß trotz der deutschen Lenkung des gesamten Kunstlebens die Zahl der aufgeführten deutschen Werke heute wesentlich geringer

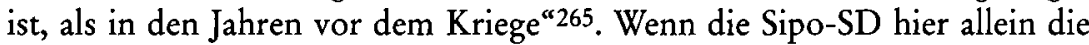
Anzahl der deutschen Stücke auf Pariser Bühnen als Mißerfolg wertete, so lohnt sich dennoch die Frage nach Erfolgen und Mißerfolgen der tatsächlich aufgeführten deutschen Theaterstücke auf Pariser Bühnen.

Während in Paris vier deutsche Gastspielensembles vor französischem Publikum auftraten, inszenierten die Pariser Bühnen sieben deutsche Theaterstücke. Trotzdem hatte das Theaterreferat der Propaganda Staffel betont, gerade das Theater sei einer der wichtigsten Bereiche in dem „Ringen um die kulturelle Weltgeltung Deutschlands“266. Inwiefern waren nun die wenigen Aufführungen deutscher Theaterstücke für sich genommen Erfolge oder Mißerfolge deutscher Kulturpolitik, gemessen an ihren Zielen? Lassen sich hier inhaltliche Vorstellungen zur deutschen Kulturpropaganda erkennen? Gab es im Vorfeld Widerstände seitens der Theaterdirektoren? Inwieweit also entsprachen die Aufführungen den Vorstellungen der deutschen Besatzer und welche Aufnahme fanden sie beim Pariser Publikum ${ }^{267}$.

Eine Besonderheit der in Paris aufgeführten deutschen Werke bildete die Inszenierung von Goethes "Iphigenie auf Tauris“" an der von Jean-Louis Vaudoyer geführten Comédie-Française, die am 10. April 1941 Premiere hatte. Es war das erste deutsche Theaterstück, das im besetzten Paris vor französischem Publikum in der Inszenierung eines Pariser Theaters gespielt wurde. Zugleich war es das erste Mal, daß dieses Werk Goethes in Frankreich aufgeführt wurde 268 . Während am renommiertesten Nationaltheater Frankreichs die "Iphigenie auf Tauris" gespielt wurde, führte am 14. und 15. April das

265 Ibid. In einem anderen Bericht des SD heißt es: „Die zahlreichere Aufführung von deutschen Schauspielen ist neben der Interesselosigkeit der franz. Theaterleiter daran gescheitert, daß keine genügende Auswahl von französischen Übersetzungen zur Verfügung steht" (BA, R58/649, fol. 1, Reichssicherheitshauptamt, Chef der Sipo-SD, Amt III, SD-Berichte zu Inlandsfragen, undatiert. Dem Inhalt nach wurde der Bericht etwa zu Beginn des Jahres 1943 geschrieben.).

266 AN, AJ40 1001-7, Prop.St., Gr.Kult.Th., Bericht, ohne Titel, 3. 2. 1942.

267 In der Einleitung zu dieser Arbeit ist bereits erläutert worden, wie schwierig eine Untersuchung der Rezeption der Theateraufführungen aufgrund der Quellenlage ist; Informationen hierzu, die aus der Pariser Presse oder den Berichten der deutschen Dienststellen stammen, haben einen eingeschränkten Aussagewert und sind kritisch zu betrachten. Angaben zu den Besucherzahlen der Aufführungen deutscher Theaterstücke wurden nicht berücksichtigt, wären hier jedoch auch nicht unbedingt hilfreich; im besetzten Paris waren ohnehin alle Theater sehr gut besucht, sei es weil die Zuschauer im Winter der Kälte ihrer schlecht beheizten Wohnungen oder aber der Realität der Okkupation entfliehen wollten. Siehe dazu Serge ADDED, L'Euphorie théâtrale dans Paris occupé, in: Rioux, La Vie culturelle, S. 315-344.

268 Bibliothek-Archiv des Bayerischen Staatsschauspiels, Programmheft zur französischen Aufführung "Iphigénie en Tauride" von Goethe vom 13.4. 1942, Vorwort des Übersetzers Pierre du Colombier. 
Bayerische Staatsschauspiel auf Einladung der Propaganda Staffel an derselben Bühne das gleiche Stück vor französischem Publikum auf; es schlossen sich zwei Vorstellungen für die Wehrmacht am 17. und 18. April im Thêâtre des Champs-Elysées an. Presse und Dienststellen verglichen anschließend die französische und deutsche Inszenierung, was gerade dieses Ereignis für eine Untersuchung der Vorstellungen von deutscher Kulturpropaganda im besetzten Frankreich besonders interessant macht. Freilich handelte es sich bei der zeitlichen Nähe beider Aufführungen nicht etwa um einen Zufall, sondern um eine seit Monaten geplante kulturpropagandistische Aktion. Für das Theaterreferat war das Gastspiel seine erste größere öffentliche Veranstaltung ${ }^{269}$. Jean-Louis Vaudoyer ist die Aufführung deutscher Stücke und Gastspiele an der Comédie-Française nach der Libération vorgeworfen worden; seine Kritiker betonten, er hätte besser seine Demission einreichen sollen, anstatt deutsche Stücke zu spielen. Zu seiner Verteidigung hat Vaudoyer angeführt, die Propaganda Staffel habe ihn um die Aufführung eines deutschen Stückes ersucht. Um kein nationalsozialistisches Werk aufführen zu müssen, habe er beschlossen, einen Iphigenien-Zyklus zu geben: Die „Iphigenie auf Aulis“ von Euripides, „Iphigenie auf Tauris“ von Goethe sowie Racines "Iphigenie" Zudem stammte die Idee zu dem Zyklus nach Aussage Vaudoyers ursprünglich von Giraudoux, mit dem er gut befreundet war ${ }^{270}$. Es ist nicht mehr eindeutig zu klären, inwieweit Vaudoyer sich tatsächlich ohne negative Folgen hätte weigern können, ein deutsches Stück aufzuführen. Generell ist kein Fall bekannt, in dem diese Weigerung Konsequenzen hatte, denn die Besatzer hatten ein starkes Interesse an einem funktionierenden Pariser Theaterleben. Allerdings hatte bereits das vom Deutschen Institut organisierte Gastspiel des Schillertheaters im Februar 1941 an der Comédie-Française stattgefunden. Es ist sehr wahrscheinlich, daß nun die Propaganda Staffel ihrerseits außergewöhnlich stark darauf drang, das Gastspiel an keiner geringeren Bühne als der Comédie-Française, dem renommiertesten Nationaltheater Frankreichs, zu geben. Dieses Argument ist auch von Vaudoyer angeführt worden, der außerdem meint, zu den Aufführungen des Schillertheaters im Februar 1941 habe man den damaligen Leiter der Comédie-Française, Jacques Copeau, gezwungen ${ }^{271}$. Im Oktober 1941 bat Vaudoyer die Propaganda Staffel darum, diese möge ihm Unterlagen über besonders gute deutsche Inszenierungen der „Iphigenie“ Goethes zukommen las$\operatorname{sen}^{272}$. Deshalb schickte das RMVP am 4. November unter anderem den Originalentwurf des Bühnenbildes einer Weimarer Inszenierung der Spiel-

269 AN, AJ40 1001-7, Prop.St., Gr.Kult.Th., Bericht über den Monat April 1942.

270 JOUBERT, La Comédie-Française, S. 171-178, siehe auch S. 260-266; Vaudoyer wurde trotz der Vorwürfe gegen ihn nicht als Kollaborateur eingestuft.

271 JOUBERT, La Comédie-Française, S. 165-171.

272 AN, AJ40 1001-7, Prop.St., Gr,Kult.Th., Aktennotiz für den Herrn Kommandeur, Betr.: Unterredung mit dem Leiter der Auslandsstelle für Theater des Propagandaministeriums, Dr. Lang, 9. 10.1941. 
zeit 1941/42 sowie Photos weiterer Inszenierungen ${ }^{273}$. Die Idee, parallel zur französischen Inszenierung ein deutsches Gastspiel zu geben, kam im August 1941 vom Theaterreferat der Staffe ${ }^{274}$. Doch die Vorbereitungen für das Gastspiel sollten sich noch lange hinziehen. Im November 1941 wurde als erstes Stück des geplanten Zyklus die „Iphigenie in Aulis“ von Euripides an der Comédie-Française aufgeführt. Zur Premiere am 13. November schrieb das Theaterreferat in dem Glauben an eine überragende Qualität des deutschen Theaters: „Die Größe des Geschehens wurde lediglich aus Text, Szene und Kostüm deutlich, für deutsches Empfinden durchaus unbefriedigend. Dieser erste Eindruck kann nur ermutigen, den Plan, ein deutsches Iphigenie-Gastspiel heranzuziehen, mit Nachdruck zu betreiben"275. Im Dezember erinnerte Lucht seine Vorgesetzten in Berlin erneut an das Gastspiel, um die Planungen voranzutreiben. Als Termin wurde nun die zweite Januarhälfte des Jahres 1942 anvisiert, weil die französische Inszenierung von Goethes „Iphigenie" nicht eher aufgeführt werden konnte. Zur Auswahl des deutschen Ensembles schrieb Lucht, sie liege selbstverständlich beim RMVP: „Sollte eine Besetzung durch Berliner Kräfte technisch nicht möglich sein, käme wohl in erster Linie die Münchner Aufführung mit Anne Kersten in Betracht" ${ }^{\text {"276. }}$ Erst Ende Januar genehmigte das RMVP schließlich das Gastspiel des Bayerischen Staatsschauspiels für den 14. und 15 April 1942.

Im Vorfeld wurden die Vorstellungen von deutscher Kulturpropaganda in den vorbereitenden Veranstaltungen für die Pariser Presse deutlich. Am 8. April fand im Presseclub der Propaganda Staffel zur Vorankündigung ein Empfang statt, zu dem neben der Pariser Presse auch die Schauspieler der Comédie-Française und zahlreiche Persönlichkeiten des Theaterlebens eingeladen waren. Curt Langenbeck ${ }^{277}$, Chefdramaturg des Bayerischen Staatsschauspiels, hielt einen französischsprachigen Vortrag über „Wesen und Aufgabe der dramatischen Kunst in Deutschland“278. Angeblich war die Pariser Presse so begeistert davon, daß die Propaganda Staffel ihn in Abschrift ver-

273 AN, AJ40 1002-2, RMVP an die Prop.St., 4. 11. 1941.

274 AN, AJ40 1001-7, Prop.St., Gr.Kult.Th., Aktennotiz, Betr.: Deutsches Gastspiel Iphigenie, 22. 10. 1941 .

275 Ibid. Tätigkeitsbericht, 31. 10.-14. 11. 1941.

276 AJ40 1002-2, Prop.St., Gr.Kult.Th., Lucht an Lang, RMVP, 11. 12. 1941.

277 Curt Langenbeck (1906-1953) war Bühnendichter, Essayist, Lyriker, Dramaturg und Regisseur; Chefdramaturg am Bayerischen Staatsschauspiel und Berater des Intendanten Max Golling war er seit 1938. Zur Person Langenbecks siehe DREWNIAK, Das Theater, S. 218-220. Drewniak schreibt: „Wegen seiner Erfolge im Dritten Reich galt er nach dem Kriege als, Nazi-Dramatiker'. Dennoch, mit diesen Erfolgen war es nicht immer so rosig. Seine Werke, besonders die späteren, waren schon damals umstritten, ebenso seine nationalsozialistische Beeinflussung, zumindest in Rosenbergs Kreisen" (Ibid. S. 218).

278 AN, AJ40 1001-7, Prop.St., Gr.Kult.Th., Bericht über den Monat April 1942. Der Vortrag wurde auszugsweise am 11. April beispielsweise in der Zeitschrift Comodia abgedruckt; BN-BA, Curt LANGENBECK, Iphigenie en Tauride à la Comédie-Française, Destin et Fatalité, in: Comœdia, 11.4. 1942. 
teilen ließ. Auszüge daraus wurden im Programmheft zum Gastspiel abgedruckt, was dem Gastspiel nach Meinung der Staffel eine „propagandistische Note" 279 verlieh. Langenbeck erläuterte, die deutschen Klassiker würden durch eine sogenannte zeitgemäße Interpretation bei den Inszenierungen im Reich keinen Schaden nehmen, sondern im Gegenteil ihre eigentliche Identität wiederfinden. Die deutsche Aufführung von Goethes „Iphigenie“ in Paris könne mitten im Kriege nicht als Zufall gesehen werden, sondern sei Zeugnis für das hohe Ziel, das Deutschland verfolge. In diesem Ereignis spiegele sich das Bild des deutschen Herzens wider, das sich nicht nur oberflächlich für kulturelle Probleme interessiere. Während Deutschland einen unerbittlichen und entscheidenden Krieg führe, suche es die Ideale moralischer Gesundheit:

On reconnaîtra plus tard combien la guerre actuelle, dont l'enjeu est le destin même de l'Occident, aura dans toute l'Europe et au-delà même de l'Europe servi ce haut ideal. Nous souhaitons que la représentation d'Iphigénie dans cette double version française et allemande, ouvre au moins un aperçu sur cette magnifique et bienfaisante perspective 280 .

Langenbecks Hoffnung zufolge sollte das deutsche Gastspiel gemeinsam mit der französischen Aufführung von Goethes "Iphigenie" ebenso wie der Krieg ein Schritt in Richtung auf ein sogenanntes moralisch gesundes Europa von wahrer Kultur sein. Der deutschen Kultur war hier gleichsam eine missionarische Funktion zugedacht, die auch das Gastspiel des Bayerischen Staatstheaters erfüllen sollte. Das Theaterreferat betonte, Langenbecks Vortrag habe eine große Wirkung gehabt. Zufrieden notierte es: „Und es zeigt sich ferner, daß es richtig ist, den an sich aufnahmewilligen Franzosen ohne Kompromiß die anspruchsvollste Kost vorzusetzen "281. Hier spiegeln sich die Vorstellungen der Nationalsozialisten von einer angeblich höherstehenden deutschen Kultur auf der einen Seite und einer angeblich leichteren und damit anspruchsloseren französischen Kultur auf der anderen Seite wider. Indem das Referat der französischen Seite eine gewisse Aufnahmewilligkeit bescheinigte, sah es in dem Vortrag Langenbecks einen Erfolg deutscher Kulturpropaganda; diese sollte demnach besser ohne Kompromiß, d.h. ohne auf die angeblich leichtere französische Mentalität einzugehen, durchgesetzt werden.

Am 10. April 1942 erschien Regisseur Albert Fischel aus München, um mit Statisten und Chorsängern der Comédie-Française zu proben und das Bühnenbild zu erstellen, dessen Materialien aus dem Fundus der Comédie-Française stammten, das sich aber von jenem der französischen Inszenierung un-

279 Archiv-Bibliothek des Bayerischen Staatsschauspiels München (ABBSM), Programmheft, Comédie-Française, Das Bayerische Staatsschauspiel, Théâtre d'Etat de Munich, „Iphigénie en Tauride" de Goethe 14 et 15 Avril.

280 BN-BA, Curt LANGENBECK, Iphigenie en Tauride à la Comédie-Française, Destin et Fatalité, in: Comodia, 11. 4. 1942.

281 BayHStA, MK 40993, Prop.St., Gr.Kult.Th., Bericht über das „Iphigenie“-Gastspiel des Bayerischen Staatsschauspiels in Paris, 22. 4. 1942. 
terscheiden sollte. Am 13. April folgten die Schauspieler: Anne Kersten (Iphigenie), Ernst Martens (Thoas), Albert Lippert (Orest), Kurt MüllerGraf (Pylades) und Karl Hanft (Arcas). Noch am gleichen Abend besuchten die Münchner Schauspieler die französische Aufführung der „Iphigenie“, was laut Propaganda Staffel angeblich zu künstlerischer Kameradschaftlichkeit zwischen beiden Ensembles führte; die französischen Schauspieler stellten ihre Garderoben zur Verfügung. Zur Begegnung der Schauspieler schrieb die Staffel: „Die offene süddeutsche Herzlichkeit der Münchner Gäste und der höfliche Charme der ehrlich begeisterten Franzosen kamen einander aufs Glücklichste entgegen "282. Dies habe das Theaterreferat sowohl bei dem von Schmidtke ausgerichteten Abendessen nach Abschluß des Gastspiels als auch bei einem Empfang in der Comédie-Française erkennen können. Da das Referat betonte, die französischen Schauspieler seien „ehrlich“ 283 begeistert gewesen, schloß es damit auch die Möglichkeit ein, daß deren Begeisterung nur vorgetäuscht war. Gerade an dieser angeblich ehrlichen Begeisterung schien dem Referat aber sehr gelegen zu sein; deutsche Kulturpropaganda sollte die Franzosen überzeugen und zu einer echten Anerkennung der deutschen Kultur führen. Zu Ehren des Münchner Ensembles gab Vaudoyer am 16. April, in Anwesenheit der französischen Besetzung der „Iphigenie“ sowie anderer französischer Künstler und bekannter Persönlichkeiten einen Empfang ${ }^{284}$. Dieser soll den guten Endruck, den das deutsche Ensemble hinterlassen hatte, widergespiegelt haben. Das Theaterreferat bezeichnete das Gastspiel als „künstlerisch und propagandistisch erfolgreich“285. Angeblich sollen auch die laut Theaterreferat sehr zahlreichen französischen Besucher begeistert gewesen sein. Zudem lobte die Staffel in ihrem Bericht die reibungslose Zusammenarbeit mit der Comédie-Française.

Die Kritiken in der Pariser Presse erschienen zum Großteil in Form eines Vergleichs der deutschen mit der französischen Aufführung, wobei erstere besonders gelobt und letztere mehr oder weniger stark verrissen wurde ${ }^{286}$. Das Theaterreferat schrieb zur Rezeption der deutschen Aufführung, die Presse habe sich äußerst anerkennend geäußert und in Gesprächen mit Franzosen stelle sich heraus, daß das Gastspiel eine nachhaltige Wirkung habe. Der Kommentar zur französischen Inszenierung lautete: „Von Regie ist nicht viel zu merken, noch weniger von gründlicher Erfassung des wesentlichen Inhalts. Der Schauspieler ist auf sich selbst gestellt und jeder agiert nach eige-

282 AN, AJ40 1001-7, Prop.St., Gr.Kult.Th., Bericht über den Monat April 1942.

283 Ibid.

284 Ibid.

285 AN, AJ40 1001-7, Prop.St., Gr.Kult., Theater, Artistik und Musik, Kurzbericht, 17.April 1942.

286 Zur Resonanz des Gastspiels in der Presse siehe BayHStA, MK 40993, Prop.St., Gr.Kult.Th., Auszüge aus französischen Pressestimmen über das „Iphigenie“-Gastspiel des Bayerischen Staatsschauspiels am 14. und 15. April 1942 in der Pariser ComédieFrançaise; siehe auch MARSH, Le Théâtre, S. 322 f.; JOUBERT, La Comédie-Française, S. 199-202. 
ner Auffassung und Schule“287. Trotzdem seien die französischen Aufführungen erfolgreich, denn das Werk erweise sich „über die Schwächen der Wiedergabe erhaben" 288 . Das Theaterreferat war also der Ansicht, die französische Inszenierung werde Goethes Werk nicht gerecht, ja erfasse nicht einmal den Inhalt des Stückes. Hier deutet sich ein weiteres Problem der Aufführung deutscher Werke an französischen Bühnen an: Die französischen Theater inszenierten die deutschen Werke nicht immer nach den Vorstellungen des Theaterreferats und stellten damit in Frage, ob es sich tatsächlich um deutsche Kulturpropaganda handelte. Das tat jedoch in diesem Fall angeblich dem Erfolg der Aufführung keinen Abbruch. Nach Meinung des kollaborierenden Theaterkritikers Alain Laubreaux war dies keineswegs der Fall. Er urteilte, die französische Inszenierung halte einem Vergleich mit der deutschen nicht stand; auch die französischen Schauspieler, abgesehen von Mary Marquet in der Rolle der Iphigenie, seien weitaus schlechter als ihre deutschen Kollegen, zu denen er notiert: „Oui, ce sont bien là les comédiens d'une nation rajeunie, régénerée, trempée dans l'œuvre, en pleine expansion de force et de sève" 289 . Der Vergleich beider Aufführungen ergebe eine Niederlage für Frankreich. Als Grund hierfür nennt er neben der Inszenierung und der Leistung der Schauspieler auch die Übersetzung Pierre du Colombiers: „Sa traduction est consciencieuse, appliqué, mais en vain on y cherchera le mouvement, la puissance d'évocation qui nous rendront les nerfs, la moelle, l'âme de l'œuvre originale. Tout y sera réduit à une sorte de mécanique verbale "290. Laubreaux behauptet ferner, neben ihm habe eine junge $\mathrm{Zu}$ schauerin gesessen, die kein Wort Deutsch verstanden habe und trotzdem von der Aufführung des Bayerischen Staatsschauspiels begeistert gewesen sei. Die Darstellung der Comédie-Française habe sie sichtlich gelangweilt ${ }^{291}$. Die letztgenannte Einschätzung von Laubreaux erscheint freilich eher unglaubwürdig, doch nahm das Gros der Pariser Kritiker eine ähnliche, wenn auch etwas gemäßigtere, Position ein ${ }^{292}$. Zum Bühnenbild der Münchner Inszenierung meinte $L e C r i d u$ peuple, es werde durch seine Einfachheit dem Geist des Stückes gerecht, während das französische Bühnenbild in einem eigenartigen Romantismus entworfen worden sei ${ }^{293}$. Der Kritiker von Paris

287 AN, AJ40 1001-7, Prop.St., Gr.Kult.Th., Bericht über den Monat April 1942.

288 Ibid.

289 BN-BA, Alain Laubreaux, Goethe chez nous et chez lui, in: Je suis partout, 18. 4. 1942.

290 Ibid.

291 Ibid.

292 BN-BA, André CASTELOT, De l'honneur ou vie, in: La Gerbe, 23. 4. 1942; Castelot beschwerte sich ebenfalls über Colombiers Übersetzung und die französische Inszenierung. Besonderes Lob für das Münchner Theater kam von Emmanuel BOUDOTLAMOTTE, Le théâtre de Munich à Paris, in: La Gerbe, 23. 4. 1942; siehe auch MARSH, Le Théâtre, S. 323.

${ }^{293}$ BayHStA, MK 40993, Prop.St., Gr.Kult, Auszüge aus französischen Pressestimmen 
Midi schrieb zum Erfolg des Gastspiels, das Publikum soll so bewegt gewesen sein, daß es nach der zweistündigen Aufführung noch auf seinen Plätzen verharrt habe: „La preuve du grand succès de cette représentation est ce petit détail: après deux heures de spectacle sans entr'acte, le public, bouleversé, ne quittait pas ses places. La vraie tragédie, jouée ainsi, est immortelle“294. Laut Cardinne-Petit war das Gastspiel Ausdruck eines deutsch-französischen kulturellen Austauschs, eines Gedankenaustausch zwischen den Künstlern der Comédie-Française mit ihren deutschen Kollegen. Darin sah er einen ersten Schritt hin zu einem Verständnis beider Völker, da ein gegenseitiger Gedankenaustausch gleichermaßen bereichere. Weiter nimmt er das Ensemble der Comédie-Française in Schutz, weil es zum ersten Mal Goethe spielte und durch die schlechte Übersetzung behindert wurde, wodurch gemessen am Original ein Teil der Subtilität des Werkes verloren gegangen sei ${ }^{295}$. Ähnlich wie Alain Laubreaux berichtete die Propaganda Staffel über die deutsche Aufführung, von Anfang bis Ende habe atemlose Stille geherrscht, die ein untrügliches Zeichen dafür gewesen sei, „daß auch die Franzosen, die der Sprache nicht mächtig waren, gepackt und ergriffen wurden"296. Nach Ansicht der Staffel war erkennbar geworden, welchen Vorsprung das deutsche Theater vor dem französischen aufgrund seiner „künstlerischen Disziplin“297 habe, weshalb der kulturpropagandistische Erfolg des Gastspiels unbestreitbar sei. Die Staffel zititerte die Kritik des Matin: „Im neuen Deutschland erlebt die antike Tragödie eine Erneuerung, die sich völlig den rassischen Bestrebungen angleicht. Das Volk strömt dorthin, wie es bei uns der leichten Komödie zuströmt" ${ }^{298}$. Was die Bedeutung dieses Gastspiels anbelangt, kam die Pariser Presse zu dem Schluß, es habe den Kulturaustausch beider Länder

über das „Iphigenie“-Gastspiel des Bayerischen Staatsschauspiels am 14. und 15. April 1942 in der Pariser Comédie-Française; Le Cri du peuple, 18. 4. 1942.

294 BN-BA, A. Michaguine, Dans la langue même de Goethe, in: Paris-Midi, 18. 4. 1942.

295 BN-BA, R. CARDINNE-PETIT, Goethe à la Comédie-Française, in: Révolution Nationale, 26. 4. 1942. Schon im Vorfeld der Vorbereitungen zu diesem Gastspiel hatte die Propaganda Staffel die wortgetreue Übersetzung du Colombiers bemängelt, da ihr die dichterische Ursprünglichkeit gefehlt habe und sie angeblich im Gegensatz zur „bildkräftigen rhythmischen Dynamik" des Originaltextes stand (BayHStA, MK 40993,

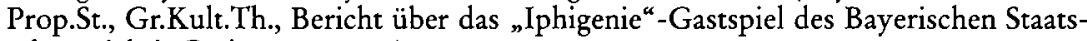
schauspiels in Paris, 22. 4. 1942).

296 Ibid.

297 Ibid.

298 BayHStA, MK 40993, Prop.St., Gr.Kult.Th., Auszüge aus französischen Pressestimmen über das „Iphigenie“-Gastspiel des Bayerischen Staatsschauspiels am 14. und 15. April 1942 in der Pariser Comédie-Française; Le Matin, 16. 4. 1942; darin wird auch die Zeitung Aujourd'hui zitiert, die betont, jedes Volk habe das Theater, das es verdiene. Während die tragische Kunst in Frankreich darniederliege, erlebe sie in Deutschland eine Renaissance. Glücklicherweise sei nun aber die Comédie-Française auf dem rechten Wege (Ibid. Aujourd'hui, 17. 4. 1942). 
gefördert und damit die Vorbedingung für eine Annäherung beider Völker erfüllt ${ }^{299}$.

Interessanterweise stammte die einzige Kritik, die das Gastspiel nicht uneingeschränkt hochjubelte, von der deutschen Pariser Zeitung. Der Artikel von Albert Buesche war nicht zensiert worden und kam anschließend auch nicht in der Presseschau der Staffel vor ${ }^{300}$. Buesche fand gleichermaßen anerkennende Worte für die französische und die deutsche Aufführung und betonte lediglich die Verschiedenheit beider Inszenierungen. Während in der deutschen Inszenierung die Monologe überwögen und die Schauspieler sich den Rücken kehrten, habe die französische Variante eine ausgeprägtere Regieleistung gezeigt. Die beiden „Iphigenien“ seien zum Vorbild des Zusammenlebens verschiedener Völker geworden"301. Die Staffel fand die Kritik der Pariser Zeitung ausgesprochen peinlich ${ }^{302}$. Doch dies waren nicht die einzigen dissonanten Töne um das Gastspiel, wie aus einem Bericht der Pariser Sipo-SD an Reichsdramaturg Schlösser in Berlin hervorgeht. Diese Stelle war zwar der Ansicht, wie schon beim Besuch des Schillertheaters sei auch diesem Gastspiel die „ungeteilte Bewunderung und Hochachtung vor der Vollendung der deutschen Schauspielkunst " 303 durch das französische Publikum zuteil geworden. Im Vergleich der deutschen und französischen Aufführung sei die deutsche Gesamtleistung besser und stilgerechter. Während die französische Bühnengestaltung eng, geschlossen und dunkel gewesen sei, habe das deutsche Bühnenbild Weiträumigkeit und Helligkeit ausgestrahlt. Nach einem Besuch der deutschen Aufführung habe man die französische Inszenierung ,mit ihren leidenschaftlichen und tränenvollen Gefühlsausbrüchen " 304 als schlecht empfunden. Vor allem aber kritisierte die Sipo-SD, daß der Regisseur Jean Yonnel, der ihrer Ansicht nach in dem Ruf stand jüdischer Herkunft zu sein, das Werk inszeniert hatte und zudem die Rolle des Thoas spielte. Während der deutsche Regisseur helles Licht auf der Bühne bevorzugt habe, habe sich Yonnel an eine Art "Wagnerische Nacht“ gehalten und das Stück in "hebräisches Geflenne" 305 verwandelt. Nach Meinung der Sipo$\mathrm{SD}$ war hierdurch das deutsche Ansehen geschädigt worden. In den Augen der deutschen Dienststellen und der Pariser Presse gab die französische Aufführung von Goethes „Iphigenie“ also vielfältigen Anlaß zur Kritik: Der

299 Ibid. Les nouveaux temps, 17. 4. 1942; Révolution, 25. 4. 1942; Petit Parisien, 16. 4. 1942.

300 BayHStA, MK 40993, Prop.St., Gr.Kult.Th., Auszüge aus französischen Pressestimmen über das „Iphigenie“-Gastspiel des Bayerischen Staatsschauspiels am 14. und 15. April 1942 in der Pariser Comédie-Française.

301 BAB, 50.01-507, Albert BuEsCHE, „Iphigenie“ auf Deutsch, Gastspiel des Bayerischen Staatsschauspiels in Paris, in: Pariser Zeitung, 16. 4. 1942.

302 Ibid. Prop.St. an Lang, RMVP, 30. 4. 1942.

303 Ibid. Chef der Sipo-SD an Reichsdramaturg Dr. Schlösser, RMVP, Betr.: Aufführung der Iphigenie durch das Bayerische Staatsschauspiel in Paris, Berlin, 20. 5. 1942. 304 Ibid.

305 Ibid. 
französische Regisseur hatte demnach das Stück nicht genügend werksgetreu inszeniert, wozu auch die schlechte Übersetzung beigetragen haben soll. Das Bühnenbild soll romantisierend und für die "Iphigenie" zu dunkel gewesen sein, während die Schauspieler ihre Rollen angeblich zu tränenreich und gefühlvoll gespielt hätten. So war diese Aufführung demnach wohl kaum ein Erfolg deutscher Kulturpropaganda. Das angeblich so „spezifisch deutsche“ Werk Goethes war in französischer Inszenierung nicht mehr „deutsch“ genug. In bezug auf den Regisseur vertrat die Sipo-SD in ihrem Bericht rassenideologisch geprägte Vorstellungen von Kultur ${ }^{306}$. Dagegen waren sich die deutschen Dienststellen mit der Pariser Presse darüber einig, daß das deutsche Gastspiel eine gelungene Demonstration der sogenannten Überlegenheit deutscher Kultur darstellte, zumal die französischen Aufführungen im Vergleich dazu angeblich so schlecht abschnitten. Dies war ganz im Sinne des angeblichen qualitativen Sieges deutscher Kultur über die französische. Es ist allerdings mehr als fraglich, ob diese Meinung der kollaborierenden Presse tatsächlich auch vom französischen Publikum geteilt wurde. Zudem ist es sicherlich vielsagend, daß die einzige offizielle Zeitungskritik mit negativerem Anklang ausgerechnet von der deutschen Pariser Zeitung kam, weil diese nicht zensiert wurde. Auch der Einwand der Sipo-SD, unter dem Publikum wären kaum Franzosen gewesen, zeigt, daß dieses Gastspiel noch lange kein wirklicher Erfolg gewesen sein muß. Die tatsächlichen Unterschiede der beiden Inszenierungen lassen sich rückblickend freilich nicht mehr rekonstruieren. Die Zeichnungen der Bühnenbilder zu beiden Aufführungen, die in den Programmheften abgedruckt sind, vermitteln nur einen unzureichenden Eindruck beider Aufführungen ${ }^{307}$. Beide Zeichnungen lassen sich theoretisch im Sinne der von der Sipo-SD vertretenen Position über das Bühnenbild interpretieren: So erscheint das französische Bühnenbild der Zeichnung nach relativ dicht und eng, während das des Münchner Ensembles eher Weiträumigkeit vermittelt. Entsprach deswegen das deutsche Bühnenbild einer "nationalsozialistischen Ästhetik"? Dies läßt sich ebensowenig klären wie die unterschiedliche Wirkung dieser Bühnenbilder, der Beleuchtung, der Regieführung und des Spieles der Schauspieler.

Gleichwohl zeigt dieses Beispiel, daß der Aufführung deutscher Stücke auf Pariser Bühnen außer den praktischen Hindernissen wie fehlenden Übersetzungen oder zögerlichen Theaterdirektoren zusätzlich noch andere Schwierigkeiten entgegenstanden. Die Übersetzungen, die Inszenierungen, das Spiel der Schauspieler - alles sollte nach Meinung des Theaterreferats das "spezifisch Deutsche" des Werkes widerspiegeln, um wirklich deutsche Kulturpropaganda zu sein. Unter einer guten Aufführung eines deutschen Stückes

$306 \mathrm{Zu}$ den Vorstellungen Hitlers über die "Juden als Kulturzerstörer" siehe bei MATHIEU, Kunstauffassungen, S. 30-37.

307 ABBSM, Programmheft, Comédie-Française, Das Bayerische Staatsschauspiel, Théâtre d'Etat de Munich, „Iphigénie en Tauride“ de Goethe 14 et 15 Avril; Programmheft zur französischen Aufführung „Iphigénie en Tauride“ von Goethe vom 13. 4. 1942. 
stellte sich das Theaterreferat offenbar etwas völlig anderes vor als das, was dann tatsächlich auf Pariser Bühnen zu sehen war. Dies wird auch in der Kritik des Referats zur Aufführung von Schillers „Don Carlos“ am 11. April 1942 im Théâtre de l'Odéon deutlich. Nach Meinung des Theaterreferenten Frank hatte du Colombiers Übersetzung von Goethes „Iphigenie“ noch den Bilder- und Gedankenreichtum der Sprache des Originals festgehalten, während die Übertragung des „Don Carlos“ durch Jean Sarment Schiller seiner „revolutionären Leidenschaft" 308 und seines "hohen Ethos" beraubt und das Stück auf das Handlungsgerüst, das Intrigenstück und das Sensationsdrama reduziert hatte. Daraus schloß Frank:

Diese Entdeckung, peinlich und gefährlich, geht nicht zu Lasten Schillers, beweist aber von neuem, wie vorsichtig bei der Auswahl der hier einzusetzenden deutschen Werke vorgegangen werden muß. Das Odéon hat die nicht leichte Aufgabe mit bemerkenswerter Gewissenhaftigkeit angepackt, doch muß auch die Aufführung im Ganzen als ungenügend bezeichnet werden. Da die Aufnahme beim Publikum gut ist, glaubte das Referat davon absehen zu dürfen, zum Schutz der Dichtung einzugreifen. Es sind lediglich einige Änderungen vorgeschlagen worden, die auch berücksichtigt wurden ${ }^{309}$.

Da Frank sogar erwog, das Stück „zum Schutz der Dichtung“ abzusetzen, gingen hier dessen Wunschvorstellungen und die tatsächliche Aufführung des „Don Carlos“ weit auseinander. Auf den ersten Blick ist es erstaunlich, daß Frank den Mangel an sogenannter revolutionärer Leidenschaft in der französischen Inszenierung kritisiert. Gerade bei diesem Stück kam es auf deutschen Bühnen im Dritten Reich, so Drewniak, zu Szenen-Beifall. Gemeint ist hier die berühmte Szene des Stückes, in der Posa zum König sagt: „Geben sie Gedankenfreiheit!“ Grundsätzlich erfuhr Schiller im Dritten Reich jedoch eine Umdeutung im Sinne der nationalsozialistischen Ideologie. Hitler sah in dem Dichter sogar den „Vorläufer des Nationalsozialismus "310. Die von Frank angemahnte „revolutionäre Leidenschaft" sollte hier also nicht unbedingt auf die Ideen der französischen Revolution bezogen werden. In Anbetracht der negativen Kritik des Theaterreferenten ist es durchaus wahrscheinlich, daß das Stück vom Publikum tatsächlich gut aufgenommen wurde. Eine allzu schlechte Resonanz beim Publikum hätte vermutlich den Referenten darin bestärkt, für dessen Absetzung zu sorgen. Die Aufführung des „Don Carlos" war also relativ erfolgreich in bezug auf seine Resonanz beim Publikum und gleichzeitig kulturpropagandistisch erfolglos, weil sie nicht im Sinne der Vorstellungen des Theaterreferats war ${ }^{311}$.

308 AN, AJ40 1001-7, Prop.St., Gr.Kult.Th., Bericht über den Monat April 1942.

309 Ibid.

310 DrewniaK, Das Theater, S. 171-173; laut Drewniak läßt sich nicht mehr genau nachvollziehen, inwieweit die Werke Schillers auf den Bühnen des Dritten Reiches umgedeutet und, wie er schreibt, mißbraucht wurden.

311 Die deutschen Dienststellen kritisierten übrigens die Aufführungen des Théâtre de l'Odéon nicht nur im Falle der Inszenierung deutscher Werke. Der Theaterreferent des Deutschen Instituts Kaspar Pinette schrieb in seinem Bericht über die Theatersaison 1940/41, das Odéon stehe weit unter dem durchschnittlichen Niveau der Pariser Thea- 
Obgleich die deutschen Funktionsträger seit Beginn 1943 auf immer mehr Widerstände stießen, um deutsche Stücke auf Pariser Bühnen zu bringen, führten die französischen Bühnen gerade in diesem Jahr fünf von insgesamt sieben deutschen Theaterstücken im besetzten Paris auf. Das Referat hatte sich seit dem Sommer 1942 verstärkt um Aufführungen zu Ehren von Hauptmanns 80. Geburtstag bemüht. Dieses Ereignis sollte im November 1942 im Reich Gegenstand großer Feierlichkeiten sein. Zur Stellung Hauptmanns im Dritten Reich meint Drewniak, jener habe zu Beginn der nationalsozialistischen Herrschaft viele Demütigungen hinnehmen müssen.

Hauptmann war jedoch ein so großer Dichter, nicht nur in Deutschland, sondern auch außerhalb seiner Grenzen, daß das Propagandaministerium die Bedeutung der Tatsache zu schätzen wußte, daß der "Senior der heutigen deutschen Dramatiker", wie er im Kreise der nächsten Mitarbeiter von Goebbels hieß, sein Deutschland, „an dem er hing wie der Sohn an der Mutter, das er liebte bis in seine düstere Verirrung hinein“, nicht verließ ${ }^{312}$.

Eine Ehrung Hauptmanns zu dessen 80. Geburtstag sollte im Reich wie in den besetzten Gebieten „die Großzügigkeit des Nationalsozialismus gegenüber dem deutschen Kulturgut, von vorgestern" demonstrieren " 313 . Inhaltlich standen die Nationalsozialisten dem Werk Hauptmanns aber skeptisch gegenüber. Wie bereits erwähnt, lehnte Goebbels die angeblich zu düsteren Werke wie den „Fuhrmann Henschel“ als Auslandsgastspiele strikt ab ${ }^{314}$. Rosenberg hatte wegen einer Aufführung von Hauptmanns "Ratten“ auf deutschen Bühnen im Juli 1942 Bedenken geäußert ${ }^{315}$. Zu Beschwerden von Angehörigen der NSDAP kam es bei einer Aufführung von Hauptmanns „Elga“ im Breslauer Nationaltheater Ende 1940. Das Stück, das in Polen spielte, wurde nun im sogenannten ehemaligen Grenzland zu Polen aufgeführt. Bemängelt wurde vor allem die Darstellung der Polen „in ihrer slawi-

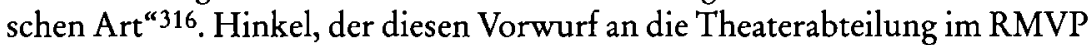
weitergegeben hatte, erhielt zur Antwort, die Kritik sei übertrieben. Polen stelle nur den Rahmen für das Theaterstück. Zwar sei auch das RMVP nicht an einer „Verherrlichung nichtdeutscher Menschen “317 auf der deutschen

ter und zeige nur selten gute Vorstellungen, obgleich es staatlich subventioniert sei (PAAA, 1379, Kult 12 Nr. 2, DBP, Epting an AA, 12. 3. 1941; Anlage, Bericht über die Weiterentwicklung des Theaterwinters in Paris, Kaspar Pinette).

312 DREWNIAK, Das Theater, S. 190; Drewniak zitiert in diesem Zitat den Autor Thomas MANN, Gerhart Hauptmann, in: DERS., Über die deutsche Literatur, Leipzig 1968, S. 294.

313 DreWNIAK, Das Theater, S. 205.

314 BAB, 50.01-291, RMVP, Ministeramt, Dr. Naumann an Schlösser, Betr.: Auslandsreisen des Schillertheaters, 2. 10. 1943.

315 BAB, 50.01-235, RMVP, Abt.Th., Schlösser an Goebbels, Betr.: Gerhart Hauptmann, 4. 7. 1942.

316 Ibid. RMVP, Ministerialdirigent Hinkel an Abt.Th., RMVP, Betr. Aufführung des Schauspiels "Elga" von Gerhart Hauptmann in Breslau, 7. 12. 1940.

${ }^{317}$ Ibid. RMVP, Abt.Th., Referent Frenzel an Ministerialdirigent Hinkel, RMVP, Betr: Gerhart Hauptmanns „Elga“ in Breslau, 23. 12. 1940. 
Bühne interessiert, doch treffe dies auf „Elga" nicht zu. Eine Ausdehnung der Zensurverbote auch auf Stücke wie dieses würde nicht nur in Deutschland, sondern vor allem auch im Ausland als Zeichen der Schwäche gedeutet. Schlösser befürwortete gegenüber Goebbels eine relativ tolerante Haltung gegenüber den Werken Hauptmanns. Er sah die Auswahl an aufführbaren Stücken auf deutschen Bühnen schwinden, weil mehr und mehr Werke verboten wurden. Das Gesamtwerk Hauptmanns beurteilte er zudem generell als politisch harmlos ${ }^{318}$. Die Entscheidung zu einer Ehrung von Hauptmanns 80. Geburtstag in Form von Aufführungen in Deutschland und in den besetzten Gebieten traf Hitler persönlich. Schlösser schlug insbesondere für Paris das Stück „Vor Sonnenuntergang“ vor, womit Goebbels einverstanden war ${ }^{319}$. Auf Anweisung des RMVP versuchte das Theaterreferat ab Sommer 1942 die Aufführung von Hauptmanns Werken im besetzten Paris durchzusetzen. Ergebnis dieser Bemühungen waren die Aufführungen von „Rose Bernd" im Januar 1943 im Palais de Chaillot, "Fuhrmann Henschel“ im Februar 1943 im Odéon und „Iphigenie in Delphi“ im Juni 1943 an der Comédie-Française. Die Pariser Aufführungen fanden ohne Ausnahme an den wenigen staatlich subventionierten französischen Bühnen statt und kamen für eine Geburtstagsehrung des Autors um einige Monate zu spät.

Ähnlich wie bei der Inszenierung des „Don Carlos“ beurteilte das Theaterreferat auch die Aufführung der „Rose Bernd“ im Palais de Chaillot im Januar 1943 negativ. Emile Bertin hatte das Bühnenbild entworfen, Juillette Verneuil und André Varennes spielten die Eheleute Flamm und eine junge unbekannte Schauspielerin namens Jandeline war Rose Bernd. Das Theaterreferat beschwerte sich, Pierre Aldebert, der Intendant des Theaters, habe sich zwar Mühe gegeben, doch sei die Aufführung nicht zu einem tieferen Verständnis des Werkes gelangt: „Davon zeugten schon die idyllischen Bühnenbilder, mehr noch die biedermeierlich-bajuwarischen Kostüme“"320. In Zukunft empfehle sich deshalb die Beratung der französischen Theater durch einen deutschen Bühnenfachmann. Zur Rezeption des Stückes heißt es:

Dennoch zeigte sich das Publikum, das den riesigen Theaterraum bis auf den letzten Platz füllte, stark ergriffen. [...] So aufschlußreich es sein mag, deutsche Werke durch die französische Brille wiedergegeben zu sehen, erscheint es doch notwendig, den seit Jahrzehnten nicht überwundenen romantisierenden Vorstellungen des Franzosen vom deutschen Wesen entgegenzuwirken ${ }^{321}$.

Hier vermittelte also die Inszenierung für den Geschmack des Theaterreferats eine falsche Vorstellung vom sogenannten deutschen Wesen. Offenbar

318 Ibid. RMVP, Abt.Th., Schlösser an Goebbels, 23. 12. 1940. Ibid. Schlösser an Goebbels, Betr.: Gerhart Hauptmann, 4. 7. 1942.

319 Ibid. RMVP, Abt.Th., Schlösser an Goebbels, Betr.: 80. Geburtstag Gerhart Hauptmanns, 5. 3. 1942.

320 AN, AJ40 1001-7, Prop.Abt., Gr.Kult.Th., Frank, Tätigkeitsbericht, Paris, den 29. Januar 1943.

321 Ibid. 
entsprach dies aber den Erwartungen der Zuschauer. In seinem Bericht über die genannten Aufführungen der Werke Hauptmanns meinte Knothe zu "Rose Bernd“, dieses Stück habe sich in Frankreich bisher nicht durchsetzen können, was aber im Wesentlichen in der verfälschenden Übersetzung begründet gewesen sei ${ }^{322}$. In einem Artikel der Pariser Zeitung zeichnete André Meyer die Geschichte der Rezeption des Stückes in Frankreich nach ${ }^{323}$. „Rose Bernd“ war im Theater Porte St. Martin am 20. April 1905 als letztes Werk Hauptmanns in Frankreich aufgeführt worden. Seit dem Mißerfolg dieses Stückes wurde Hauptmann gleichsam von den französischen Bühnen verbannt. Der Autor war dort mit den „Webern“ bekannt geworden und „Rose Bernd“ beendete schließlich eine erfolgreiche Serie der Aufführung seiner Werke. Die zeitgenössische Presse führte den Mißerfolg des Stückes unter anderem auf die Übersetzung Thorels zurück, der bereits die "Weber", „Hanneles Himmelfahrt" und „Fuhrmann Henschel" übersetzt hatte. Allerdings war die französische Übersetzung des schlesischen Dialektes der „Rose Bernd" problematisch, was jedem einleuchten wird, der heutzutage den Text dieses Schauspiels zur Hand nimmt ${ }^{324}$. Thorel verwandelte die schlichte Sprache der Personen in bäuerliche Redewendungen. So übersetzte er beispielsweise Sätze wie "Gottes Wege sind wunderbar" mit „Le bon dieu sais ce

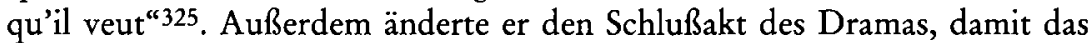
Ende weniger traurig wirkte. In der Originalfassung redet Rose zuletzt bitter und starrköpfig davon, daß sie ihr Kind erwürgt hat, damit es nicht den gleichen Lebensweg wie die Mutter gehen muß. Ihr Verbrechen bereut sie nicht. Über das Kind sagt sie: „'s sullde ni laba! Ich wullte’s ni!!“326. In Wien war das Stück aufgrund dieses Ausgangs auf Wunsch klerikaler Kreise nach sechs Aufführungen verboten worden. In der französischen Fassung von Thorel war Rose zwar immer noch ein Opfer des Schicksals, doch keine Aufrührerin mehr, sondern eine reuige Sünderin. Im Schlußakt des Stückes sagt die französische Rose nicht, sie habe ihr Kind nie haben wollen, sondern verkündet: „Wir haben noch ein ganzes Leben vor uns, zum Arbeiten, zum ehrlich sein und zum Wiedergutmachen und das will ich tun“327.

Anläßlich der Wiederaufnahme des Stückes im Jahre 1943 hatte Intendant Aldebert beschlossen, den letzten Akt neu bearbeiten lassen, doch lehnten sämtliche Übersetzer ab, weil ihnen diese Aufgabe als zu schwierig erschien.

322 PA-AA, 1142, Kult 12 Nr. 2, DBP, Knothe an AA, Durchdruck als Konzept, Betr.: Aufführung Hauptmannscher Werke in Frankreich anläßlich des 80. Geburtstages des Dichters, 11. 2. 1943.

323 Ibid. André MEYer, übers. von Ilse Backhoff, „Rose Bernd“ in Paris, Erste Hauptmann-Aufführung nach 38 Jahren, in: Pariser Zeitung, 23. 1. 1943.

324 Gerhart HaUPTMANN, Rose Bernd, Schauspiel, Berlin 1996.

325 PA-AA, 1142, Kult 12 Nr. 2, André MEYER, übers. von Ilse Backhoff, „Rose Bernd“ in Paris, Erste Hauptmann-Aufführung nach 38 Jahren, in: Pariser Zeitung, 23. 1. 1943.

326 HauptmanN, Rose Bernd, S. 96.

327 PA-AA, 1142, Kult 12 Nr. 2, André Meyer, übers. von Ilse Backhoff, „Rose Bernd“ in Paris, Erste Hauptmann-Aufführung nach 38 Jahren, in: Pariser Zeitung, 23. 1. 1943. 
Aldebert entschied sich schließlich, die Fassung Thorels beizubehalten, strich aber die Passagen, die dem Original Hauptmanns zu sehr widersprachen. In dieser neuen Variante sank Rose im Schlußakt nun weder fluchend zusammen noch bekundete sie Reue. Intendant Aldebert ließ sie mit einem einfachen Seufzer auf den Lippen sterben, weil er die Schlußtiraden Roses im Original des Autors für wenig zeitgemäß hielt. Nach Ansicht des Kritikers Meyer entsprach diese Variante nicht den eigentlichen Absichten des Autors. Hauptmann habe die unabänderliche Einsamkeit Roses zeigen wollen, die nur durch eine leidenschaftliche Liebe hätte gerettet werden können. In der Fassung Aldeberts würden jedoch die letzten Augenblicke Roses „durch

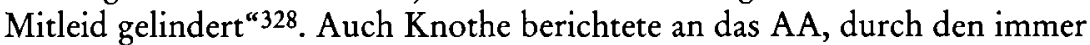
noch milden Ausgang des Stückes, werde die französischen Inszenierung der Intention des Autors nicht gerecht. Allerdings hätten die Aufführungen lebhaften Zuspruch beim französischen Publikum gefunden, der von Vorstellung zu Vorstellung angestiegen sei ${ }^{329}$. Verärgert war Knothe insbesondere über eine kritische Besprechung der Aufführung, die wie im Falle des „Iphigenien"-Gastspiels ausgerechnet wieder aus der Feder Albert Buesches von der Pariser Zeitung stammte. Der Artikel trug den bezeichnenden Titel "Grenzen des Verstehens" 330 und setzte sich grundsätzlich mit der Gefahr und Notwendigkeit auseinander, daß deutsche Werke auf französischen Bühnen eine Art Umschmelzung in Richtung auf die „spezifisch französische Empfindungswelt “331 erführen. Knothe war zwar der Ansicht, daß diese Kritik zweifellos richtig sei, hielt derartige Ausführungen jedoch kulturpolitisch eher für unangebracht ${ }^{332}$. Tatsächlich liest sich die Besprechung Buesches wie eine Satire auf das ernste Schauspiel Hauptmanns. Der Kritiker war der Ansicht, deutsche Zuschauer hätten diese Aufführung nicht ohne eine gewisse Verwirrung verlassen können:

Die weite schlesische Landschaft war in den engen Rahmen von naturalistischer Kulisse und Hängesoffitte gezwängt. Die Innenräume mit ihrem romantischen Dekorationssinn schienen eher für ein Singspiel geschaffen. Die Leute waren in lustige Bauerntrachten gekleidet, in denen das Tirolerische vorherrschte: Stutzen, nackte Knie und hohe spitze Filzhüte. Der am Leben kranke Flamm war mit gekräuseltem Spitzbart ein besorgter Familienvater auf Abwegen, was ihm bei passender Gelegenheit vom Publikum auch durch Lachen quittiert wurde. Der kraftstrotzende Streckmann zeigte sich als ein eitler, im Grunde schwächlicher Dorf Don Juan. Rose blieb irgendein Dorfmädchen

328 Ibid.

329 PA-AA, 1142, Kult 12 Nr. 2, DBP, Knothe an AA, Durchdruck als Konzept, Betr.: Aufführung Hauptmannscher Werke in Frankreich anläßlich des 80 . Geburtstages des Dichters, 11.2. 1943.

330 Ibid. Dr. Albert Buesche, Grenzen des Verstehens, Gerhard Hauptmanns „Rose Bernd" auf Französisch, in: Pariser Zeitung, 26. 1. 1943.

331 Ibid.

332 Ibid. Knothe an AA, Durchdruck als Konzept, Betr: Aufführung Hauptmannscher Werke in Frankreich anläßlich des 80. Geburtstages des Dichters, 11. 2. 1943. 
ohne dramatisches Gewicht und der Akzent verschob sich von ihr auf das Ehepaar Flamm $^{333}$.

Aus der Tragödie Hauptmanns sei eine Art dörfliches Sittenbild geworden, rührend und mit moralischer Belehrung. Buesche bescheinigte der französischen Inszenierung trotzdem viel guten Willen und Einfühlungsvermögen. Obgleich dieses Werk Hauptmanns nämlich der "französischen Eigenart" große Schwierigkeiten bereite und ihr zuwiderlaufe, sei die französische Inszenierung bemüht gewesen, das Stück umzuschmelzen. Seiner Ansicht nach zeigten solche Aufführungen die Grenzen des Verstehens zwischen Deutschen und Franzosen. „Diese Aufführung verschaffte uns das seltene Erlebnis der Spiegelung einer deutschen Dichtung in französischem Wesen. Handgreiflich und in Gestalten von Fleisch und Blut vollzog sich eine deutschfranzösische Begegnung “334. Verständnis bedeute nicht Übereinstimmung, sondern Erkennen der Grenzen. Buesche hielt es für vollkommen natürlich, daß beispielsweise Racine die deutschen Zuschauer befremde. Demgemäß dürfe man auch dem französischen Theater nicht seine Einfühlungskraft absprechen, wenn ein deutsches Drama auf französischen Bühnen nicht so aussehe wie auf deutschen. Die Grenzen des Verstehens seien gerade fruchtbar für den Kontakt beider Völker, weswegen man sich offen zu diesen Grenzen bekennen sollte. In der Wiederholung dieser fruchtbaren Begegnungen liege "ein gutes Stück kommenden Europäertums" 335 . Buesche geht in seiner Argumentation von den Vorstellungen der sogenannten Kulturkunde bzw. der Frankreichkunde der zwanziger und dreißiger Jahre aus; demnach waren dem gegenseitigen Verstehen verschiedener Völker Grenzen gesetzt. Er schließt dabei den Glauben an eine übernationale Welt sowie an eine universalistische Kultur aus. Das deutsche und französische Volk besitzen nach dieser Vorstellung eine jeweils eigene, spezifische Kultur ${ }^{336 .}$

Konsequenterweise sind für Buesche französische Inszenierungen deutscher Theaterstücke Begegnungen beider Kulturen und nur möglich, wenn das "deutsche Wesen“ in die "französische Wesensart" gleichsam transponiert wird. Demnach wäre es allerdings theoretisch vollkommen unmöglich gewesen, auf Pariser Bühnen sogenannte wesensgetreue Aufführungen deut-

333 Ibid. Dr. Albert BuEsche, Grenzen des Verstehens, Gerhard Hauptmanns „Rose Bernd" auf Französisch, in: Pariser Zeitung, 26. 1. 1943.

334 Ibid.

335 Ibid.

336 Die sogenannte Kulturkunde, die sich während der zwanziger und dreißiger Jahre in Deutschland entwickelte, fügte die "Wesenszüge“ eines Volkes zu einem Gesamtbild zusammen und reduzierte das jeweilige Volk auf ein spezifisch „deutsches“ oder „französisches Wesen“. Siehe Michael WERNER, Le prisme franco-allemand: à propos d'une histoire croisée des disciplines littéraires, in: Entre Locarno, S. 303-342. Zur Frankreichkunde siehe Gerhard BOTT, Deutsche Frankreichkunde 1900-1933, 2 Bde., Rheinfelden 1982. Ähnliche Vorstellungen wie die Buesches hat Michels für den Leiter des Deutschen Instituts, Karl Epting, herausgearbeitet, MICHELS, Das Deutsche Institut, S. 22. 
scher Theaterstücke zu geben, die den Vorstellungen der deutschen Funktionsträger von einer „spezifisch deutschen“ Aufführung entsprochen hätten. Dieses Ziel deutscher Kulturpropaganda wurde jedoch von den deutschen Dienststellen, vor allem vom Theaterreferat der Propaganda Staffel, verfolgt. Mit seinen kritischen Reflexionen stellte Buesche die gedanklichen Grundlagen der hier verfolgten deutschen Kulturpropaganda in Frage, was die Verärgerung Knothes erklärt. Allerdings stimmte Knothe trotzdem mit Buesches Kritik überein. Die deutschen Funktionsträger im besetzten Paris hatten selbst also starke Zweifel an der Wirkung der von ihnen verfolgten Kulturpropaganda. Buesche ging zudem noch einen Schritt weiter: Seiner Ansicht nach war die sogenannte Umschmelzung der deutschen Dichtung durch das „französische Wesen“ notwendig, denn er sah darin einen Schritt zum Europäterum der Zukunft. In dieser Vorstellung waren die deutsche und französische Kultur gleichberechtigte Partner, deren Begegnung die Vorstufe zu einem geistigen Europäertum bildete. Mit dem von den Nationalsozialisten verfolgten sogenannten Sieg der deutschen Kultur über die französische waren solche Gedanken nicht vereinbar.

Wohlwollender als die Aufführungen der "Rose Bernd“ beurteilte Buesche die Inszenierung von Hauptmanns „Fuhrmann Henschel“ im Théâtre de l'Odéon im Februar 1943. Auch diese Aufführungen waren von deutscher Seite als Beitrag zur Ehrung Hauptmanns zu seinem 80. Geburtstag gedacht. In seiner Kritik bedauerte Buesche, daß diesem realistischen Drama nicht eines der romantischen Dramen und Märchendramen Hauptmanns vorgezogen worden war. Seiner Ansicht nach war der „Fuhrmann Henschel“ dem französischen Publikum und den Schauspielern zumindest weitaus zugänglicher als „Rose Bernd“, denn: „Alles was die Bezirke der Eifersucht berührt

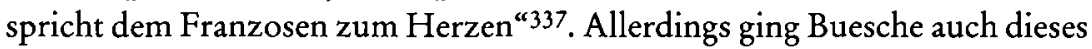
Mal erneut ausgiebig darauf ein, wie die französische Inszenierung das deutsche Stück interpretiert und somit des "deutschen Wesens" beraubt hatte. Aus Hauptmanns "Drama der Innerlichkeit und Stille" 338 war seiner Ansicht nach ein Intrigenstück geworden, in dem die Hauptpersonen oft Zuflucht zum Schreien genommen hätten. Buesche bewertete die französische Inszenierung eher negativ, doch hätten sich die Schauspieler bemüht, „eine ihnen in manchem wesensfremde Gestalt zu verkörpern" ${ }^{339}$. Zudem hätte sich das Werk Hauptmanns trotz der „Umformung in fremde Sprache und fremden Geist" behauptet. Auch in dieser Aufführung sah er ein Bemühen der Völker umeinander. Das Theaterreferat war ebenfalls mit dem „Fuhrmann Henschel“ am Odéon weit zufriedener als vorher mit „Rose Bernd“. Frank schrieb im Februar, das Odéon habe mit dieser Aufführung einen bedeutsamen Triumph errungen: „Die Inszenierung ist sogar nach deutschem Maß-

337 PA-AA, 1142, Kult 12 Nr. 2, Dr. Albert BuEsCHE, Hauptmann im Odéon, Zu der französischen Aufführung des „Fuhrmann Henschel“, in: Pariser Zeitung, 15. 2. 1943. 338 Ibid.

339 Ibid. 
stab als außergewöhnlich gut zu bezeichnen. Es scheint, daß dieser Erfolg die Franzosen deutschen Stücken gegenüber etwas gefügiger macht “340. Ebenso notierte Knothe von der Deutschen Botschaft, die Inszenierung sei ein Erfolg 341 . Offenbar waren also nach Ansicht der deutschen Funktionsträger einige der deutschen Stücke dem sogenannten französischen Wesen näher als andere, was ihre Aufführung auf französischen Bühnen erleichterte.

Schließlich führte die Comédie-Française im Juni 1943, beinahe ein Jahr nach Hauptmanns 80. Geburtstag, seine "Iphigenie in Delphi“ im besetzten Paris auf. Aufgrund der Bedeutung des Theaters war Knothe der Ansicht, die Inszenierung dieses in Frankreich bisher unbekannten Werkes sei als „offizielle französische Hauptmann-Ehrung " ${ }^{342}$ anzusehen. Die Comédie-Française hatte allerdings absichtlich immer wieder den Premierentermin verzögert. Bereits im Juli 1942 hatte sich der Intendant Vaudoyer auf Drängen des Theaterreferats bereiterklärt, anläßlich des 80 . Geburtstages ein Werk von Hauptmann an der Comédie-Française aufzuführen ${ }^{343}$. Das Theaterreferat schlug ihm mehrere Werke vor. Am 14. August 1942 besprachen Rittmeister von Heyden-Linden, Curt Langenbeck und Pierre du Colombier, der das Werk übersetzen sollte, die Auswahl des Stückes, konnten sich jedoch nicht einigen. Generell wurde beschlossen, noch im Winter ein Stück Hauptmanns an der Comédie-Française aufzuführen ${ }^{344}$. Erst im Oktober 1942 fiel die Wahl auf "Iphigenie in Delphi“345. Vaudoyer bat sogar, Breker möge das Bühnenbild zu dieser Aufführung entwerfen, wozu es jedoch niemals $\mathrm{kam}^{346}$. Vaudoyer wollte als drittes Werk in seinem Iphigenien-Zyklus eigentlich die "Iphigenie“ von Racine aufführen. Als ihm das Theaterreferat jedoch vorschlug, anläßlich von Hauptmanns 80. Geburtstag „Fuhrmann Henschel" aufzuführen, schlug er seinerseits dessen „Iphigenie“ vor ${ }^{347}$. Vaudoyer zog dem realistischen Gegenwartsdrama die Mythengestalt der „Iphigenie" vor, die im November 1941 im Berliner Staatstheater uraufgeführt worden war. In der Beurteilung dieses Werkes ist konstatiert worden, Hauptmann habe sich hier in die ferne Mythenwelt geflüchtet; ferner soll es sogar

340 AN, AJ40 1001-7, Prop.Abt., Gr.Kult.Th., Tätigkeitsbericht, 1. 3.-30. 3. 1943.

341 PA-AA, 1142, Kult 12 Nr. 2, DBP, Knothe an AA, Durchdruck als Konzept, Betr.: Aufführung Hauptmannscher Werke in Frankreich anläßlich des 80 . Geburtstages des Dichters, 11. 2. 1943.

342 Ibid.

343 AN, AJ40 1001-7, Prop.St., Gr.Kult.Th., Kurzbericht, 17. 7. 1942.

344 Ibid. Prop.Abt., Tätigkeitsbericht, 14. 8.-21. 8. 1942, Rittmeister v. Heyden-Linden über eine Besprechung mit Curt Langenbeck und Pierre Colombier am 14. 8. 1942. Es konnte nicht ermittelt werden, weshalb hier Langenbeck, der sich normalerweise nicht in Paris aufhielt, zu Rate gezogen wurde.

345 AN, AJ40 1001-7, Prop.St., Gr.Kult.Th., Tätigkeitsbericht, 30. 12. 1942.

346 PA-AA, 1142, Kult 12 Nr. 2, DBP, Knothe an Breker, 8. 10. 1942; ibid. Piersig, Aufzeichnung für Knothe, Im Nachgang zu dem Bericht vom 26. 8., 7. 10. 1942.

347 AN, AJ40 1001-7, Prop.St., Gr.Kult.Th., Tätigkeitsbericht, 30. 12. 1942; JouberT, La Comédie-Française, S. 178-182. 
Angriffe gegen die nationalsozialistische Herrschaft enthalten haben ${ }^{348}$. In der Folge verzögerte Vaudoyer absichtlich die endgültige Entscheidung für dieses Werk und gab zwischenzeitlich vor „Und Pippa tanzt" aufführen zu wollen ${ }^{349}$, bis man sich schließlich doch auf die "Iphigenie" einigte ${ }^{350}$. Knothe notierte später, bei der Auswahl dieses Stückes sei ausschlaggebend gewesen, daß die Comédie-Française damit ein in Frankreich bisher unbekanntes Stück herausbringen würde. Die deutschen Dienststellen hätten jedoch viel Mühe und Beharrlichkeit aufwenden müssen, um Vaudoyer zur Einhaltung seines Versprechens zu bewegen. Als Grund dafür nannte er un-

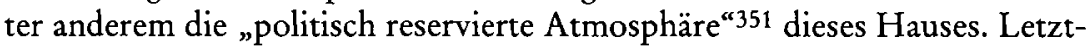
lich haben sich die französischen Schauspieler jedoch im Laufe der Probenarbeit, so Knothe, doch noch für dieses Schauspiel erwärmen können. Tatsächlich herrschte an der Comédie-Française keineswegs etwa eine freundliche Stimmung gegenüber der Besatzungsmacht. Mehrere Schauspieler der Comédie-Française waren Mitglieder der Résistance ${ }^{352}$.

So lassen sich nach der Entscheidung für das Stück in den Berichten des Theaterreferats immer wieder Klagen über Verzögerungen der Vorbereitungen für die Aufführung finden. In einem Bericht vom Dezember 1942 heißt es: „Auch die zögernde Haltung, die in der Frage einer Gerhart-HauptmannAufführung eingenommen wird, ist Beweis für die lustlose Tendenz an der kulturpolitischen Börse " 353 . Die Comédie-Française lasse sich mit den Aufführungen der "Iphigenie“ erheblich viel Zeit. Wie andere Pariser Theater verfolgte das Haus eine Hinhaltetaktik in Bezug auf die Aufführung deutscher Werke ${ }^{354}$. Die Comédie-Française verzögerte die Aufführung der "Iphigenie in Delphi“ bis Ende Mai 1943. Kurz vor der Premiere erwog Knothe noch, den Dichter persönlich zu dieser französischen Uraufführung einzuladen ${ }^{355}$. Der MBF befürwortete die Einladung Hauptmanns, da jener gesundheitlich alle Veranstaltungen zur Feier seines 80. Geburtstages gut überstanden hatte und einem Besuch in Paris nicht abgeneigt war ${ }^{356}$. Knothe

348 Drewniak, Das Theater, S. $191 \mathrm{f}$; siehe auch MARSH, Le Théâtre, S. 283-285.

349 PA-AA, 1142, Kult 12 Nr. 2, DBP, Piersig an GK Knothe, 26. 8. 1942.

$350 \mathrm{Zu}$ Vaudoyers Verzögerungstaktik siehe JOUBERT, La Comédie-Française, S. $183 \mathrm{f}$. 351 PA-AA, 1142, Kult 12 Nr. 2, DBP, Knothe an AA, 28. 7. 1943 (26?), Betr.: Aufführung der "Iphigenie in Delphi“ von Gerhart Hauptmann in der Comédie-Française. 352 JOUBERT, La Comédie-Française, S. $431 \mathrm{f}$.

353 AN, AJ40 1001-7, Prop.Abt., Gr.Kult.Th., Tätigkeitsbericht, 30. 12. 1942.

354 Siehe dazu Ibid. Prop.St., Tätigkeitsbericht, 1. 7.-31. 7. 1942: Im Juli 1942 berichtete das Theaterreferat, Charles Dullin wolle im städtischen Théâtre de la Cité, dem zu Beginn der Okkupation umbenannten Thêâtre Sarah Bernard, den „Zerbrochenen Krug“ von Kleist spielen. Das Werk werde bereits von Pierre du Colombier übersetzt. Dullin zögerte die Aufführung des Stückes aber so lange hinaus, bis er im Juni 1944 erklärte, er könne es nun aufgrund finanzieller Schwierigkeiten nicht mehr aufführen (Ibid. Prop.Abt., Bericht über den Monat Juni 1944). Die Alliierten waren bereits in der Normandie gelandet.

355 PA-AA, 1142, Kult 12 Nr. 2, DBP, Knothe an AA, 24. 5. 1943.

356 Ibid. DBP, Piersig, Aufzeichnung für Knothe, 10. 5. 1943. 
betonte in seinen Berichten an das AA mehrfach die Wichtigkeit des Besuchs und nannte die Aufführung der "Iphigenie" an dem traditionsreichen Hause der Comédie-Française ein „großes kulturpolitisches Ereignis“357, das durch die Anwesenheit Hauptmanns an Bedeutung erheblich gewinnen würde. Seiner Ansicht nach mußten die Franzosen dies als besondere Ehrung empfinden. Schließlich teilte jedoch das RMVP mit, der Gesundheitszustand Hauptmanns erlaube keine Reise nach Paris ${ }^{358}$. Es ist denkbar, daß dies nicht allein der Grund für die Absage war. Immerhin war Goebbels, der Paris als Kulturmetropole in Europa durch Berlin ersetzen wollte, generell wenig geneigt, dem französischen Theaterbetrieb eine solche Ehrung durch Hauptmanns Anwesenheit zuteil werden zu lassen.

Kurz vor seiner Versetzung an die Ostfront schrieb Theaterreferent Frank, der bis dahin nur den Proben der "Iphigenie“ beigewohnt hatte, sowohl die Übersetzung als auch die Inszenierung ließen erhebliche Anstrengungen erkennen, doch sei der Stil des Werkes ,in der üblichen romantisierenden Form “ 359 verändert worden. Nach Franks Meinung war die propagandistische Bedeutung der Aufführung aber dennoch stark, weil es aufgrund der politischen Situation immer schwieriger werde, überhaupt deutsche Werke in den französischen Spielplan zu bringen. Goldmann, der wenig später Frank als Theaterreferenten ersetzte, schrieb in seinem Bericht, die "Iphigenie" sei Anfang Juni mit reichlicher Verspätung „nach der Überwindung unzähliger Schwierigkeiten und undurchsichtiger Intrigen in der Comédie-Française" 360 aufgeführt worden. Die Vorführungen seien jedoch ein Erfolg. Diese Beurteilung Goldmanns dürfte stark übertrieben sein, wenn man bedenkt, daß das Werk vor der Sommerpause ganze acht Vorstellungen erlebte und in der neuen Spielzeit (1943/44) im Oktober nur für drei Vorstellungen wieder aufgenommen wurde. Es wurde abgesetzt, weil das Publikum kein Interesse an der Aufführung gezeigt hatte, obwohl die Kritiken in der Pariser Presse positiv gewesen waren ${ }^{361}$. Knothe lobte besonders die schauspielerischen Leistungen Mary Marquets als Iphigenie. Er meinte zwar, das Pathos der Übersetzung Pierre du Colombiers habe die Leidenschaftlichkeit der Sprache Hauptmanns nur erahnen lassen, doch beurteilte er die Regie Pierre Bertins als geschickt und einfühlsam ${ }^{362}$.

Wie erfolglos und geradezu ruinös sich die Aufführungen deutscher Werke im besetzten Paris gestalten konnten, zeigt das Beispiel von Friedrich For-

357 Ibid. DBP, Knothe an AA, Fernschreiben, Eilt, Betr.: Einladung Gerhart Hauptmann zur französischen Erstaufführung "Iphigenie in Delphi“, 12. 5. 1943.

${ }^{358}$ Ibid. AA an DBP, Betr.: Einladung von Gerhart Hautmann zur frz. Erstaufführung "Iphigenie in Delphi“, 1.7.1943.

${ }_{359}$ AN, AJ40 1001-7, Prop.Abt., Gr.Kult.Th., Tätigkeitsbericht, 26. 5. 1943.

360 Ibid. Tätigkeitsbericht, 30. 6. 1943.

361 JouberT, La Comédie-Française, S. 186; MARSH, Le Théâtre, S. 325.

362 PA-AA, 1142, Kult 12 Nr. 2, DBP, Knothe an AA, 28. 7. 1943, Betr.: Aufführung der „Iphigenie in Delphi“ von Gerhart Hauptmann in der Comédie-Française. 
sters "Robinson soll nicht sterben" in der beschlagnahmten Comédie des Champs-Elysées im September 1943. Vorher hatte das Theaterreferat dieses Haus an eine junge Schauspielertruppe, das Théâtre d'Essai, vermietet. Deren Aufführungen war jedoch nur wenig Erfolg beschieden. Daraufhin sollte die Comédie des Champs-Elysées für jeweils drei Monate an andere Theatertruppen vermietet werden, wobei das Theaterreferat Einfluß im Sinne der Aufführung deutscher Stücke ausüben wollte ${ }^{363}$. Diese Bühne sollte kollaborationswilligen französischen Theatertruppen zur Verfügung stehen. Schließlich hatte das Referat den französischen Regisseur Marist für die Aufführung des Werkes von Forster interessieren können ${ }^{364}$. Allerdings erwies sich auch diese Maßnahme keineswegs als erfolgreich. Der Regisseur des „Robinson“ führte zwar ein deutsches Stück auf, doch verband er damit auch eine finanzielle Unterstützung der deutschen Dienststellen, die er zum Teil erreichte, indem er sie gegeneinander ausspielte. Zunächst einmal stellte ihm das Theaterreferat die Bühne für drei Monate zur Verfügung, was nach Ansicht des Referenten etwa einer Subvention von 100000 Francs entsprach. Unabhängig davon bemühte sich Marist auch beim Deutschen Institut um finanzielle Unterstützung. Epting vermittelte ihm mehrere Zuschüsse der Botschaft, obgleich das Theaterreferat und Knothe dagegen plädierten. Sie befürchteten, es könne der Eindruck entstehen, die Aufführung deutscher Stücke habe automatisch die finanzielle Unterstützung der Besatzungsmacht zur Folge ${ }^{365}$. Um seine Inszenierung auf Theatereinstudierungen im Reich abzustimmen, entschloß sich Marist, mehrere Aufführungen in Deutschland zu besuchen $^{366}$. Als er bei der Botschaft darum bat, in rund zehn deutsche Städte reisen zu dürfen, genehmigte ihm diese drei bis fünf Städte. Erst danach erfuhr die Botschaft, daß Theaterreferat und RMVP diese Reise bereits seit längerem planten, jedoch Marists Bitte um einen Reisekostenzuschuß abgelehnt hatten $^{367}$. Im August 1943 fuhr er nach Deutschland und traf dort Friedrich Forster, Richard Strauß und Franz Lehár ${ }^{368}$. Während die Aufführungen der "Rose Bernd" nicht den Vorstellungen des Theaterreferats entsprochen hatten, aber offenbar beim Publikum relativ erfolgreich gewesen waren, war dies im Falle der Aufführung des „Robinson“ genau umgekehrt. Die Inszenierung entsprach den Vorstellungen des Referats, fand aber nicht das Gefallen des französischen Publikums. So meinte der Theaterreferent zur Premiere des Stückes am 17. September 1943.

363 AN, AJ40 1001-7, Prop.Abt., Gr.Kult.Th., Bericht über den Monat Februar 1943. 364 PA-AA, 1215, Kult 12 Nr. 2, DBP, Piersig, Aufzeichnung für Knothe, Betr.: Theater Marist, Aufführung Robinson soll nicht sterben, 4. 9. 1943.

365 Ibid.

366 AN, AJ40 1001-7, Prop.Abt., Gr.Kult.Th., Tätigkeitsbericht, 24. 7. 1943.

367 PA-AA, 1215, Kult 12 Nr. 2, DBP, Piersig, Aufzeichnung für Knothe, Betr.: Theater Marist, Aufführung Robinson soll nicht sterben, 4. 9. 1943.

368 AN, AJ40 1001-7, Prop.Abt., Gr.Kult.Th., Tätigkeitsbericht, 30. 8. 1943. 
Der Führer der Kinderschar und das junge Mädchen waren fast „deutsch“ in ihrer jugendlichen Frische und Anständigkeit. Sie brachten die lebensbejahende Einfalt und Reinheit des Stückes gut zum Ausdruck und unterschieden sich weit von der üblichen Verdorbenheit Pariser Boulevardschauspieler. Die französische Pressekritik hat das anerkannt. Doch scheint dieser Mangel an Pfeffer auch der Grund für den zunächst schwachen Besuch zu sein ${ }^{369}$.

Die schlechte Aufnahme durch das Publikum änderte sich auch in der Folge nur wenig, obgleich Goldmann im Oktober von schwach ansteigenden Besucherzahlen berichtete ${ }^{370}$. Das sogenannte deutsche Wesen in nationalsozialistischem Sinne voll angeblicher Frische und Anstand kam also nicht sehr gut beim Pariser Publikum an. Da der Theaterreferent sogar selbst von einem „Mangel an Pfeffer" spricht, klingt hier an, daß auch er diese Inszenierung nicht besonders interessant gefunden haben kann. Zudem bemängelte die Botschaft, in den Pressekritiken werde kaum oder gar nicht darauf eingegangen, daß es sich bei dem Stück um ein deutsches Werk handele. Die Zeitungen nannten den Autor fast ausschließlich nur mit dem Nachnamen, so daß der Leser annehmen konnte, es handele sich bei Forster um einen Engländer. Schließlich, so die Botschaft behandelte das Stück einen englischen Stoff, weswegen es für den Zuschauer nicht leicht wäre, „die durch die künstlerische Formung gegebenen deutschen kulturpropagandistischen Ausstrahlungen " 371 zu erkennen. Die Einnahmen der Aufführungen deckten bei weitem nicht die Ausgaben, nicht nur wegen des schlechten Besuchs, sondern auch aufgrund der hohen Kosten. Deswegen versuchte der Regisseur mehrfach bei den unterschiedlichen Dienststellen zusätzliche finanzielle Unterstützung zu erhalten ${ }^{372}$. So wurden von Mai bis Oktober 1943 an die Theatergruppe Marist von der Botschaft insgesamt 715000 Francs gezahlt ${ }^{373}$. Unabhängig davon hatte der Regisseur für seine Produktion 40000 Francs vom französischen Secrétariat des Beaux-Arts erhalten ${ }^{374}$. Zudem hatte er sogar eigenen Besitz verkauft, um die Theaterproduktion selbst mit 800000 Francs zu finanzieren ${ }^{375}$. Am 21. November 1943 wurde das Stück schließlich vom Spielplan abgesetzt ${ }^{376}$. Die Aufführungen von „Robinson soll nicht sterben“" waren also ein finanzieller und kulturpropagandistischer Mißerfolg, während sie aber den Vorstellungen des Theaterreferats von einer sogenannten typisch deutschen Inszenierung entsprachen.

369 Ibid. Tätigkeitsbericht, 29.9.1943.

370 Ibid. Tätigkeitsbericht über den Monat Oktober 1943.

371 PA-AA, 1215, Kult 12 Nr. 2, DBP, Piersig, Aufzeichnung für Knothe, 29. 9. 1943. 372 Ibid.

373 PA-AA, 1215 Kult 12 Nr. 2, DBP, Kasse, Herrn Gesandtschaftsrat Dr. Hofmann, u. Dr. von Kutzschenbach, 8. 3. 1944; siehe auch ibid. Piersig, Aufzeichnung, 6. 10. 1943; ibid. Knothe, Herrn Generalkonsul Gerlach, Aufzeichnung, 6. 10. 1943.

374 F21/5273-1, Ministère de l'Education nationale, Secrétariat des Beaux-Arts, Subventions accordées à des théâtres parisiens, 1940-1944

375 PA-AA, 1215, Kult 12 Nr. 2, DBP, Piersig, Aufzeichnung, 6. 10. 1943.

376 Ibid. DBP, Piersig, Herrn Gesandtschaftsrat Dr. Hofmann, über Dr. von Kutzschenbach, Aufzeichnung, 29. 3. 1944. 
Die Vorstellungen von deutscher Kulturpropaganda waren auch in Bezug auf die Aufführung von deutschen Theaterstücken, die an französischen Bühnen inszeniert wurden, keineswegs deutlich umrissen. Vielmehr waren sie zum Teil widersprüchlich und schwer miteinander zu vereinbaren. Grundsätzlich wollten die deutschen Dienststellen und ihre Vorgesetzten in Berlin der französischen Bevölkerung eine angeblich höherstehende deutsche Kultur vermitteln, die durchdrungen sei vom sogenannten deutschen Wesen. Insbesondere das RMVP hätte idealerweise sogar gerne zeitgenössische Werke - also Autoren mit nationalsozialistischer Tendenz - auf französische Bühnen gebracht. Doch die Pariser Dienststellen versuchten gleichzeitig, den Geschmack des französischen Publikums zu treffen, um auf diese Weise eine positive Resonanz der deutschen Kulturveranstaltungen zu erreichen. Einmal mehr zeigte sich hier die stillschweigende Anerkennung und der Respekt vor der französischen kulturellen Ausstrahlungskraft. Offenbar waren beide Ziele nur schwer miteinander zu vereinbaren, wie die Ausführungen zu Erfolgen und Mißerfolgen der an Pariser Bühnen inszenierten deutschen Stücke deutlich gemacht haben. Entsprach eine Aufführung den Vorstellungen der deutschen Funktionsträger, so kam sie beim Publikum wie im Falle von Forsters „Robinson soll nicht sterben“ nicht an. Die Resonanz des Publikums schien jedoch zumindest positiver zu sein, wenn die Inszenierung das Stück so sehr änderte, daß es in den Augen des deutschen Theaterreferenten kaum noch dem ursprünglichen Werk entsprach. Es schien durch eine "französische Perspektive", der romantisierende Vorstellungen vom "deutschen Wesen“ zugrunde lagen, gewandelt zu sein. Nach Ansicht der deutschen Funktionsträger war die deutsche Dichtung durch die französische Mentalität verändert worden. So entsprach etwa die Inszenierung der „Rose Bernd“ französischen Vorstellungen von deutscher biedermeierlichbajuvarischer Lebensart.

Deutsche Kulturpropaganda im besetzten Paris, verstanden als planmäßige Herausstellung der deutschen Kultur implizierte, daß es tatsächlich eine deutsche Kultur, durchdrungen vom „deutschen Wesen“, gab; wechselseitige Beeinflussung der Kulturen verschiedener Länder sowie eine Internationalisierung der Kultur hatten in dieser Vorstellung keinen Raum. Dementsprechend mußte es auch eine spezifisch französische Kultur, einen Ausdruck der rein „französischen Wesensart“ geben. Wie sie nun die in ihrer eigenen Kultur verhafteten Franzosen von dem angeblich so hohen Wert der deutschen Kultur überzeugen sollten, war offenbar auch den mit dieser Aufgabe befaßten deutschen Dienststellen letztlich ein Rätsel. Besonders widersprüchlich waren auch die inhaltlichen Vorstellungen von dem, was genau die Dienststellen in Paris als "deutsche Kultur" vermitteln wollten. Es sei nur darauf hingewiesen, daß ein Großteil der an französischen Bühnen inszenierten Werke von Hauptmann stammte, weil für die deutschen Dienststellen sein 80. Geburtstag ein willkommener Anlaß war, die Inszenierung deutscher Stücke gegen die Widerstände der französischen Theaterdirektoren durchzu- 
setzen. Tatsächlich war dieser Autor aber im Reich nicht unumstritten, weil seine Stücke aus nationalsozialistischer Sicht als zu depressiv empfunden wurden. Waren Stücke wie „Rose Bernd“ und „Fuhrmann Henschel“ von diesem Standpunkt aus etwa dazu geeignet das "neue Deutschland" in Frankreich zu repräsentieren? Goebbels dürfte dies sicherlich verneint haben. Unter diesen inhaltlichen Gesichtspunkten sind also die kulturpropagandistischen Bemühungen der Besatzungsmacht im Bereich des Theaters gemessen an ihren Zielen - als mißlungen anzusehen.

Die Auswahl der Stücke und damit der Inhalte deutscher Kulturpropaganda, die Initiativen zu Gastspielen, deren Durchführung und propagandistische Begleitung - all diese Aspekte lassen keine planmäßige, inhaltlich auch nur annähernd klar definierte Politik deutscher Kulturpropaganda erkennen. Deutsche Gastspiele und Aufführungen deutscher Theaterstücke waren von vielfältigen Bedingungen und Umständen beeinflußt. Einer der wichtigsten Faktoren war der Konkurrenzkampf der deutschen Dienststellen, der zu einer treibenden Kraft für die Aktivitäten deutscher Kulturpropaganda wurde. Für die im besetzten Paris durchgeführten Gastspiele waren in erstaunlichem Maße auch die Initiativen von Intendanten deutscher Theater und Opernhäuser verantwortlich. Diese nutzten die Situation der Besatzung, die Kulturpolitik der Besatzungsmacht, um endlich einmal in der Kulturmetropole Paris gastieren zu können und verneigten sich damit vor der Ausstrahlungskraft dieser Stadt und der französischen Kultur. Sogar aus den offiziellen Berichten der deutschen Dienststellen, die tendenziell ein eher positiv gefärbtes Bild von Aktivitäten deutscher Kulturpropaganda vermittelten, geht hervor, wie problematisch es war, mit den Aufführungen deutscher Werke auf Pariser Bühnen keine offensichtlichen Mißerfolge zu erzielen.

\subsection{Künstler im Dienste deutscher Kulturpropaganda - Ein Exkurs}

Die Erfolge oder Mißerfolge deutscher Theatergastspiele und Spielfilme hingen im besetzten Frankreich unter anderem davon ab, ob die mitwirkenden deutschen Schauspieler in Frankreich bereits bekannt waren. Den Stars kam sowohl im Reich als auch im Ausland eine propagandistische Bedeutung $\mathrm{zu}^{377}$. In ähnlicher Weise nutzten die deutschen Dienststellen im besetzten Paris auch die Kontakte zu bekannten französischen Künstlern, die stets zu den Empfängen der Deutschen Botschaft und des Deutschen Instituts eingeladen waren, für die Ziele der deutschen Kulturpolitik. Die deutschen Theatergastspiele wurden von ihren Veranstaltern als Ereignisse eines vorgeblich gegenseitigen deutsch-französischen Kulturaustauschs gefeiert. Insbesondere das Beispiel der Pariser Aufführungen des Schillertheaters mit Heinrich George macht deutlich, wie die Besatzungsmacht Kontakte und Begegnun-

377 Siehe beispielsweise KREIMEIER, S. 337-355, das Kapitel: Soldaten der Kunst? Stars der Ufa. 
gen deutscher und französischer Künstler für die deutsche Kulturpropaganda instrumentalisierte. George war in Frankreich vor allem durch seine Filme bekannt. Im Februar 1941 hoben die Presseberichte im Umfeld des Gastspiels des Schillertheaters mit „Kabale und Liebe“ über die Empfänge zu Ehren des Schauspielers ganz besonders die Anwesenheit französischer Künstler sowie anderer bekannter Persönlichkeiten des Theaterlebens hervor. So trug ein Artikel der Pariser Presse den Titel „L'arrivée de Heinrich George, un amical échange d'idées entre artistes français et allemands" 378 , eine weitere Überschrift lautete: „Le grand comédien allemand Heinrich George a reçu l'élite artistique à l'Institut allemand" 379 . Die Empfänge und Veranstaltungen, die das umfangreiche Begleitprogramm zum Gastspiel bildeten, waren vor allem auf die Person Georges ausgerichtet ${ }^{380}$. Als George am 22. Februar zunächst ohne sein Ensemble am Pariser Bahnhof eintraf, war die Pariser Presse zugegen. Er wohnte im prestigeträchtigen Hotel Ritz und gab dort am darauffolgenden Morgen den ersten der zahlreichen Presseempfänge während seines Aufenthaltes. Noch an demselben Abend absolvierte er eine Lesung mit Auszügen aus Werken deutscher Schriftsteller und des französischen Autors Victor Hugo. Anwesend waren neben Botschafter Abetz und seiner Frau vorwiegend deutsche Offiziere und die „bekanntesten Persönlichkeiten des französischen Geistes-, Theater- und Wissenschaftslebens" 381 . Das geladene Publikum soll George gefeiert haben. Ein von der Botschaft organisiertes geselliges Beisammensein beendete den Abend. Lesungen waren eigentlich im französischen Literaturbetrieb völlig unüblich, was bei deutschen Dichterlesungen abgesehen von den Sprachschwierigkeiten nicht gerade zu ihrem Erfolg beitrug. Aus diesem Grund schlug sogar Knothe im September 1943 vor, auf deutsche Lesungen solle zukünftig vollständig verzichtet werden, weil sie beim französischen Publikum nicht ankä$m^{2}{ }^{382}$. So wird es also den geladenen Gästen, der Werbung des Deutschen Instituts und der Starpersönlichkeit Georges zu verdanken sein, daß die obige Veranstaltung in der Presse ein positives Echo erhielt und sogar in der französischen Wochenschau gezeigt wurde ${ }^{383}$. Am Abend der Lesung traf

378 Zit. n. CDJC, Le Film, Nr. 10, 1. 3. 1941

379 Ibid.

380 PA-AA, 1379, Kult 12 Nr. 2, DIP, Bökenkamp an AA, Betr.: Kult K - Gesamtbericht über die Veranstaltungen anläßlich des Gastspiels des Schiller-Theaters in Paris, 5. 3. 1941.

${ }^{381}$ Unter der Auswahl an deutschen Autoren waren Friedrich von Schiller, Johann Wolfgang von Goethe, Heinrich von Kleist, Matthias Claudius, Karl Hans Jacob, Hermann Stehr, Wilhelm Busch, Christian Morgenstern; PA-AA, 1379, Kult 12 Nr. 2, DIP, Bökenkamp an AA, Betr.: Kult $\mathrm{K}$ - Gesamtbericht über die Veranstaltungen anläßlich des Gastspiels des Schiller-Theaters in Paris, 5. 3. 1941.

382 PA-AA, 1144-1, D Kult 1 Nr. 1, DBP, Knothe an AA, 11. 9. 1943.

383 PA-AA, 1379, Kult 12 Nr. 2, DIP, Bökenkamp an AA, Betr.: Kult K - Gesamtbericht über die Veranstaltungen anläßlich des Gastspiels des Schiller-Theaters in Paris, 5. 3.1941 . 
auch das Ensemble des Schillertheaters in Paris ein, dessen Ankunft sofort mit einer weiteren Pressekonferenz am Morgen des 24. November flankiert wurde. Mittags veranstaltete die deutsche Filmverleihgesellschaft ACE einen Empfang zu Ehren Georges, zu dem erneut französische Filmschauspieler und speziell die Filmpresse geladen wurden. Abends verfolgte das deutsche Ensemble eine Aufführung von Shakespeares „La nuit des rois“ (Was Ihr wollt") an der Comédie-Française. In der Pause wurde im Künstlerfoyer ein Empfang gegeben, bei dem es laut offiziellem Bericht zu einem persönlichen Kontakt zwischen beiden Ensembles gekommen sein soll. Das Deutsche Institut betonte, das Schillertheater sei mit liebenswürdiger Gastfreundschaft empfangen worden und die französischen Künstler hätten den deutschen ihre Künstlerlogen für den Abend der Aufführung von „Kabale und Liebe“ gerne zur Verfügung gestellt ${ }^{384}$. Daß die Reaktion der französischen Seite nicht unbedingt so positiv war wie hier beschrieben, geht aus einem Bericht des Theaterreferenten der Propaganda Staffel hervor. Dort heißt es, ein Schauspieler der Comédie-Française habe seine Kollegen gewarnt, sie sollten ihre Sachen aus den Garderoben entfernen, weil sie ansonsten von den deutschen Schauspielern beklaut würden. Angeblich sollen einige seiner Kollegen daraufhin gegen diesen „taktlosen Ausspruch“ ${ }^{385}$ protestiert haben.

Nach umfangreichen vorbereitenden Veranstaltungen führte das Ensemble des Schillertheaters schließlich am 25. Februar 1941 „Kabale und Liebe“ in der ausverkauften Comédie-Française auf. Anwesend waren neben Abetz und seiner Frau auch hohe Offiziere der Wehrmacht. Aus Berlin waren sogar der Stadtpräsident von Steeg sowie der Reichsdramaturg Rainer Schlösser gekommen; auf französischer Seite verfolgten das Gastspiel Fernand de Brinon und andere Persönlichkeiten des französischen Theater- und Geisteslebens, wie es in dem Bericht des Deutschen Instituts heißt. Der Aufführung wohnten fast sämtliche Pariser Theaterdirektoren, zahlreiche Schauspieler und Schriftsteller und beinahe alle Mitglieder, die sociétaires, der Comédie-Française bei. Zur Reaktion des Publikums, das angeblich vorwiegend aus Franzosen bestanden haben soll, heißt es: „Der Beifall, teilweise auf offener Szene, war sehr groß"386. Freilich schloß sich erneut ein sogenanntes geselliges Beisammensein an. Die Zeitungen lobten die Aufführung, die am darauffolgenden Tag wiederholt wurde und erneut ausverkauft war. Nach dem enormen Aufwand zur Vorbereitung des Gastspiels mag dies kaum verwundern. Auch der Ausverkauf des Hauses verliert an Bedeutung, wenn man bedenkt, daß es

384 Ibid.

385 AN, AJ40 1001-7, Prop.St., Gr.Kult.Th., Tätigkeitsbericht für die Zeit vom 19.25. 2. 1941; zu dem Vorfall siehe auch JouBerT, La Comédie-Française, S. 166.

386 PA-AA, 1379, Kult 12 Nr. 2, DIP, Bökenkamp an AA, Betr.: Kult K - Gesamtbericht über die Veranstaltungen anläßlich des Gastspiels des Schiller-Theaters in Paris, 5.3. 1941. 
sich nur um zwei Vorstellungen gehandelt hat, zu denen Institut und Botschaft etliche Personen eingeladen hatten ${ }^{387}$.

Sogar nach den Vorstellungen des Schillertheaters wurden weiterhin noch Empfänge und Begegnungen mit französischen Künstlern organisiert, die eine Atmosphäre von gleichberechtigtem Kulturaustausch und Freundschaft propagieren sollten. Zu den Begegnungen des Ensembles des Schillertheaters mit dem der Comédie-Française meinte der Theaterreferent des Deutschen Instituts, die hohe Qualität beider Truppen habe die Begegnungen erleichtert und es habe sich ein "herzliches Verhältnis" 388 entwickelt. Am 27. Februar sah das Ensemble des Schillertheaters auf Einladung des Theaterdirektors Jacques Hébertot eine Aufführung der „Kameliendame" im Théâtre des Arts. Wiederum trafen sich nach der Vorstellung deutsche und französische Schauspieler zu einem, wie es heißt, freundschaftlichen Beisammensein. Bei einem weiteren Empfang, den Abetz am selben Abend in der Botschaft gab, sollen französische Schauspieler und Intellektuelle ihren deutschen Kollegen angeblich ganz zwanglos begegnet sein. Sogar das Frühstück des darauffolgenden Tages stand wieder unter dem Stern der Propagierung deutsch-französischer Begegnung. Einige Pariser Theaterdirektoren luden Heinrich George, Paul Wegener und Ernst Legal zu einem intimen Frühstück ein, wobei sie noch einmal ihren Beifall für die Aufführungen des Schillertheaters zum Ausdruck gebracht haben sollen. Auch dieses Essen soll angeblich zu einer Vertiefung der Beziehungen zwischen den Künstlern beider Länder beigetragen haben ${ }^{389}$. Am Nachmittag fand sich das deutsche Ensemble bei der Union des Artistes, dem französischen Schauspielerverband, wiederum $\mathrm{zu}$ einer angeblich intensiven deutsch-französischen Begegnung ein. Das Deutsche Institut notierte, die französischen Ansprachen hätten gezeigt, daß die französischen Künstler einer Zusammenarbeit im künstlerischen und geistigen Bereich zustimmen würden. Am nächsten Nachmittag besuchte das deutsche Ensemble eine Aufführung von Gustave Flauberts „Madame Bovary“ im Théâtre Montparnasse, dessen Direktor Gaston Baty sich persönlich um die deutschen Gäste kümmerte. Danach resümierte das Deutsche Institut:

Der Erfolg des Gastspiels und aller damit verbundenen Veranstaltungen für eine deutsch-französische Verständigungsarbeit war noch größer als man vorher erwarten konnte. Das Gastspiel war lange Zeit das Tagesgespräch des geistigen Paris und wird noch lange als ein Markstein deutscher Kulturpolitik in Frankreich gelten dürfen ${ }^{390}$.

387 Zudem gab das Ensemble noch am 28. Februar und 1. März zwei von der KDF organisierte Aufführungen vor Wehrmachtsangehörigen im Thêâtre des Champs-Elysées. 388 PA-AA, 1379, Kult 12 Nr. 2, DBP, Epting an AA, 12. 3. 1941, Anlage, Bericht über die Weiterentwicklung des Theaterwinters in Paris, Kaspar Pinette.

389 PA-AA, 1379, Kult 12 Nr. 2, DIP, Bökenkamp an AA, Betr:: Kult K - Gesamtbericht über die Veranstaltungen anläßlich des Gastspiels des Schiller-Theaters in Paris, 5. 3. 1941 .

390 PA-AA, 1379, Kult 12 Nr. 2, DIP, Bökenkamp an AA, Betr.: Kult K - Gesamtbe- 
Sicherlich ist diese Einschätzung übertrieben. Mit dem ausgesprochen umfangreichen Rahmenprogramm zu dem Gastspiel, das sich wie ein Marathon für George und sein Ensemble liest, versuchten die Organisatoren die Resonanz in der Presse zu steigern. Die Vielzahl an Veranstaltungen sollte den Erfolg des Gastspieles sichern und die französischen Künstler und Intellektuellen Glauben machen, die Besatzungsmacht sei tatsächlich an einem deutschfranzösischen Kulturaustausch interessiert. Das Deutsche Institut benutzte hier das Gastspiel zur Propagierung einer deutsch-französischen Kollaboration. Sowohl die deutschen wie auch die französischen Künstler standen hier gleichermaßen - ob gewollt oder ungewollt - im Dienste deutscher Kulturpropaganda. Die tatsächliche Wirkung dieser Politik auf die französische Seite sei hier jedoch dahingestellt. So war beispielsweise die vielzitierte Freundschaft zu den Künstlern der Comédie-Française sicherlich mehr als übertrieben, denn deren Leitung versuchte in der Folge mehrfach, weitere deutsche Gastspiele an ihrer Bühne abzuwehren. Und die Propaganda Staffel notierte nur wenige Monate später, einige Mitarbeiter dieser Bühne hätten den Plan, im Falle eines weiteren deutschen Gastspiels die Lichtanlagen zu sabotieren ${ }^{391}$.

Gastspiel und Begleitveranstaltungen stellten die Person Georges besonders in den Vordergrund, weshalb sich eine Nachbereitung der Veranstaltung - im Sinne deutscher Kulturpropaganda - durch den Schauspieler anbot. George schrieb in Erinnerung an seinen Paris-Aufenthalt einen französischsprachigen Artikel in den Deutsch-französischen Monatsheften. In „Visite à Paris" zitiert George allgemein die Pariser Presse, die betont hatte, wie sehr der Besuch des Schilltheaters zu einem deutsch-französischen Kulturaustausch beigetragen habe. George schildert den freundlichen und höflichen Empfang der französischen Schauspieler der Comédie-Française. In Gesprächen sei zum Ausdruck gekommen, daß alle ein gemeinsamer Geist verbinde, der sich in einem Zitat Schillers am besten ausdrücken lasse: „Tout art est voué à la joie, et rendre l'homme heureux est sa mission suprême "“392! Die Be-

richt über die Veranstaltungen anläßlich des Gastspiels des Schiller-Theaters in Paris, 5. 3. 1941.

391 AN, AJ40 1001-7, Prop.St., Gr.Kult.Th., Tätigkeitsbericht, 27. 6. 1941; zur abwehrenden Haltung siehe auch JOUBERT, La Comédie-Française, S. 167. Als das Schillertheater noch in Paris weilte, gab die Comédie-Française zwei literarische Matineen am 21. und 28. Februar 1941. Es wurden Auszüge aus Goethes Faust I und II, in einer Übersetzung von Gérard de Nerval gebracht. Der bekannte Schauspieler Jean Louis Barrault las den Mephisto, Julien Bertheau übernahm die Rolle des Faust und Madeleine Renaud die des Gretchens. Laut Bericht der Botschaft war das Theater zu beiden Terminen voll besetzt, und das Publikum soll angeblich starken Beifall gespendet haben; PA-AA, 1379, Kult 12 Nr. 2, DBP an AA, Betr.: Faustlesungen in der ComédieFrançaise, 3. 3. 1942. Dennoch gelang es der Führung dieses Theaters in der Folge, eine weitere deutsche Einflußnahme auf die literarischen Matinéen zu verhindern, siehe JOUBERT, La Comédie-Française, S. 315.

392 Heinrich GEORGE, Visite à Paris, in: DFMH 3-4 (1941) S. 107 f. 
gegnung mit den französischen Kollegen habe die Bereitschaft zur Kollaboration gezeigt, um ein „Europa neuer Ordnung“ aufzubauen. Besonders nach dem Gastspiel hätten die französischen Schauspieler dem ganzen Ensemble des Schillertheaters begeistert die Hände geschüttelt. Er habe deutlich ihre Dankbarkeit dafür gespürt, daß die deutsche Theatertruppe nicht als Sieger zu den Besiegten kam, sondern daß das génie de l'art der einzige Sieger gewesen sei ${ }^{393}$.

Auch im November 1943, als das Schillertheater zum zweiten Mal mit Heinrich George auf Einladung des Deutschen Instituts nach Paris kam, diente George als Zugpferd deutscher Kulturpropaganda. Die Vorankündigungen zu Calderons „Richter von Zalamea“ zielten erneut vor allem auf die Person Georges ab. So betonte Le Petit Parisien, George sei mit Filmen wie "Maître de Poste“, „Le Juif Suss" und „L'Implacable destin“ als Filmschauspieler in Frankreich längst bekannt; außerdem bezeichnete er das Gastspiel als Förderung eines rapprochement spirituel zwischen Deutschland und Frankreich ${ }^{394}$. Wiederum begleiteten zahlreiche Empfänge das Gastspiel, die den Kulturaustausch zwischen beiden Ländern symbolisieren sollten. Knothe kritisierte dieses Mal jedoch in seinem Bericht, daß die Werbung etwa in der Presse allein auf George als bekanntem Filmkünstler abzielte. Demnach wurde George zu sehr als individueller Künstler gefeiert, während das Ensemble und die allgemeinen Leistungen des deutschen Theaters dahinter zurücktraten. Das deutsche Theater an sich hätte stärker als kultureller Wert präsentiert werden müssen ${ }^{395}$. Hier wird erneut deutlich, wie problematisch die Vorstellungen von deutscher Kulturpropaganda waren. Zum einen spannten die deutschen Dienststellen bekannte Schauspieler wie George für die Zwecke der Kulturpropaganda ein und nutzen damit die individuelle Star-Wirkung. Zum anderen sollten die Schauspieler trotzdem nicht nur als Individuen gefeiert werden, sondern das deutsche Theater in seiner Gesamtheit repräsentieren.

Die Berichte und Pressekritiken zu dem Gastspiel vor französischem Publikum waren wie im Falle der übrigen Gastspiele positiv. Auch hier betonte Knothe die Wirkung Georges. So soll das Publikum vor allem von seiner Darstellungskunst begeistert gewesen sein. Das Gastspiel habe eine Aufnahmebereitschaft der Franzosen für deutsches Schauspiel in Paris deutlich werden lassen, die positive Resonanz beim Publikum sei offensichtlich gewe$\operatorname{sen}^{396}$. Dies ist angesichts der Tatsache, daß das Gastspiel vor geladenem Pu-

393 Ibid. S. 108. George erwähnte unter anderem Begegnungen mit Künstlern wie Sacha Guitry und Pierre Renoir sowie den Theaterdirektoren Gaston Baty und Jacques Hébertot.

${ }^{394}$ BN-BA, Le celèbre acteur Heinrich George et la troupe du Schilltertheater de Berlin joueront ce soir à la Comédie-Française, Le Petit Parisien, 3. 11.1943.

395 PA-AA, 1215, Kult 12 Nr. 2, DBP, Knothe an AA, Betr.: Gastspiel des Berliner Schillertheaters am 3. 11. 1943 in Paris, 31. 1. 1944. (auch BAB, 50.01-291) 396 Ibid. 
blikum stattfand, nicht unwahrscheinlich. Le Petit Parisien lobte neben Bühnenbild und Inszenierung die Darstellungsweise der Schauspieler. Auch hier betonte die Zeitung, die Zuschauer seien auch dann begeistert gewesen, wenn sie selbst der deutschen Sprache nicht mächtig waren. ${ }^{397}$ Der Kritiker HenriRené Lenormand betonte, wie gut solche künstlerischen Leistungen gerade mitten im Krieg für die Völkerverständigung seien:

Il est bon qu'au moment ou des forces de destruction semblent se déchaîner contre l'espèce, de telles croisades soient entreprises. Il est bon que des rapports internationaux et interprofessionnels se renouent entre artistes et que Schiller, Calderon, Molière et Shakespeare voyagent ainsi d'un pays à l'autre ${ }^{398}$.

$\mathrm{Da} ß$ bei der Instrumentalisierung deutscher wie französischer Künstler für die deutsche Kulturpropaganda auch Pannen passieren konnten, zeigt das Beispiel des Schauspielers Harry Baur, dem George ebenfalls während seines Aufenthaltes in Paris begegnete. Während der dreißiger Jahre war Baur als Schauspieler in Frankreich mit George verglichen worden. Die Freundschaft $z$ wischen George und Baur wurde nun in der Presse besonders betont. Fotos zeigten beide Arm in Arm, was das Mißfallen des Theaterreferats erregte, da Baur, wie bereits ausgeführt wurde, in Verdacht stand, jüdischer Herkunft zu sein. Das Referat verbot daraufhin die Veröffentlichung weiterer Aufnahmen, die eine „Verbrüderung " 399 beider Schauspieler zeigten.

Die Besatzungsmacht nutzte also grundsätzlich den Besuch der deutschen Schauspieler in Paris, um deutsch-französische Begegnungen von Künstlern zu inszenieren. So wurde der Anschein eines Kulturaustauschs und einer Kollaboration beider Länder erweckt. Diesen Eindruck versuchten die deutschen Dienststellen nicht nur durch Empfänge, sondern auch über Reisen französischer Künstler und Intellektueller nach Deutschland zu vermitteln. Ende 1941 fuhren beispielsweise französische Musiker zur Mozartwoche nach Wien, um den 150 . Todestag des Komponisten zu feiern. Drieu La Rochelle, Ramon Fernandez, André Fraigneau, Robert Brasillach, Jacques Chardonne und Marcel Jouhandeau verbrachten im Oktober 1941 drei Wochen in Deutschland. Anlaß für diese Reise war der sogenannte europäische Schriftstellerkongreß in Weimar. Im Januar 1942 begaben sich französische Maler nach Berlin. Verschiedene Sänger, darunter Maurice Chevalier, Edith

397 PA-AA, 1215, Kult 12 Nr. 2, Heinrich George et la troupe du Schillertheater de Berlin ont emporté un triomphe à la Comédie-Française, in: Le Petit Parisien, 4. 11. 1943; die Zeitung schrieb weiter: „De telles beautés sont rares au théâtre, et ceux qui ont eu le privilège d'assister, hier soir, à la représentation de l'Alcade de Zalamea emporteront le souvenir d'un spectacle dont la perfection et la qualité attestent l'exceptionnel éclat du théâtre en Allemagne, en dépit de la guerre terrible que la nation mène en Europe “ (Ibid.).

398 BN-BA, H.-R. LENORMAND, L'Alcade de Zalamea et le Schiller-Theater, in: Panorama, 11.11.1943.

399 AJ40 1001-7, Prop.St., Gr.Kult.Th., Tätigkeitsbericht, 27. 2.-4. 3. 1941. Zu dem Fall der Anschuldigungen und der Verhaftung von Harry Baur durch die Sipo-SD siehe Kapitel II. 2.2. dieser Arbeit. 
Piaf, Charles Trenet, Jane Sourza, Fréhel und Lys Gauty fuhren nach Deutschland, um Vorstellungen für französische Kriegsgefangene oder Arbeiter zu geben. Serge Lifar, ein bekannter Tänzer und Choreograph, reiste 1942 drei Mal nach Deutschland ${ }^{400}$. Presseberichte zu diesen Reisen dienten häufig der Propagierung eines positiven Bildes des nationalsozialistischen Deutschland.

Auf Goebbels Initiative wurde seit dem Sommer 1941 auch eine Reise französischer Filmschaffender und Theaterschauspieler nach Deutschland geplant und organisiert. Im Juli 1941 forderte das RMVP bei der Propaganda Abteilung eine Liste mit Schauspielern und Regisseuren an, die für eine solche Reise nach Deutschland in Frage kämen ${ }^{401}$. Wenig später teilte das RMVP Diedrich noch einmal mit, Goebbels lege großen Wert auf diese Liste. Diese Reise sowie ein Empfang der französischen Künstler bei der Reichsregierung müsse möglichst bald verwirklicht werden. Auch könne das Referat Filmautoren und Filmkritiker in die Liste mit einbeziehen ${ }^{402}$. Sowohl die Gruppe Kultur der Propaganda Staffel als auch das Referat Film sandten daraufhin Namenslisten nach Berlin ${ }^{403}$. Im August legte das RMVP den Termin der Reise auf den Herbst des Jahres ${ }^{404}$ fest, im Dezember wurde er jedoch auf Veranlassung von Goebbels auf Februar 1942 verschoben. Allerdings gaben etliche Schauspieler an, durch Theaterverpflichtungen nicht zu diesem Termin an der Reise teilnehmen zu können. Außerdem wies das Referat Film darauf hin, daß Sacha Guitry und dessen Frau bereit wären, mitzufahren, doch müsse man in dem Falle aufgrund persönlicher Animositäten mit Absagen der übrigen Filmschauspieler rechnen ${ }^{405}$. Erst am 18. März 1942 fuhren schließlich die Schauspieler Danielle Darrieux, Viviane Romance, Junie Astor, Suzy Delair, Albert Préjean, René Dary, der Filmautor André Legrand und Pierre Heuzé, ein Journalist von Ciné-Mondial, nach Berlin, Diedrich war Reiseleiter ${ }^{406}$. Am Abend vor der Abreise hatte Schmidtke zu Ehren der genannten Künstler ein Essen im Ritz gegeben, an dem unter anderem auch Greven von der Continental und Knothe von der Deutschen Botschaft teilnahmen. Der Sonderbericht des Referats über diese Reise besteht zum groBen Teil aus einer Liste zahlloser Empfänge und Festessen, die für die Reisegruppe in Deutschland gegeben wurden sowie aus genauen Aufzählungen zu den jeweils anwesenden deutschen bekannten Persönlichkeiten des kulturellen Lebens. Ein Großteil dieser Veranstaltungen wurde durch eine ständige

400 RAGACHE, La Vie quotidienne, S. 156-161.

401 BA-MA, RW35 222, Prop.Abt., Ref.Film, Tätigkeitsbericht, 2. 7.-9. 7.1941.

402 Ibid. Tätigkeitsbericht, 25. 7.-31. 7. 1941.

403 Ibid. Tätigkeitsbericht, 1. 8.-7. 8. 1941; ibid. RW35 224, Prop.Abt., Ref.Film, Tätigkeitsbericht, 20.12.1941-2.1.1942.

404 Ibid. RW35 222, Prop.Abt., Ref.Film, Tätigkeitsbericht, 8. 8.-15. 8. 1941.

405 BA-MA, RW35 224, Tätigkeitsbericht, 20. 12. 1941-2. 1. 1942.

406 BA-MA, RW35 225, Gr.Film, Tätigkeitsbericht, 20.3. 1942. Zu dieser Reise siehe bei Thalmann, S. 209-211. 
Berichterstattung sowohl in den deutschen als auch in den französischen Zeitungen begleitet ${ }^{407}$.

Nach ihrer Ankunft in Berlin empfing zunächst das AA die Künstler am 19. März 1942 im Auslandspresseclub des Auswärtigen Amtes. Anschließend besichtigten sie die Studios des deutschen Fernsehrundfunks, wo den Gästen die Fortschritte des deutschen Fernsehens erklärt wurden. Abends gab Carl Froelich, der Präsident der Reichsfilmkammer, für die Gruppe einen Empfang. Anwesend waren unter anderem Hippler, Reichsfilmintendant und Leiter der Abteilung Film im RMVP, von Eicke von der Continental, die Schauspielerin Marika Rökk mit Ehemann Georg Jacoby, Henny Porten, Mathias Wiemann, sowie Harry Baur, der zu diesem Zeitpunkt „Symphonie eines Lebens" in Berlin drehte. Am Abend des 20. März besuchte die Reisegruppe die deutsche Uraufführung des von der Continental produzierten Filmes "Premier rendez-vous" (1941) von Henri Decoin mit Danielle Darrieux in deutscher Synchronisation. Der Film war in Deutschland relativ erfolgreich. Diedrich schrieb am 22. März an das Referat Film:

Melde als stärkste bisherige Eindrücke den Erfolg der Berliner Uraufführung von „Premier rendez-vous". Die Besucher brachen schon bei der Aufführung des Films in spontanen Beifall aus, der sich am Schluß in einem derartigen Applaus kundtat, daß Darrieux mehrfach auf das Drängen des Publikums auf der Bühne erscheinen mußte ${ }^{408}$.

Der Sonderbericht über die Reise betonte, der Empfang nach dieser Vorführung habe die französischen Künstler „mit führenden Persönlichkeiten des deutschen Films, mit zahlreichen deutschen Filmschaffenden und Vertretern der deutschen Presse ${ }^{\text {" } 409}$ zusammengeführt. Freilich fehlte bei dem BerlinBesuch auch nicht eine Besichtigung der Ufa-Studios im nahegelegenen Babelsberg, den die Deutsche Wochenschau filmte. In der Kantine, so wird berichtet, sollen die Künstler unter anderem Brigitte Horney, Lotte Koch, Marina von Dittmar, Karl Ritter und Max Walter Kimmich begegnet sein. Ferner stand auch der Besuch eines größeren Betriebes in Berlin-Reinickendorf auf dem Terminplan. Diedrich schrieb dazu: „Die Filmschaffenden besuchten einen Berliner Betrieb, in dem mehrere 100 französische Arbeiter beschäftigt sind, und wo ein bunter Nachmittag für diese Arbeiter mit französischen Artisten, die z.Zt. in Deutschland vor französischen Arbeitern spielen, veranstaltet wurde ${ }^{* 410}$. Die Franzosen sollen die Künstler mit begeisterten Zurufen empfangen haben. Ein französischer Arbeiter des Betriebes soll angeblich seinen Dank an die Künstler mit der Feststellung verbunden haben, die anwesenden französischen Arbeitskräfte wollten eine „nationale und

407 Die Ausführungen zu der Reise beruhen im wesentlichen auf diesem Sonderbericht: BA-MA, RW35 225, Prop.Abt., Gr.Film, Zusammenfassender Bericht über die Reise französischer Filmschaffender nach Deutschland in der Zeit vom 18.-31. 3. 1942.

408 Ibid. Tätigkeitsbericht, 28. 3. 1942.

409 Ibid.

410 Ibid. 


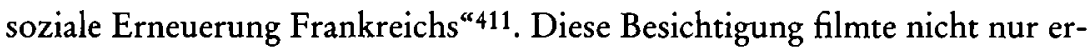
neut die Wochenschau, sondern es wurden auch Aufnahmen für einen Propagandafilm zur Anwerbung französischer Arbeitskräfte gemacht, der in Vorbereitung war.

Höhepunkt des Aufenthaltes in Berlin war, so der Bericht, ein abendlicher Empfang im Hause von Goebbels. Neben ihm und seiner Frau befanden sich unter den deutschen Gästen wiederum Fritz Hippler und Carl Froelich, der bekannte Schauspieler und Regisseur Wolfgang Liebeneiner, Emil Jannings, Arno Breker, Marika Rökk und Brigitte Horney. Laut Bericht hinterließ die Begegnung mit Goebbels angeblich einen tiefen Eindruck bei den französischen Künstlern. Weiter fuhr die Reisegruppe nach Wien, wo sie ebenfalls zu verschiedenen Anlässen mit weiteren Funktionsträgern und bekannten Schauspielern zusammentraf. Zu nennen wären unter anderem Reichsstatthalter Baldur von Schirach, Richard Strauß, Willi Forst, Heinrich George, Paul Hörbiger und Gustav Ucicky. Ein weiteres Reiseziel war München, wo die Künstler unter anderem das „Braune Haus“ und die sogenannten Führerbauten besichtigten. Angeblich sollen die französischen Gäste davon beeindruckt gewesen sein: „Sie, die bis dahin vom Führer gewiß keine rechte Vorstellung hatten, erlebten ihn hier auch als Künstler und großzügigen Förderer aller Künste "412. Während eines offiziellen Frühstücks mit Münchner Intendanten und Bühnenleitern am 28. März, zwei Tage vor der Rückreise nach Paris, hielt Albert Préjean eine Tischrede: „Herr Préjean sagte bei der Gelegenheit, daß die französischen Filmschaffenden außerordentlich beeindruckt und ergriffen seien vom Geiste der Begegnung in München, und daß sie nach diesem Erleben als die besten Propagandisten des neuen Deutschland nach Paris zurückkehrten"413. In diesem Sinne wurden die gewonnenen Reiseeindrücke nach der Rückkehr der Gruppe in der Pariser Presse verwertet. Am 3. April 1942 veranstaltete die Propaganda Staffel Paris ein Abschlußessen für alle Teilnehmer der Reise; Marika Rökk und Georg Jacoby, die in Paris weilten, waren auch anwesend. $\mathrm{Zu}$ dem anschließenden Presseempfang erschienen außer der Presse auch Vertreter von Radio Paris und von der Wochenschau. Eine Woche später schilderte Pierre Heuzé, Hauptschriftleiter von Ciné Mondial, seine Eindrücke auf einem weiteren Presseempfang. André Legrand hielt eine Rede mit dem Titel „Die Augen eines französischen Autors sehen Deutschland“414. In den Presseberichten kam immer wieder ein besonders positives Bild des nationalsozialistischen Deutschland zum Ausdruck. Der Bericht des Referats Film war sehr positiv gehalten. Eventueller Druck, der auf die Reisegruppe ausgeübt wurde, oder etwaige Unstim-

411 Ibid.

412 BA-MA, RW35 225, Prop.Abt., Gr.Film, Zusammenfassender Bericht über die Reise französischer Filmschaffender nach Deutschland in der Zeit vom 18. 3.-31.3. 1942.

413 Ibid.

414 Ibid. Tätigkeitsbericht, 4. 4.-11. 4. 1942. 
migkeiten sind darin verschwiegen worden ${ }^{415}$. So unternahm beispielsweise Danielle Darrieux diese Reise, um ihren in Deutschland inhaftierten Verlobten wiederzusehen. Nach einem dreitägigen Aufenthalt in Berlin weigerte sie sich, weiter mit zu reisen. Im Anschluß an die Rückkehr der Gruppe nach Paris wurde sie deswegen gezwungen, fünfzehn Monate in Megève unter deutscher Beobachtung zu verbringen ${ }^{416}$. Offenbar war Goebbels aber mit dem propagandistischen Ergebnis dieser Reise zufrieden, denn er sprach ausdrücklich den Wunsch aus, „daß die Reisen weiter durchgeführt werden sollen “417. In der Folge führte das Referat Film zwar entsprechende Verhandlungen, doch kam es letztendlich zu keiner weiteren Reise von französischen Schauspielern in das nationalsozialistische Deutschland. Ausschlaggebend waren mehrfach terminliche Probleme und schließlich mußten die Vorbereitungen zu einer weiteren Reise im Zuge der Umorganisation der Gruppe Film zur reinen Filmprüfstelle im Sommer 1942 an Knothe von der Deutschen Botschaft abgegeben werden ${ }^{418}$.

Nach Ende der Besatzungszeit ist im Zuge der Épuration den französischen Künstlern, die Reisen ins Reich unternommen hatten, oft vorgeworfen worden, sie hätten mit den Besatzern kollaboriert. Außerdem wurden etliche Künstler der Kollaboration beschuldigt, weil sie im besetzten Paris auch weiterhin aktiv gewesen waren und sich mit den nationalsozialistischen Besatzern arrangiert hatten ${ }^{419}$. Zur Rechtfertigung dieses Verhaltens ist unter anderem das Argument angeführt worden, sie hätten die französische kulturelle Ausstrahlungskraft erhalten. Ein blühendes Kulturleben hätte den Zuschauern Freude und Ablenkung vermittelt und ihnen die Möglichkeit gegeben, den Alltag der Besatzung zu vergessen. Schließlich hätten auch die Künstler weiterhin ihren Unterhalt verdienen müssen. Außerdem impliziere im allgemeinen das Metier der Schauspieler die Tatsache, daß sie im Licht der Öffentlichkeit stehen, was während der Okkupation notgedrungen auch zu Kontak-

415 Dies zeigt beispielsweise der Vergleich mit Franks Bericht über die Reise französischer Musiker zur Reichs-Mozartwoche in Wien. Frank war hier Reiseleiter gewesen. Sein Vorgesetzter Lucht kürzte den Bericht dazu um eine mehrere Seiten umfassende Passage, in der auch negative Aspekte der Reise zur Sprache kamen und detailliert Unstimmigkeiten zwischen Angehörigen der Deutschen Botschaft und Frank dargelegt wurden (AN, AJ40 1002-2, Prop. St., Gr.Kult.Th., Bericht über die Reichs-Mozartwoche in Wien, 15. 12. 1941).

416 BeRTiN-MAGHIT, Le Cinéma sous l'Occupation, S. 167. Unter der Androhung von Repressionen gegen ihren Verlobten, hatte Darrieux einen Vertrag für drei Filme mit der Continental abgeschlossen. Abgesehen von „Premier rendez-vous" spielte sie in "Caprices" von Léo Joannon und in "La Fausse maîtresse" von André Cayatte. 417 BA-MA, RW35 225, Prop.Abt., Gr.Film, Tätigkeitsbericht, 4. 4.-11. 4. 1942.

$418 \mathrm{Zu}$ den Vorbereitungen siehe ibid. RW35 226, Prop.Abt., Tätigkeitsberichte, 2. 5. 9.5.1942; 15.-23.5. 1942; 23.5.-1.6.1942; 1.6.-6.6.1942; 3.7.1942 und 18.7.-24.7.1942. ${ }^{419}$ Zur Epuration von Schauspielern und Regisseuren vor allem im Bereich des Filmes siehe die umfassende Darstellung von BERTIN-MAGHIT, Le Cinéma sous l'Occupation, S. 191-239, im Anhang S. 393-436. Für den Bereich des Theaters siehe ADDED, Le Thêâtre, S. 311-328. 
ten mit den Besatzern geführt habe ${ }^{420}$. Inwiefern die französischen Künstler nun kollaborierten, indem sie während der Okkupation an den offiziellen Reisen nach Deutschland - oder an den Pariser Empfängen der Botschaft teilnahmen, sei hier dahingestellt. In jedem Falle stießen die Besatzer mit ihren Einladungen nicht nur auf Ablehnung; es war durchaus möglich, beispielsweise unter Angabe von Terminschwierigkeiten die Teilnahme an den Reisen abzulehnen. Über die Reisen französischer Künstler nach Deutschland schmückte sich der nationalsozialistische Staat gleichsam mit den französischen Stars und vermittelte damit der Öffentlichkeit den Anschein einer kulturellen Toleranz. Bei ihrer Rückkehr galten die Künstler in der Presse als Zeugen für ein positives Bild des "neuen Deutschland“. Ob nun freiwillig oder unfreiwillig - bekannte französische Künstler wurden auf diese Weise Teil der von den Nationalsozialisten verfolgten Kulturpropaganda.

Die zahlreichen Empfänge, die anläßlich der Gastspiele das vielzitierte gesellige Beisammensein von Künstlern beider Länder beinhalteten, sollten den Gastspielen ein umfangreicheres, möglichst positives Echo in der Presse garantieren. Zusätzlich sollten sie der französischen Öffentlichkeit einen deutsch-französischen Kulturaustausch zwischen vorgeblich gleichberechtigten Partnern vorgaukeln. Diese Politik der Deutschen Botschaft und des Deutschen Instituts stand im Kontext der allgemein verfolgten Politik der Kollaboration. Im Falle der Gastspiele verwendeten die Veranstalter viel Energie auf deren Vorbereitung. Abgesehen davon, daß nur die besten Künstler in Paris gastieren durften und im Falle Georges sogar ein Filmstar als propagandistisches Zugpferd dienen konnte, wurde in der Presse stets schon im voraus für die Veranstaltungen geworben. Gastspiele waren begleitet von einem Programm von Empfängen, welche die Veranstaltung als Ereignis des deutsch-französischen Kulturaustauschs gleichsam tarnen sollten. Karten für die wenigen Aufführungen, die zudem in deutscher Sprache waren, gaben die Dienststellen vor allem an die der Botschaft und dem Deutschen Institut nahestehenden Kreise von französischen Künstlern und Intellektuellen. Die kontrollierte und kollaborierende Presse sorgte für ein positives Echo der Gastspiele. Doch auch im Falle der Werbung für die Gastspiele waren die Vorstellungen der deutschen Funktionsträger zum Teil widersprüchlich, wenn sie sich einerseits der Person Georges als Filmstar bedienten, später aber bemängelten, George wäre zu sehr in den Vordergrund gestellt worden und das deutsche Theater in seiner Gesamtheit deswegen nicht als eigener kultureller Wert vermittelt worden. Obgleich bei den Empfängen und Reisen vor allem ein deutsch-französischer Kulturaustausch propagiert wurde, konnte dies jedoch nicht verbergen, daß die Besatzer einen wirklichen Austausch gar nicht wünschten. Besonders deutlich wurde dies in der deutschen Filmpolitik im besetzten Frankreich, die sich weit rigoroser als die

420 Burrin, La France, S. 329-361; Michel, Paris Allemand, S. 318; Bertin-Maghit, Le Cinéma sous l'Occupation, S. 166-171. 
Theaterpolitik an dem langfristigen Ziel der Errichtung einer deutschen „kulturellen Hegemonie“ orientierte.

\section{Deutsche Filme in Frankreich - Unterhaltung und propagandistischer Filmeinsatz}

Es gibt heute viele Länder und viele Völker, die Deutschland überhaupt nur durch den Rundfunk und den Film kennen. Sie sehen keinen Deutschen, jedenfalls keinen Nationalsozialisten. [...] Sie müssen also ihre Rückschlüsse auf Deutschland aus diesen beiden Dokumenten schöpfen. [...] Es mußte hier also eine Konkurrenzsetzung zwischen dem, was die Welt sagt, und dem, was wir sind, stattfinden. Und ich muß konstatieren mit tiefer Befriedigung, wie ich schon sagte, daß unsere deutschen Filmschaffenden dieses Problem nicht nur erkannt, sondern auch gelöst haben ${ }^{421}$.

Goebbels sprach diese Worte während einer Rede anläßlich der Kriegstagung der Reichsfilmkammer am 15. Februar 1941 in Berlin. Demnach sollten deutsche Filme im Ausland zu einem positiveren Bild des "neuen Deutschland“ beitragen. Diese generelle Sorge um das Ansehen des nationalsozialistischen Staates im Ausland gehörte zu Goebbels kulturpolitischen Grundsätzen ${ }^{422}$. Weniger in Frankreich, wo deutsche Produktionen vorwiegend in französischer Synchronisation liefen, als vor allem in den besetzten Ostgebieten sollte der deutsche Film zusätzlich zur Verbreitung der deutschen Sprache beitragen. In seiner Rede vor den Filmschaffenden am 28. Februar 1942 in Berlin meinte Goebbels: „Wir können nicht ein Weltreich besitzen, ohne gleichzeitig eine Weltsprache zu besitzen. Die besten Verbreiter der deutschen Sprache aber sind der Rundfunk und der Film. Allein in dieser Beziehung also ist der deutsche Film ein nationalpolitisches Behelfsmittel allererster Klasse ${ }^{* 423}$. Trotzdem war der Film nach den Vorstellungen der Nationalsozialisten vor allem ein sogenanntes Erziehungs- und Führungsmittel, das sich an das deutsche Volk richtete. Goebbels hat dies immer wieder betont. In der genannten Rede vor Filmschaffenden hat der Propagandaminister zum Filmeinsatz im Dritten Reich gesagt, der Staat habe ein eminentes Interesse an der Führung des Filmes, der nicht nur ein bloßes Mittel zur Unterhaltung sei, sondern auch ein "nationales Führungsmittel“424. Weiter heißt es: „Wobei ich nicht etwa die Auffassung von der Hand weisen wollte, daß der Film selbstverständlich auch zur Unterhaltung da ist, da die Unterhaltung ja besonders in Kriegszeiten einen nationalen Faktor ersten Ranges darstell ${ }^{\text {“425. }}$.

421 Goebbels Rede anläßlich der Kriegstagung der Reichsfilmkammer am 15. 2.1941 in Berlin, abgedruckt in: ALBRECHT, Nationalsozialistische Filmpolitik, S. 479.

422 MATHIEU, Kunstauffassungen, S. 132-134.

423 Rede vor den Filmschaffenden am 28. 2. 1942 in Berlin, zit. n.: ALBRECHT, Nationalsozialistische Filmpolitik, Dokument 6, S. 488.

424 Ibid.

425 Ibid. 